THAÍS BOCCIA DA COSTA

\title{
PAPEL DOS INFLAMASSOMAS NA ATIVAÇÃO DE CÉLULAS DENDRÍTICAS E NA MODULAÇÃO DA RESPOSTA IMUNE ADAPTATIVA
}

Tese apresentada ao Programa de Pós-Graduação em Imunologia do Instituto de Ciências Biomédicas da Universidade de São Paulo para obtenção do Título de Doutor em Ciências. 
THAÍS BOCCIA DA COSTA

\section{PAPEL DOS INFLAMASSOMAS NA ATIVAÇÃO DE CÉLULAS DENDRÍTICAS E NA MODULAÇÃO DA RESPOSTA IMUNE ADAPTATIVA}

Tese apresentada ao Programa de Pós-Graduação em Imunologia do Instituto de Ciências Biomédicas da Universidade de São Paulo para obtenção do Título de Doutor em Ciências.

Área de concentração: Imunologia

Orientador: Prof ${ }^{\mathrm{a}}$. Dr ${ }^{\mathrm{a}}$. Karina Ramalho Bortoluci

Versão original

São Paulo

2014 


\section{DADOS DE CATALOGAÇÃO NA PUBLICAÇÃO (CIP)}

Serviço de Biblioteca e Informação Biomédica do

Instituto de Ciências Biomédicas da Universidade de São Paulo

reprodução não autorizada pelo autor

Costa, Thaís Boccia da.

Papel dos inflamassomas na ativação de células dendríticas e modulação da resposta imune adaptativa / Thaís Boccia da Costa. -São Paulo, 2014.

Orientador: Profa. Dra. Karina Ramalho Bortoluci.

Tese (Doutorado) - Universidade de São Paulo. Instituto de Ciências Biomédicas. Departamento de Imunologia. Área de concentração: Imunologia. Linha de pesquisa: Inflamassomas na imunidade adaptativa.

Versão do título para o inglês: Role of inflammasomes in dendritic cell maturation and modulation of adaptive immunity.

$\begin{array}{llll}\text { 1. Inflammasomas } & \text { 2. Caspase-1 } & \text { 3. MyD88 4. IL-1a 5. Flagelina }\end{array}$ 6. S. typhimurium I. Bortoluci, Profa. Dra. Karina Ramalho II. Universidade de São Paulo. Instituto de Ciências Biomédicas. Programa de Pós-Graduação em Imunologia III. Título. 
UNIVERSIDADE DE SÃO PAULO

INSTITUTO DE CIÊNCIAS BIOMÉDICAS

Candidato(a): $\quad$ Thaís Boccia da Costa.
Título da Tese: $\quad \begin{aligned} & \text { Papel dos inflamassomas na ativação de células } \\ & \text { dendríticas e modulação da resposta imune adaptativa. }\end{aligned}$

Orientador(a): $\quad$ Profa. Dra. Karina Ramalho Bortoluci.

A Comissão Julgadora dos trabalhos de Defesa da Tese de Doutorado, em sessão pública realizada a ............................................., considerou
( ) Aprovado(a)
( ) Reprovado(a)

\begin{tabular}{|c|c|}
\hline Examinador(a): & Assinatura: . \\
\hline & Nome: $\ldots \ldots \ldots \ldots \ldots \ldots$ \\
\hline & 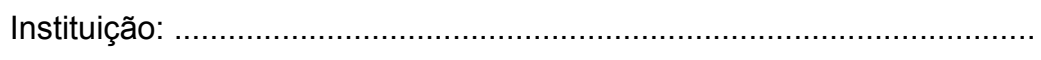 \\
\hline Examinador(a): & Assinatura: ......... \\
\hline & Nome: ............. \\
\hline & Instituição: ....... \\
\hline Examinador(a): & Assinatura: ...... \\
\hline & Nome: ............ \\
\hline & Instituição: ........................ \\
\hline Examinador(a): & Assinatura: ... \\
\hline & Nome:...$\ldots \ldots \ldots \ldots \ldots$ \\
\hline & Instituição: \\
\hline Presidente: & Assinatura: ..... \\
\hline & Nome: ......... \\
\hline & Instituição: .... \\
\hline
\end{tabular}




\begin{tabular}{|l|l|}
\hline UNIVERSIDADE DE SÃO PAULO \\
INSTITUTO DE CIÊNCIAS BIOMÉDICAS \\
Cidade Universitária "Armando de Salles Oliveira" \\
Av. Prof. Lineu Prestes, 2415 - Cep. 05508-900 São Paulo, SP - Brasil \\
Telefone :(55) (011) 3091.7733 - telefax : (55) (011)3091-8405 \\
e-mail: cep@icb.usp.br \\
COMISSÃO DE ÉTICA NO USO DE ANIMAIS
\end{tabular}

Decl. CEUA-029/ICB/USP

D E C L A R A Ç Ã O

Em adendo ao Certificado 109/07/CEUA, datado de 06.12.07, por solicitação da Profa. Dra Karina Ramalho Bortoluci, responsável pela linha de Pesquisa, autorizo a inclusão da aluna ThaIs Boccia DA CosTA ao Projeto de Pesquisa "Papel dos receptores do tipo Toll e do tipo NOD-LRR na ativação metabóilica e funcional de macrófagos", uma vez que se trata de utilização da mesma espécie animal e de métodos experimentais similares ao referido certificado.

São Paulo, 12 de julho de 2011.

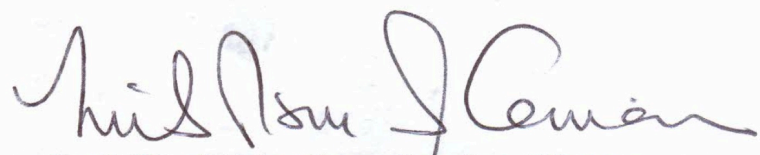

Prof. Dr. Niels Olsen Saraiva Câmara

Vice-Coordenador da CEUA $\mathrm{ICB} / \mathrm{USP}$ 
À minha mãe, por acreditar em mim desde o primeiro momento além de me dar todo incentivo que precisei até hoje, e aos meus amigos por estarem sempre comigo. Muito obrigada! 


\section{AGRADECIMENTOS}

Em primeiro lugar gostaria de agradecer à minha orientadora, Prof $^{\mathrm{a}}$. $\mathrm{Dr}^{\mathrm{a}}$. Karina Ramalho Bortoluci, pela oportunidade de fazer parte de um laboratório tão importante não só para a realização dos inúmeros experimentos do grupo, mas também repleto de pessoas que foram importantíssimas para a minha formação acadêmica e pessoal. Muito obrigada pelas conversas durante as reuniões e por confiar no meu potencial.

Ao Laboratório de Imunologia Molecular e seus integrantes, vocês foram muito importantes para mim. Tenho muito a agradecer à Carla Longo, por sempre estar ao meu lado, não só durante os experimentos, mas também durante os almoços, jantares, cafés e passeios no parque com a cachorra mais gostosa do mundo. Você é uma amiga que eu quero para a vida toda.

À Ivanete, Marcinha e todos os funcionários do CTC-Mol que nos ajudam tanto.

À Eni e a todos os amigos do Departamento de Imunologia da USP que desde o mestrado fazem parte da carreira que escolhi.

Ao Laboratório de Biologia Celular do Prof. Gustavo e todos os seu alunos, pela troca constante de conhecimento e por proporcionar um ambiente tão agradável para trabalhar.

Aos meus amigos Guilherme Abuchahla, Marta Giannichi e Julia de Lima que, dentre os amigos tão queridos da faculdade, são os melhores amigos do mundo.

À minha família pelo suporte e apoio em todos os sentidos, e principalmente à minha mãe que foi, é e será sempre imprescindível nesta jornada.

Às agências de fomento FAPESP e CNPq pelo apoio financeiro durante o desenvolvimento do projeto.

Muito obrigada a TODOS! 
A adversidade desperta em nós capacidades que, em circunstâncias favoráveis, teriam ficado adormecidas. Horácio

"The best way to get a good idea is to have a lot of ideas" Albert Einstein 


\section{RESUMO}

da Costa TB. Papel dos inflamassomas na ativação de células dendríticas e modulação da resposta imune adaptativa. [tese (Doutorado em Imunologia)]. São Paulo: Instituto de Ciências Biomédicas, Universidade de São Paulo; 2014.

A flagelina é um composto microbiano amplamente empregado pelo seu efeito adjuvante, entretanto os mecanismos pelos quais a flagelina exerce esse efeito ainda não estão completamente esclarecidos. O reconhecimento da flagelina pelos NLRs Naip5 e NLRC4 leva à formação do complexo multiproteico denominado inflamassoma que culmina na ativação da caspase-1, com consequente clivagem da forma inativa das citocinas pró-inflamatórias IL-1 $\beta$ e IL-18 e morte da célula infectada, o que poderia indicar um mecanismo de controle de patógenos. O papel do TLR5 na indução da resposta imune adaptativa pela flagelina já é conhecido, porém pouco se sabe a respeito da influência de Naip5 e NLRC4 nesse processo. Neste trabalho pudemos observar que in vitro, a maturação de BMDCs com a estimulação com flagelina citosólica, inserida em vesículas lipídicas que permitem a transfecção da flagelina para o citosol, foi independente da ativação de NLRC4, caspase-1 e TLR5, mas somente de MyD88. Já a ativação de linfócitos T por estas BMDCs ativadas por flagelina citosólica é parcialmente dependente de caspase-1 e totalmente dependente de MyD88. Nossos resultados sugerem a participação destas duas moléculas na montagem de resposta imune contra flagelina e indicam, também que a ativação de inflamassomas também pode contribuir para esse processo, pela produção de citocinas como a IL-1 $\alpha$ e IL-1 $\beta$. A neutralização da citocina IL-1a, levou à inibição da ativação de linfócitos $T$, indicando a contribuição desta para a montagem de resposta imune. A neutralização de IL-1a também levou a uma redução na produção de IL-12, que seria a citocina responsável pela polarização dos linfócitos para Th1. A imunização com flagelina leva ao desenvolvimento de imunidade protetora contra o desafio com S. typhimurium, igualmente dependente de caspase-1 e MyD88. Até o presente momento, nossos resultados nos permitem dizer que a flagelina induz resposta imune tanto in vivo quanto in vitro e que, em ambos os casos, há a participação das moléculas caspase-1 e MyD88.

Palavras-chave: Flagelina. Caspase-1. MyD88. S. typhimurium. IL-1a. Inflamassomas. 


\begin{abstract}
da Costa TB. Role of inflammasome activation in the maturation of dendritic cells and in the development of adaptive imune response. [Ph. D thesis (Immunology)]. São Paulo: Instituto de Ciências Biomédicas, Universidade de São Paulo; 2014.

Flagellin is a highly effective adjuvant for humoral and CD4 T cell responses used in several developing vaccines. It is recognized by TLR5 and by cytosolic NLRs members NAIP5/NLRC4. TLR5 activates inflammatory genes through MyD88 pathway whereas NLRC4 and NAIP5 assemble multiprotein complexes called inflammasomes, leading to caspase-1 activation and secretion of proinflammatory cytokines IL-1 $\beta$ and IL-18. Despite the described adjuvant properties of flagellin, little is known about the mechanisms through which inflammasomes shape adaptive immune responses. Thus, we investigated the effects of inflammasome activation in dendritic cell maturation and T cell activation. Purified flagellin in its free form (FLA-BS) was able to stimulate BMDCs via TLR5 and MyD88. FLA-BS-stimulated BMDC pulsed with OVA also induces IFN- $\gamma$ production by OT-II splenocytes in a TLR5 and MyD88dependent manner. Surprisingly, cytosolic flagellin (FLA-BSDot) induced upregulation of costimulatory molecules independent on TLR5, NLRC4 and Caspase-1, but dependent on MyD88. In addition, FLA-BSDot-stimulated OVA-pulsed BMDCs induced proliferation and production of IFN- $\gamma$ g by OT-II splenocytes, dependent on caspase-1 and MyD88. FLA-BSDot stimulation leads to the secretion of IL-1 $\beta$ and IL-1 $\alpha$, both cytokines that act on IL-1R1 and recruit MyD88. To verify the factor responsible for the Th1 polarization in response to FLABSDot, we used neutralizing antibodies for IL-1 $\alpha$ and IL-1b. Neutralization of IL-1 $\alpha$ but not IL-1 $\beta$, inhibited BMDCs maturation in response to FLA-BSDot and led to decreased IFNg production by OT-II splenocytes. Searching for the effector mechanism by which IL-1 $\alpha$ induces Th1 polarization in response to FLA-BSDot, we observed a significant reduction in IL-12 production when IL-1 $\alpha$ was neutralized, which could interfere with IFN- $\gamma$ production by OT-II splenocytes. Also, we could see that adaptive immune responses induced by flagellin in vivo was protective against S.typhimurium lethal challenge, showing again a role for caspase-1 and MyD88. From these data we can infer that caspase-1 and MyD88 are both involved in the adaptive response induced by flagellin both in vitro and in vivo.
\end{abstract}

Keywords: Flagellin. Caspase-1. MyD88. S. typhimurium. IL-1 $\alpha$. Inflammasomes. 


\section{LISTA DE ILUSTRAÇÕES}

Figura 1: Avaliação da pureza das flagelinas utilizadas nos ensaios in vitro e in vivo...... 27

Figura 2: Flagelina em suas formas livre e citosólica induzem maturação de BMDCs.......

Figura 3: Flagelina citosólica induz maturação funcional de BMDCs de maneira dependente de caspase-1 e MyD88.

Figura 4: TLR4 não está envolvido na produção de IL-1 $\alpha$ em resposta à flagelina citosólica. 36

Figura 5: LPS e proteínas não relacionadas são incapazes de induzir ativação de DCs. .38

Figura 6: A catepsina B está envolvida na ativação de BMDCs por flagelina citosólica. .40

Figura 7: IL-1 influencia a maturação de BMDCs por flagelina citosólica. .42

Figura 8: IL-1 participa na maturação funcional de DCs por flagelina citosólica.

Figura 9: IL-1 é necessária para a produção de IL-12 por DCs estimuladas com flagelina citosólica. .45

Figura 10: : IL-1 induz maturação funcional de DCs. .46

Figura 11: : Detecção de flagelina proveniente de S. typhimurium no interior de macrófagos peritoneais.

Figura 12: Flagelina induz ativação da resposta imune adaptativa in vivo. .51

Figura 13: A imunização com flagelina interfere no controle de S.typhimurium. 54 


\section{SUMÁRIO}

1 INTRODUÇÃO .........................................................................................................13

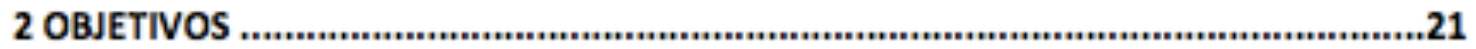

2.1 Objetivo geral .....................................................................................................................................21

2.2 Objetivos específicos........................................................................................................................21

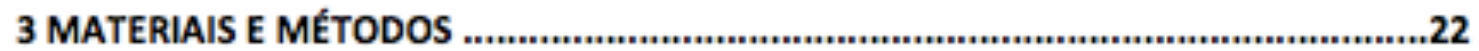

3.1 Animais ...........................................................................................................................................22

3.2 Obtenção de DC derivadas da medula óssea .......................................................................22

3.3 Ativação dos NOD-like receptors por flagelina citosólica ................................................23

3.4 Ativação e proliferação de linfócitos $\mathrm{T}$ in vitro por BMDCs..................................................23

3.5 Deteç̧ăo da produçăo de citocinas ........................................................................................24

3.6 Análise fenotípica........................................................................................................................24

3.7 Imunização dos animais com flagelina de S.typhimurium ..................................................24

3.8 Avaliação da produção de citocinas por linfócitos $T$ dos animais imunizados....................25

3.9 Desafio dos animais imunizados com $S$. typhimurium .....................................................25

3.10 Detecção de anticorpos no soro de animais imunizados com flagelina ..........................25

3.11 Detecção da presença da flagelina no citosol das células .................................................26

3.12 Pureza das flagelinas utilizadas dos ensaios in vitro e in vivo .........................................27

3.13 Análise estatística ..................................................................................................27

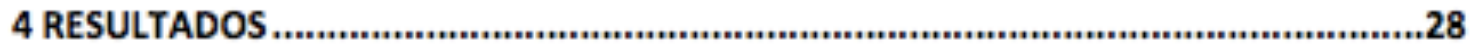

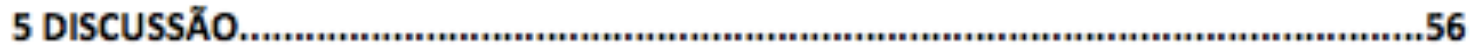

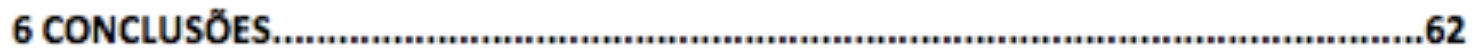

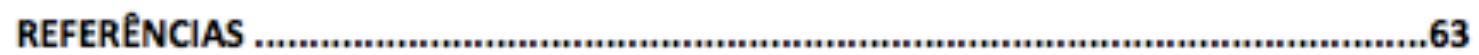

APÊNDICE - Emerging concepts about NAIP/NLRC4 inflammasomes - Trabalho submetido para a revista Frontiers in Immunology ....................................................71 


\section{INTRODUÇÃO}

O sistema imunológico é um sistema de reconhecimento molecular que tem como função a manutenção da homeostasia, em situações infecciosas ou fisiológicas. O sistema é composto pela imunidade inata, que, em última instância, é responsável pelo controle inicial de uma infecção, além de gerar condições propícias para que a imunidade adquirida seja gerada. A imunidade adquirida, por sua vez, tem o papel ativo de eliminar a infecção de modo específico envolvendo células e anticorpos produzidos em resposta específica ao micro-organismo em questão.

Fazem parte da imunidade inata, vários tipos celulares, dentre eles as células dendríticas (DCs) que são imprescindíveis para o desenvolvimento da resposta imunológica. As DCs são responsáveis pela captura, processamento e apresentação de antígenos para células da imunidade adquirida, os linfócitos T. Sendo assim, as DCs são chamadas de APCs (do inglês antigen presenting cells) profissionais e são especializadas nos processos que envolvem a ativação dos linfócitos T $(1,2)$.

A etapa inicial para ativação das DCS é a discriminação entre padrões moleculares de agentes exógenos e danos celulares, de estruturas próprias preservadas. Alguns mecanismos fazem parte dessa distinção como o reconhecimento de padrões moleculares associados a patógenos (PAMPs do inglês pathogen associated molecular patterns) por receptores específicos (PRRs do inglês pathogen recognition receptors) $(3,4)$. Dentre os PRRs, destacamse os receptores do tipo Toll (do inglês, toll like receptors, TLR) que são proteínas transmembrânicas com ectodomínios contendo regiões ricas em leucina, pelas quais ocorre o reconhecimento dos PAMPs; um domínio transmembrânico e um domínio intracelular, semelhante ao domínio intracelular do receptor para IL-1, e responsável pela transdução do sinal para dentro da célula.

Até hoje foram descritos treze tipos de TLR, sendo onze em humanos e treze em camundongos. Cada TLR possui uma função distinta no reconhecimento dos PAMPs e direcionamento da resposta imune (3). Entre os ligantes de TLR estão peptideoglicanas e lipoproteínas bacterianas, glicofosfatidil inositol (GPI) presente em protozoários e zimozan encontrado em fungos, todos reconhecidos por TLR2, RNA dupla-fita encontrado em vírus, 
reconhecido por TLR3, lipopolissacarídeo (LPS) presente em bactérias Gram negativas e reconhecido por TLR4, flagelina, componente do flagelo de bactérias móveis e reconhecida por TLR5 e sequências de DNA ricas em sequências CpG não metiladas, encontradas em vírus e bactérias e reconhecidas por TLR9 (5). A ativação de TLRs por seus ligantes induz o recrutamento de proteínas adaptadoras específicas como MyD88 (myeloid differentiation factor 88), MAL/TIRAP (MyD88-adaptor like/TIR-associated protein), TRIF (Toll-receptorassociated activator of interferon), TRAM (Toll-receptor-associated molecule) ou SARM (Sterile $\alpha$ - and armadillo-motif containing protein) (6). Essa cascata de sinalização culmina na ativação de fatores de transcrição como o NFKB e IRFs (Interferon responsive factors) e na liberação de citocinas pró-inflamatórias (7).

Após a descoberta dos TLRs, diversos tipos de PRR citosólicos foram identificados, como os RLRs e NLRs (do inglês, RIG-like receptors e Nod-like receptors, respectivamente). A família dos RLRs possui três membros, RIG-I, Mda5 e LGP2 que reconhecem RNA viral (8). A família dos NLRs ou NLR-LRR (do inglês, nucleotide-binding oligomerization domain - leucine rich repeats) possui mais de vinte membros e vários deles reconhecem diversos PAMPs e fatores de dano celular, (DAMPs do inglês danger associated molecular patterns) (9). A família dos NLRs pode ser subdividida nas subfamílias NOD, NLRCs (NLR-CARD (caspase activation and recruitment domain) containing); NLRPs (NLR- PYD (pyrin domain) containing) e NAIPs, que contêm o domínio CARD e os que contêm o domínio PYD. O domínio CARD permite a ligação e ativação da caspase-1 e da serina-treonina kinase RIP2, enquanto o domínio PYD é responsável pela ligação e ativação de proteínas adaptadoras que recrutam caspase-1 (10-12).

Os NLRs NLRP1, NLRP2, NLRP3 e NLRC4 (também chamado IPAF do inglês ICE protease-activating factor) são capazes de formar complexos de alto peso molecular, chamados inflamassomas, que ativam a caspase-1 e induzem a liberação de IL-1 $\beta$, IL-18 e IL33 pela célula em questão (12). Alguns NLRs não possuem o domínio CARD para recrutar e ativar a caspase-1 e para esse fim, utilizam proteínas adaptadoras como a ASC (do inglês, apoptosis-associated speck-like protein containing a CARD) que contem ambos os domínios PYD e CARD. Apesar de, em alguns casos, a ação conjunta de NLRs e moléculas adpatadoras como a ASC ser requerida para algumas funções do NLRP1 e inflamassoma NLRC4, estes podem interagir diretamente com a caspase-1, pois ambos possuem domínio CARD e não 
necessitariam do auxílio da molécula adaptadora ASC para recrutar e ativar caspase-1 (12, 13).

A formação de inflamassomas é induzida a partir de diversos estímulos, como: dano à membrana plasmática, toxinas formadoras de poros e a presença de produtos microbianos que agem como PAMPs. A ativação do inflamassoma leva à liberação de IL-1 $\beta$ que é induzida pela ação conjunta de TLRs e NLRs, que induzem a transcrição de pró-IL-1 $\beta$ e liberação da citocina na sua forma ativa, respectivamente $(14,15)$. Devido à grande importância da IL-1 $\beta$ na inflamação, os inflamassomas foram indicados como sensores para danos celulares causados por bactérias ou para as bactérias em si, encontradas em compartimentos intracelulares e não expostas a receptores da resposta imune inata (16).

Apesar de apresentarem respostas distintas, TLR e NLR parecem compartilhar ligantes. A flagelina é uma proteína que faz parte de uma subunidade do flagelo de bactérias móveis, e, no espaço extracelular, é reconhecida por TLR5 (17). Ainda, a flagelina pode ser encontrada no citosol, levada por sistemas de transporte, como o sistema de secreção tipo III (SPI-1 T3SS de Salmonella) e tipo IV (T4SS de Legionella), encontrados em bactérias virulentas. Uma vez no citosol, a flagelina pode ser reconhecida pelos NLRs NAIP5 que recruta NLRC4 e inicia a formação do inflamassoma, levando à ativação de caspase-1 com consequente liberação das citocinas IL-1 $\beta$, IL-18 e morte da célula em questão (18-22), secreção de mediadores lipídicos (23), regulação de autofagia (24) e ativação de iNOS, demonstrado pelo nosso grupo (25), entre outros mecanismos efetores. A morte celular induzida pela ativação de caspase-1 vem sendo relacionada a mecanismos de controle de patógenos, como controle da replicação de Legionella pneumophila (26) e Salmonella typhimurium, independente da produção de IL-1 $\beta$ e IL-18, uma vez que a morte inflamatória leva à remoção do patógeno dos tecidos adjacentes por neutrófilos (27).

Como a ativação de NLRs é capaz de induzir uma forma de morte pró inflamatória, surge a dúvida de como o sistema imune consegue discriminar entre diferentes tipos de morte celular, ou como a morte celular pode modular a resposta imune. Para isso, duas abordagens são utilizadas: estudar os sinais emitidos por células em processo de morte e as consequências dos diferentes tipos de morte. Uma das teorias sugeridas diz que o reconhecimento de PAMPs é suficiente para determinar se a morte celular é silenciosa, na ausência de patógenos ou se é imunogênica, com a presença de patógenos (28). Entretanto, 
simplesmente a presença ou não de PAMPs pode não ser o único critério para determinar se a morte será imunogênica ou não, uma vez que há a chamada inflamação estéril que pode levar ao desenvolvimento de doenças autoimunes, indicando que células que morrem de formas distintas podem sim estimular o sistema imune (29). Com isso, foi proposta a teoria de DAMPs para explicar o potencial imunogênico de células em processo de morte ou estresse.

Os DAMPs são liberados por células em processo de morte e são capazes de induzir resposta imune contra antígenos celulares, sejam essas células tumorais, tecido autólogo ou células infectadas por patógenos. Para que a morte celular seja imunogênica, é preciso que haja a liberação de DAMPs e consequente ativação de células do sistema imune (30). A segunda teoria sugerida diz que tipos de morte celular distintos induzem tipos distintos de resposta imune, sendo a apoptose uma morte intrinsicamente tolerogênica e a necrose altamente imunogênica e capaz de induzir processos inflamatórios (31). Contudo, já foi demonstrada a capacidade de células apoptóticas em induzir inflamação, quando comparadas a células em necrose $(32,33)$, e com isso, a ideia proposta foi de que há diferentes subtipos de morte celular e que diferenças sutis na composição das substâncias presentes na superfície das células e os produtos liberados, incluindo DAMPs, determinam se a morte celular é imunogênica ou não (34).

No caso da piroptose, essa morte vêm sendo relacionada à liberação não apenas das citocinas inflamatórias IL-1 $\beta$ e IL-18, mas também de DAMPs, como por exemplo, HMGB1 (do inglês high mobility group box 1) e a alarmina IL-1 $\alpha$. HMGB1 é uma proteína de 25kDa, expressa constitutivamente, altamente conservada evolutivamente e com $98 \%$ de homologia entre os mamíferos (35). Sua função principal é estabilizar a estrutura da cromatina e modular a transcrição gênica por auxiliar no processo de dobramento da molécula do DNA (36), mas também está presente no citoplasma, sugerindo que esta proteína possa ter outras funções fora do núcleo (37). Estudos mais antigos revelam que a morte de células por apoptose impede a liberação de HMGB1, mais um fato que faz com que este tipo de morte celular seja tolerogênico $(38,39)$. Apesar de ser liberado passivamente por células mortas com membrana danificadas, estudos recentes vêm atribuindo um papel para os inflamassomas na secreção desse fator. A inibição farmacológica de caspase-1 reduz a liberação de HMGB1 durante o choque séptico, aumentando a sobrevivência dos animais. 
In vitro, em cultura de macrófagos, a inibição não específica de caspases diminui a liberação desta molécula, indicando que células do sistema imune liberam ativamente HMGB1 de maneira caspase dependente (40). Recentemente, outros trabalhos mostraram a liberação de HMGB1, em resposta à ativação de inflamassomas por vários estímulos $(41,42)$. Outro fato importante é que em animais deficientes para as proteínas do inflamassoma, a liberação de HMGB1 é drasticamente reduzida durante o choque séptico $(41,42)$.

A citocina IL-1 foi descrita inicialmente como uma proteína que era capaz de induzir febre e foi chamada de human leukocyte pyrogen (43). Pouco tempo depois foram descobertos 2 tipos de IL-1 que conhecemos hoje como IL-1 $\alpha$ e IL-1 $\beta$ (44). A citocina IL-1 é produzida por vários tipos celulares incluindo macrófagos, monócitos, linfócitos, queratinócitos, microglia, neutrófilos, DCs entre outras, juntamente com o receptor para IL1. A forma pró de IL-1 $\alpha$ e IL-1 $\beta$ é produzida em resposta a ativação de TLRs e possui atividades distintas. A forma pró da IL-1 $\alpha$ já é capaz se ligar ao receptor e exercer suas ações pró-inflamatórias. Já a IL-1 $\beta$ não é capaz de se ligar a IL-1R1 na forma pró, e requer processamento pela caspase-1 para tornar-se ativa (45). A pró IL-1 $\alpha$ pode ser processada pela enzima calpaína, mas os efeitos desta clivagem ainda não foram totalmente elucidados (46). A IL-1 tem papel importante no sistema imune inato e também é capaz de modular funções da imunidade adaptativa. Ambas IL-1 $\alpha$ e IL-1 $\beta$ são potentes moléculas pró inflamatórias e têm diversos efeitos na proliferação, diferenciação e função de células da imunidade adaptativa ou inata (47). A sinalização de IL-1 $\beta$ induz a diferenciação de células T CD4 para Th17 (48), que por sua vez pode ser regulada pela expressão diferencial de IL-1R1, controlada por IL-7 e IL-15 (49). A estimulação de células T com IL-1 $\beta$ e IL-23 leva à produção de IL-17 (50) e essa IL-17 pode ter papel no desenvolvimento de várias doenças autoimunes como artrite reumatoide, esclerose múltipla, lúpus entre outras (51).

Assim como o HMGB1, foi sugerido que a liberação de IL-1 $\alpha$ envolve a ativação de inflamassomas. O trabalho de Gross et al. (2012) (52) mostrou que a ativação de inflamassomas leva à liberação de IL-1 $\alpha$, mas em células de animais deficientes em caspase1 a liberação de IL-1 $\alpha$ é diminuída, mas estes resultados foram observados apenas com a estimulação de NLRP3, NLRP1 e AIM2. Estes resultados demonstram que a ação dos inflamassomas não está totalmente elucidada, faltando ainda dados sobre o seu mecanismo 
de ação na liberação destes e outros DAMPs e a sua influência na montagem da resposta imune.

Os TLRs são muito estudados quanto à sua capacidade de induzir resposta imune inata e adaptativa. Estes receptores são responsáveis pela indução de respostas diversas incluindo produção de anticorpos de várias classes como $\lg M$, IgG e $\lg \mathrm{A}$, respostas de células T CD4 ${ }^{+}$do tipo Th1 e Th17 e também T CD8 ${ }^{+}$(53). Sporri e Reis e Sousa (2005) (54) mostraram que DCs podem ser ativadas via citocinas, na ausência de ligantes de TLRs, mas estas DCs são incapazes de induzir diferenciação de linfócitos T. Trabalhando com DCs ativadas diretamente via TLRs ou via citocinas, este trabalho consegue evidenciar a importância do reconhecimento dos PAMPs não somente para imunidade inata, mas principalmente para o desenvolvimento da imunidade adquirida. Ainda, o reconhecimento de PAMPs pelos TLRs, é necessário para que haja a apresentação de antígenos. O conteúdo dos fagolisossomos só é apresentado via MHC II, se houver algum ligante de TLR associado aos antígenos, e na ausência de ligantes de TLRs não há geração de complexos MHC IIpeptídeo (55). Entretanto, Já foi demonstrado que animais knockouts para as proteínas MyD88 e TRIF, responsáveis pela sinalização dos TLRs, apresentam imunidade adaptativa inalterada a antígenos T-específicos administrados juntamente com adjuvantes $(56,57)$. Estes resultados sugerem a participação de outras moléculas, que não os TLR, na montagem da resposta imune adaptativa.

Apesar dos TLRs serem os PRRs mais estudados, a maior parte dos PRRs que ativam os fatores de transcrição NFKB, NFAT e IRFs, é capaz de induzir resposta adaptativa (58). Entre os PRRs que ativam esses fatores de transcrição estão NOD1 e NOD2. E, apesar de os inflamassomas não envolverem diretamente a ativação de NFKB, NFAT e IRFs, esses complexos também estão envolvidos no desenvolvimento de resposta imune adaptativa.

A flagelina é capaz de induzir resposta imune adaptativa, sendo amplamente utilizada como adjuvante em diversos estudos com vacinas. A ação da flagelina sobre as DCs já foi descrita, apesar dos relatos encontrados serem divergentes. Enquanto alguns trabalhos demonstram a modulação de moléculas co-estimuladoras em DCs humanas (59-62), em camundongos os dados presentes na literatura são controversos. Em BMDCs (do inglês, bone marrow-derived dendritic cells) de camundongos $\mathrm{C} 3 \mathrm{H} / \mathrm{HeJ}$, a flagelina purificada de Salmonella typhimurium é capaz de aumentar a expressão de MHC II, CD86, CD80 e CD40 
(63), mas em BMDCs de camundongos da linhagem C57BL/6, esta modulação das moléculas co-estimuladoras não é observada $(60,64)$ e também não há aumento de produção de IL-6, uma citocina pró-inflamatória produzida por DCs ativadas com outros ligantes de TLRs como o LPS e CpG (64). Já a administração de flagelina in vivo resulta em grande modulação das moléculas co-estimuladoras em DCs esplênicas $(63,65,66)$ e esta ativação é dependente de MyD88 e TLR5 $(63,65,67)$.

A capacidade da flagelina em induzir resposta imune adaptativa foi avaliada em modelos utilizando células de animais OT-II para determinar a capacidade adjuvante deste composto microbiano, gerando resposta contra a proteína OVA. A imunização de animais C57BL/6 com flagelina e OVA conseguiu induzir a ativação e proliferação de linfócitos T CD4 ${ }^{+}$ e este fenômeno se mostrou dependente de TLR5 e MyD88 (64). Ainda a capacidade das DCs em induzir a ativação e proliferação de células $\mathrm{T} \mathrm{CD4}^{+}$se mostrou parcialmente dependente da expressão de TLR5 nas DCs, uma vez que a transferência de DCs TLR5 ${ }^{-1-}$ para um animal CD11c DTR depletado de DCs, reduziu, mas não aboliu a proliferação de linfócitos T CD4 ${ }^{+}$em comparação ao animal que recebeu $\mathrm{DCS} \mathrm{TLR}^{+/+}$(64). A flagelina também induz resposta contra a própria proteína, e dados publicados por Cunningham et al. (2004) (68) e Bobat et al. (2011) (69) demonstram a indução de resposta do tipo Th2 com produção de IL-4 após administração de flagelina in vivo. Sendo um componente da bactéria $S$. typhimurium, o desafio com a bactéria, em animais previamente imunizados com flagelina, leva à produção de IFN- $\gamma$ e indução de padrão de resposta Th1, com melhor controle da infecção (69).

Há escassos estudos envolvendo o inflamassoma NAIP5/NLRC4 na indução da resposta adaptativa à flagelina. O trabalho de Kupz et al. (2011) (70) mostra a ativação de células T CD8 não específicas para flagelina durante a infecção com S. typhimurium. Esta ativação se dá pela sinalização de IL-18 nas células CD8, induzida pela produção desta por DCs infectadas. Ainda, Naip5/NLRC4 exerce um papel redundante com TLR5 na indução da produção de anticorpos contra a flagelina ou contra a OVA co-administrada $(65,71)$, provavelmente pelo fato deste componente bacteriano ser reconhecido também pelos NLRS NLRC4 e Naip5, indicando mais uma vez, que os NLRs podem ter papel importante na indução da resposta imune adaptativa. Uma vez que a flagelina é capaz de induzir resposta imune adaptativa via TLRs e NLRs, nossa proposta principal foi identificar a importância do inflamassoma Naip5/NLRC4 para a modulação do perfil de diferenciação de linfócitos T 
ativados por DCs estimuladas com flagelina citosólica ou livre e também em modelos de imunização com flagelina purificada. 


\section{OBJETIVOS}

\subsection{Objetivo geral}

Avaliar o papel da ativação do inflamassoma Naip5/NLRC4 na maturação de DCs e ativação de linfócitos T CD4 em resposta à flagelina livre ou citosólica, e na modulação da resposta imune in vivo.

\subsection{Objetivos específicos}

- Determinar a importância da ativação de Naip5/NLRC4, caspase-1, MyD88 e TLR5 na maturação de DCs por flagelina e na ativação de linfócitos $T$ in vitro;

- avaliar a participação dos receptores TLR5, NLRC4 e das moléculas caspase-1 e MyD88 na montagem de resposta imune contra flagelina de S. typhimurium in vivo;

- avaliar o potencial protetor da imunização com flagelina durante a infecção com S. typhimurium in vivo. 


\section{MATERIAIS E MÉTODOS}

\subsection{Animais}

Camundongos C57BL/6, knockouts para TLR5, NLRC4, caspase-1, MyD88 e OT-II com 6-8 semanas de idade foram fornecidos pelo Biotério de camundongos isogênicos do Instituto de Ciências Biomédicas da Universidade de São Paulo e pelo Centro de

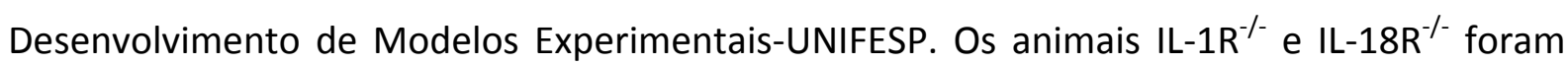
cedidos pela Professora Maria Bellio da Universidade Federal do Rio de Janeiro.

\subsection{Obtenção de DC derivadas da medula óssea}

O método para obtenção e cultura de células derivadas da medula óssea utilizado foi descrito por Inaba et al. (72) com algumas modificações. As células da medula óssea foram removidas dos fêmures dos animais e colocadas em cultura, na concentração de $2 \times 10^{5} / \mathrm{mL}$, por 7 dias em meio RPMI 1640 suplementado com penicilina (100 U/mL), streptomicina (100 $\mu \mathrm{g} / \mathrm{mL}$ ), 2-mercaptoetanol (50 $\mu \mathrm{M})$, L-glutamina (2 mM), piruvato de sódio (1 mM) e 10\% de soro fetal bovino (SFB) contendo $\mathrm{rGM}-\mathrm{CSF}(20 \mathrm{ng} / \mathrm{mL})$ e para geração de DCs. O meio com as citocinas foi trocado no $4^{\circ}$ dia de cultura e o sobrenadante foi coletado no $7^{\circ}$ dia para os experimentos de maturação e co-cultura.

Para os estímulos in vitro, as DCs foram cultivadas em placas de 96 poços com fundo U ( $3 \times 10^{5}$ células/poço), em meio RPMI completo, suplementado com $10 \%$ de SFB (SigmaAldrich, St Louis, $\mathrm{MO}, \mathrm{EUA})$, a $37{ }^{\circ} \mathrm{C}$ e a $5 \%$ de $\mathrm{CO}_{2}$ e foram estimuladas com flagelina purificada proveniente de Bacillus subtilis em sua forma livre, ou inseridas em vesículas lipídicas catiônicas (DOTAP), na concentração de $4 \times 10^{-10} \mathrm{M}$. Para a dosagem de citocinas, as DCs foram estimuladas com LPS a $100 \mathrm{ng} / \mathrm{mL}$ por 2 horas antes do estímulo com flagelina citosólica como indicado nos resultados. 


\subsection{Ativação dos NOD-like receptors por flagelina citosólica}

A flagelina purificada foi adicionada ao DOTAP, na concentração de $1 \mu \mathrm{g}$ de flagelina para cada $5 \mu \mathrm{L}$ de DOTAP, na presença de HBS (HEPES-salina tamponada). Essa mistura foi homogeneizada gentilmente por 1 minuto e, então, mantida por 15 minutos em temperatura ambiente para a formação de complexos estáveis gerados espontaneamente. Após esse período, adicionou-se a quantidade apropriada de meio de cultura ao preparado flagelina/DOTAP e este foi então, diretamente adicionado às culturas. Desta maneira, a flagelina pode ser levada ao citosol celular. Como controle, as células foram colocadas em meio de cultura ou juntamente com a vesícula DOTAP vazia. As flagelinas proveniente das bactérias S.typhimurium SL3261 e Bacillus subtilis foram obtidas com o Professor Luís Carlos Ferreira, do Instituto de Ciências Biomédicas da Universidade de São Paulo, reconstituída com água livre de endotoxina e estocada a $-20^{\circ} \mathrm{C}$. Para análise da produção das citocinas IL$1 \alpha$ e IL-1 $\beta$ estimulamos previamente as DCs com LPS $100 \mathrm{ng} / \mathrm{mL}$ por 2 horas.

\subsection{Ativação e proliferação de linfócitos T in vitro por BMDCs}

BMDCs geradas como descrito na seção 4.2 foram estimuladas com flagelina citosólica ou com a vesícula lipídica vazia na presença de $5 \mu \mathrm{g} / \mathrm{mL}$ da proteína OVA (SigmaAldrich, St Louis, MO, EUA). Após $18 \mathrm{~h}$ de estímulo, adicionamos as células provenientes do baço de camundongos OT-II na proporção de 1 DC: 4 esplenócitos (10 ${ }^{5}$ DCs para $4 \times 10^{5}$ esplenócitos) e deixamos a cocultura a $37{ }^{\circ} \mathrm{C}$ e a $5 \%$ de $\mathrm{CO}_{2}$ por 5 dias para que houvesse acúmulo de citocinas no sobrenadante. Para a análise da proliferação, os esplenócitos foram marcados com CFSE (1 $\mu \mathrm{M})$ (Life Technologies) por 30 minutos em meio de cultura RPMI, livre de soro fetal, por 30 minutos a $37{ }^{\circ} \mathrm{C}$ e $5 \%$ de $\mathrm{CO}_{2}$ e o excesso de CFSE não internalizado foi neutralizado por 3 lavagens com meio RPMI com 10\% de SFB. A proliferação das células T CD4 foi analisada por citometria de fluxo pela perda da fluorescência do CFSE, 3 dias após o plaqueamento. 


\subsection{Detecção da produção de citocinas}

A análise da produção das citocinas IL-1 $\beta$, IL-1 $\alpha$ IL-6, IL-12p70 e IFN- $\gamma$ nos sobrenadantes das culturas, foi determinada por ELISA de captura (Becton Dickinson, Mountain View, CA, EUA), de acordo com instruções do fabricante. As citocinas IL-17 e IFN- $\gamma$ foram analisadas pela técnica de CBA de acordo com as instruções do fabricante (Becton Dickinson, Mountain View, CA, EUA).

\subsection{Análise fenotípica}

Para avaliação fenotípica, DC e linfócitos $T$ foram incubados com anticorpos monoclonais para CD11c, CD80, CD86 e CD4 (Becton Dickinson, Mountain View, CA, EUA). $3 \times 10^{5}$ DCs e $10^{6}$ esplenócitos foram incubados em placas de 96 poços em fundo $U$ e a diluição de 1:100 de cada anticorpo foi utilizada. A placa foi mantida a $4{ }^{\circ} \mathrm{C}$ ao abrigo da luz, e após 30 minutos as células foram lavadas com "Staining buffer" (PBS SFB 0,1\%) e centrifugadas a $200 \mathrm{~g}$. Após a lavagem, as células foram ressuspendidas em "Staining buffer" e mantidas a $4{ }^{\circ} \mathrm{C}$ e ao abrigo da luz até o momento da leitura. As células foram analisadas por citometria de fluxo em FACS Canto II (Becton Dickinson, Mountain View, CA, EUA) e com auxílio do software FlowJo (TreeStar, Ashland, OR, EUA).

\subsection{Imunização dos animais com flagelina de S.typhimurium}

Para o protocolo de imunização, animais C57BL/6 e knockouts para TLR5, NLRC4, caspase-1 e MyD88 foram administrados com $20 \mu \mathrm{g}$ de flagelina pela via intraperitoneal em um regime de "prime e boost" homólogo. Após 35 dias do "prime", foi administrado o "boost" com mais $20 \mu \mathrm{g}$ de flagelina pela via intraperitoneal. Em cada linhagem, 3 animais foram imunizados com flagelina e 3 receberam PBS. 


\subsection{Avaliação da produção de citocinas por linfócitos T dos animais imunizados}

Ao fim dos 4 dias depois do "boost", os animais foram sacrificados e tiveram seus baços retirados para cultura in vitro. Para a dosagem de citocinas, $10^{6}$ esplenócitos foram plaqueados por $24 \mathrm{~h}$ ou 5 dias para acúmulo de citocinas no sobrenadante. A produção de IL$1 \alpha$ foi analisada por ELISA dos sobrenadantes após 24 h de cultura e a produção de IL-12 e IFN- $\gamma$ após 5 dias de cultura.

\subsection{Desafio dos animais imunizados com S. typhimurium}

Após a imunização das diferentes linhagens utilizadas, os animais foram desafiados com $5 \times 10^{3} \mathrm{CFU}$ de S. typhimurium administradas por via intraperitoneal 4 dias após o boost. Para determinar a capacidade da imunização em proteger os animais da morte, um grupo de animais imunizados ou não $(n=5)$, foram observados para a análise da mortalidade. No quarto dia após a infecção, os animais foram sacrificados e o baço, fígado e pulmões foram retirados para análise da quantidade de bactérias presentes em cada órgão. $A$ análise da quantidade de bactérias foi feita por plaqueamento em meio LB ágar sem antibióticos, e crescimento de aproximadamente $16 \mathrm{~h}$ a $37^{\circ} \mathrm{C}$.

\subsection{Detecção de anticorpos no soro de animais imunizados com flagelina}

Coletamos o soro dos animais imunizados 4 dias após o "boost". Para dosar a quantidade de anticorpos produzidos contra a flagelina utilizamos duas abordagens, o ELISA e o Western Blotting. Para o ELISA, sensibilizamos placas EIA/RIA de 96 poços (Costar, MN, EUA) com $2 \mu \mathrm{g} / \mathrm{mL}$ de flagelina recombinante de S. typhimurium em tampão carbonato $\mathrm{pH}$ 9,6, $50 \mu \mathrm{L}$ por poço. A placa foi mantida a $4{ }^{\circ} \mathrm{C}$ "overninght". Os poços foram lavados com PBS tween 0,05\% 3 vezes antes de adicionarmos $100 \mu \mathrm{L} /$ poço de solução de bloqueio (Leite em pó desnatado 5\% e BSA 2\% - Sigma-Aldrich, St Louis, MO, EUA). A placa foi bloqueada por $2 \mathrm{~h}$ a $37^{\circ} \mathrm{C}$. Ao final das $2 \mathrm{~h}$ de bloqueio desprezamos o sobrenadante dos poços e adicionamos o soro dos animais imunizados iniciando com uma diluição de 1:200 e seguindo uma diluição seriada até 1:25600. Após $1 \mathrm{~h}$ a $37^{\circ} \mathrm{C}$, lavamos os poços com PBS tween $0,05 \%$ 
5 vezes e adicionamos o anticorpo secundário, anti mouse-IgG peroxidase (Sigma-Aldrich, St Louis, MO, EUA) na diluição de 1:5000 e $50 \mu \mathrm{L} /$ poço. Após $1 \mathrm{~h}$ a $37^{\circ} \mathrm{C}$, os poços foram lavados com PBS tween 0,05\% 5 vezes e foram adicionados $100 \mu \mathrm{L} /$ poço de solução de revelação de OPD 5\% (Sigma-Aldrich, St Louis, MO, EUA) e água oxigenada 0,01\% em tampão citrato pH 5. A solução de revelação foi deixada por 10 minutos e as placas mantidas no escuro. A reação é cessada com a adição de $50 \mu \mathrm{L} /$ poço de ácido sulfúrico $4 \mathrm{~N}$ e a placa é lida em espectofotômetro em comprimento de onda de $495 \mathrm{~nm}$.

Para calcular o título de anticorpos dos animais imunizados, fizemos a diluição seriada até que a D.O. obtida caia entre 0,1-0,2. Com esta D.O., observa-se a diluição realizada para alcançar este valor e consideramos que o animal tem maior título de anticorpos quanto maior for a diluição com D.O. entre 0,1 e 0,2. Ainda, há outra maneira para classificar os títulos. Faz-se uma relação com a diluição e o resultado é mostrado em potência de 10 , permitindo assim, classificar os animais com título de $10^{1}, 10^{2}, 10^{3}$ e assim por diante.

\subsection{Detecção da presença da flagelina no citosol das células}

Para determinar se a flagelina proveniente de S. typhimurium era capaz de entrar nas células sem o auxílio de vesículas lipídicas, $3 \times 10^{5}$ macrófagos peritoneais de animais C57BL/6 foram cultivados em placas de 96 poços, de fundo chato, e estimuladas com $3 \mu \mathrm{g} / \mathrm{mL}$ de flagelina por $30 \mathrm{~min}, 1 \mathrm{~h} 30 \mathrm{~min}, 3 \mathrm{~h} \mathrm{e} 6 \mathrm{~h} 37^{\circ} \mathrm{C}$ e $5 \%$ de $\mathrm{CO}_{2}$. A cada período de estimulação, as células foram retiradas da estufa e preparadas para o protocolo de imunofluorescência. As células foram fixadas por 30 minutos com $200 \mu \mathrm{L}$ de paraformaldeído a $4 \%$ em temperatura ambiente. Em seguida, os poços foram lavados com PBS 1x e adicionamos a solução de bloqueio (BSA 2\%) por uma hora. Os poços foram lavados com PBS 1x e as células foram permeabilizadas com Triton $0,5 \%$ por 10 minutos. Após os 10 minutos, os poços foram lavados com PBS 1x e o anticorpo primário anti-FLICi, produzido em coelhos e cedido pelo Professor Luís Carlos Ferreira, foi adicionado em solução de bloqueio, na diluição de 1:10000, por $18 \mathrm{~h}$ a $4{ }^{\circ} \mathrm{C}$ ao abrigo da luz. Em seguida, os poços foram lavados com PBS tween $0,05 \%$ e a solução contendo o anticorpo secundário anti-rabbit Alexa 568 (Life Technologies, Carlsbad, CA, EUA), na diluição de 1:1000, foi adicionada por uma hora. Em 
seguida os poços foram lavados com PBS tween $0,05 \%$ e a solução de DAPI, na diluição de 1:100, foi adicionada imediatamente antes da leitura em microscópio de fluorescência.

\subsection{Pureza das flagelinas utilizadas dos ensaios in vitro e in vivo}

Para avaliar a pureza das amostras de flagelina utilizadas para estimulação in vitro e in vivo, utilizamos a técnica de SDS-PAGE. Para isso, realizamos a eletroforese em gel de poliacrilamida $12 \%$ de $2 \mu \mathrm{g}$ de flagelina recombinante de $B$. subtilis e $S$. typhimurium a $140 \mathrm{~V}$ por volta de 1 h 30 min. O gel foi corado em solução de Comassie Blue por 1 h sob agitação, e descorado em água destilada até que as bandas de flagelina ficassem visíveis. Os géis exemplificando a pureza das flagelinas utilizadas estão representados na figura 1A e 1B.

A

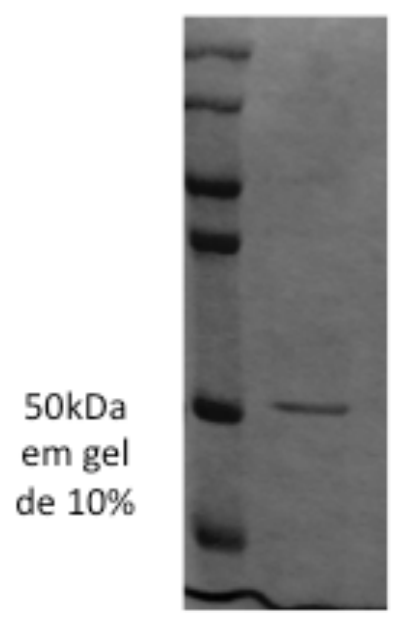

B

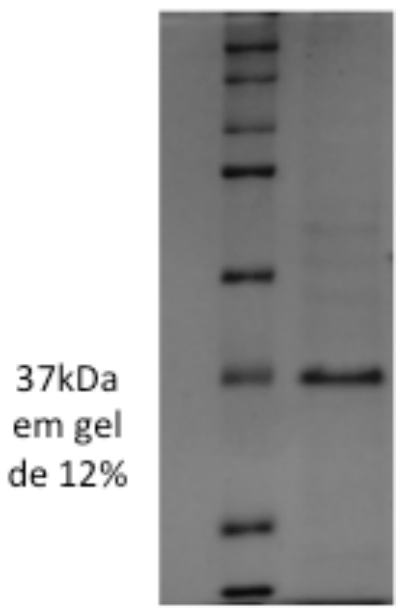

Figura 1: Avaliação da pureza das flagelinas utilizadas nos ensaios in vitro e in vivo. A: Flagelina de S. typhimurium em gel SDS-PAGE acrilamida 10\%. B: Flagelina de B. subtilis em gel SDS-PAGE acrilamida $12 \%$. Géis corados com Coomassie Blue.

\subsection{Análise estatística}

Os resultados obtidos foram apresentados como média \pm desvio padrão e analisados pelos testes de Student T e paramétrico de análise de variância One-way Anova. Todas as análises estatísticas serão realizadas com o auxílio de um software computacional chamado Graphpad Prism, da companhia Graphpad Software Incorporation. Valores de $p<0,05$ foram considerados estatisticamente significativos. 


\section{RESULTADOS}

Para determinar os efeitos da flagelina citosólica como indutora de maturação de DCs, utilizamos as DCs diferenciadas como descrito na seção 4.2 e estimulamos com flagelina em sua forma livre ou inserida em vesículas lipídicas (descrito na seção 4.3), capazes de induzir a liberação da flagelina no citosol. A flagelina em sua forma livre, induz maturação de DCs observada pelo aumento da expressão de moléculas coestimuladoras e produção da citocina pró-inflamatória IL-6 (Figura 2B e 2D). Da mesma maneira, a flagelina citosólica (FLABsDOT) também foi capaz de induzir o aumento da expressão de moléculas coestimuladoras nestas células (Figura 2B). Utilizamos como controle da maturação, células não estimuladas (iDC) e células estimuladas somente com a vesícula lipídica vazia (DOT). A estratégia de seleção das populações por citometria de fluxo está esquematizada na figura 2A. Surpreendentemente, a maturação de DCs por flagelina citosólica se mostrou independente de TLR5 (Figura 2B). A produção de IL-6 pelas DCs foi dependente de TLR5, e também só foi observada quando as células foram estimuladas com flagelina na sua forma livre, não inserida em vesículas lipídicas, indicando que não houve estimulação de TLR5 por uma possível contaminação com flagelina livre nos preparados com vesículas lipídicas (Figura 2D). Já a produção de IL-1 $\beta$ só ocorreu quando as DCs foram estimuladas com flagelina citosólica (Figura 2C). Como esperado, a estimulação de DCs com flagelina citosólica induziu aproximadamente $20 \%$ de morte celular, vista pela marcação com brometo de etídeo e laranja de acridina (Figura 2E). 
Figura 2: Flagelina em suas formas livre e citosólica induzem maturação de BMDCs. A: Estratégia de seleção de populações para apresentação dos resultados em histogramas. B: Expressão de CD80 e CD86 em células CD11 ${ }^{+}\left(3 \times 10^{5}\right.$ células) dos animais $\mathrm{C} 57 \mathrm{BL} / 6$ e $\mathrm{TLR}^{-/-}$cultivadas por $18 \mathrm{~h}$ com $3 \mu \mathrm{g} / \mathrm{mL}$ de flagelina livre (FLA-Bs) ou citosólica (FLABsDOT) (inserida em vesículas lipídicas). Histograma preenchido em cinza: iDC. Linha tracejada: vesícula lipídica vazia. Linha preta: flagelina citosólica $3 \mu \mathrm{g} / \mathrm{mL}$. BMDCs não primadas com LPS. C: Produção de IL-1 $\beta$ por DCs ( $3 \times 10^{5}$ células) dos animais $\mathrm{C} 57 \mathrm{BL} / 6$ e $\mathrm{TLR}^{-}{ }^{-}$cultivadas por $18 \mathrm{~h}$ com $3 \mu \mathrm{g} / \mathrm{mL}$ de flagelina livre (FLA-Bs) ou citosólica (FLA-BsDOT). BMDCs previamente primadas com LPS $(100 \mathrm{ng} / \mathrm{mL})$ por $2 \mathrm{~h}$. D: Produção de IL-6 por DCs $\left(3 \times 10^{5}\right.$ células) dos animais C57BL/ 6 e $\mathrm{TLR}^{\%}$ cultivadas por $18 \mathrm{~h}$ com $3 \mu \mathrm{g} / \mathrm{mL}$ de flagelina livre (FLA-Bs) ou citosólica (FLA-BsDOT) . BMDCs não primadas com LPS. E: Microscopia de fluorescência com marcação para laranja de acridina e brometo de etídeo de BMDCs não estimuladas (iDC), vesícula lipídica vazia (DOT) e flagelina citosólica $(3 \mu \mathrm{g} / \mathrm{mL}$ ) (FLA-BsDOT). Aumento de 40x. Dados representativos de seis ou mais experimentos. $(n=3)$ 

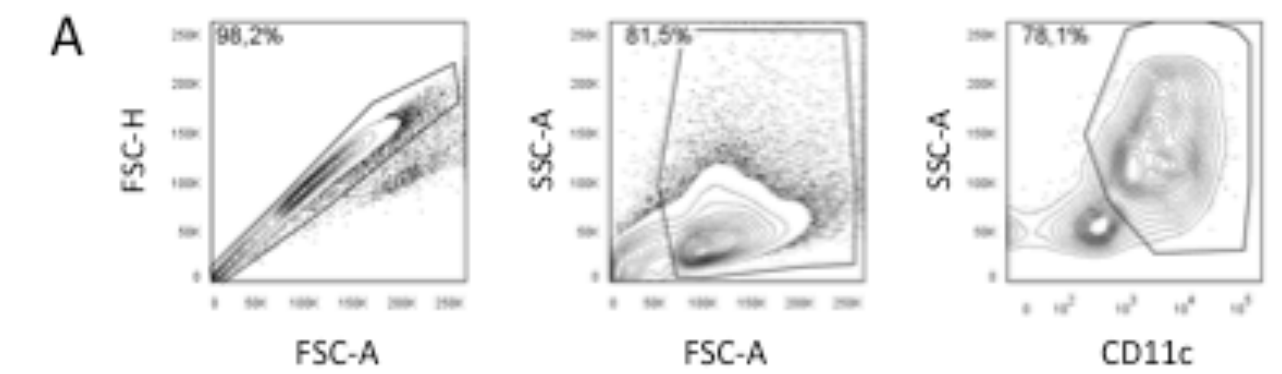

B
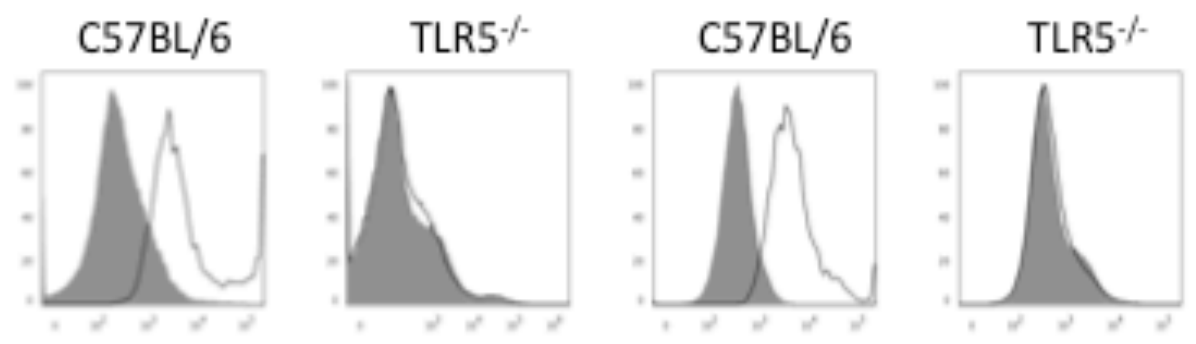

FLA-BS
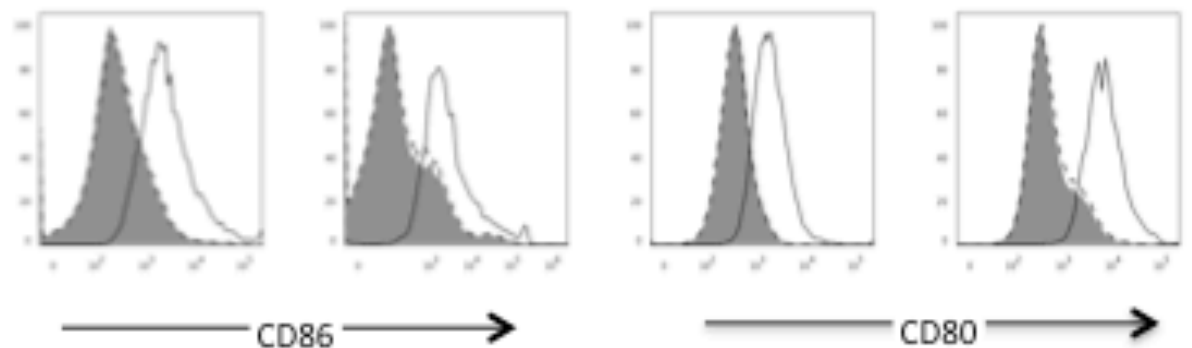

FLA-BsDOT

C

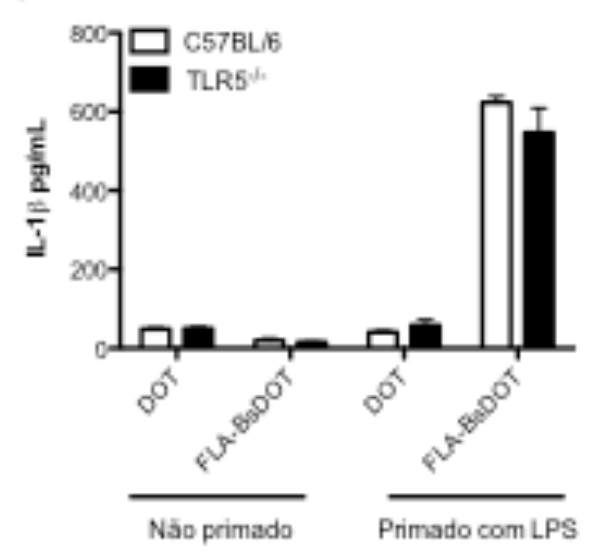

D

E

iDC
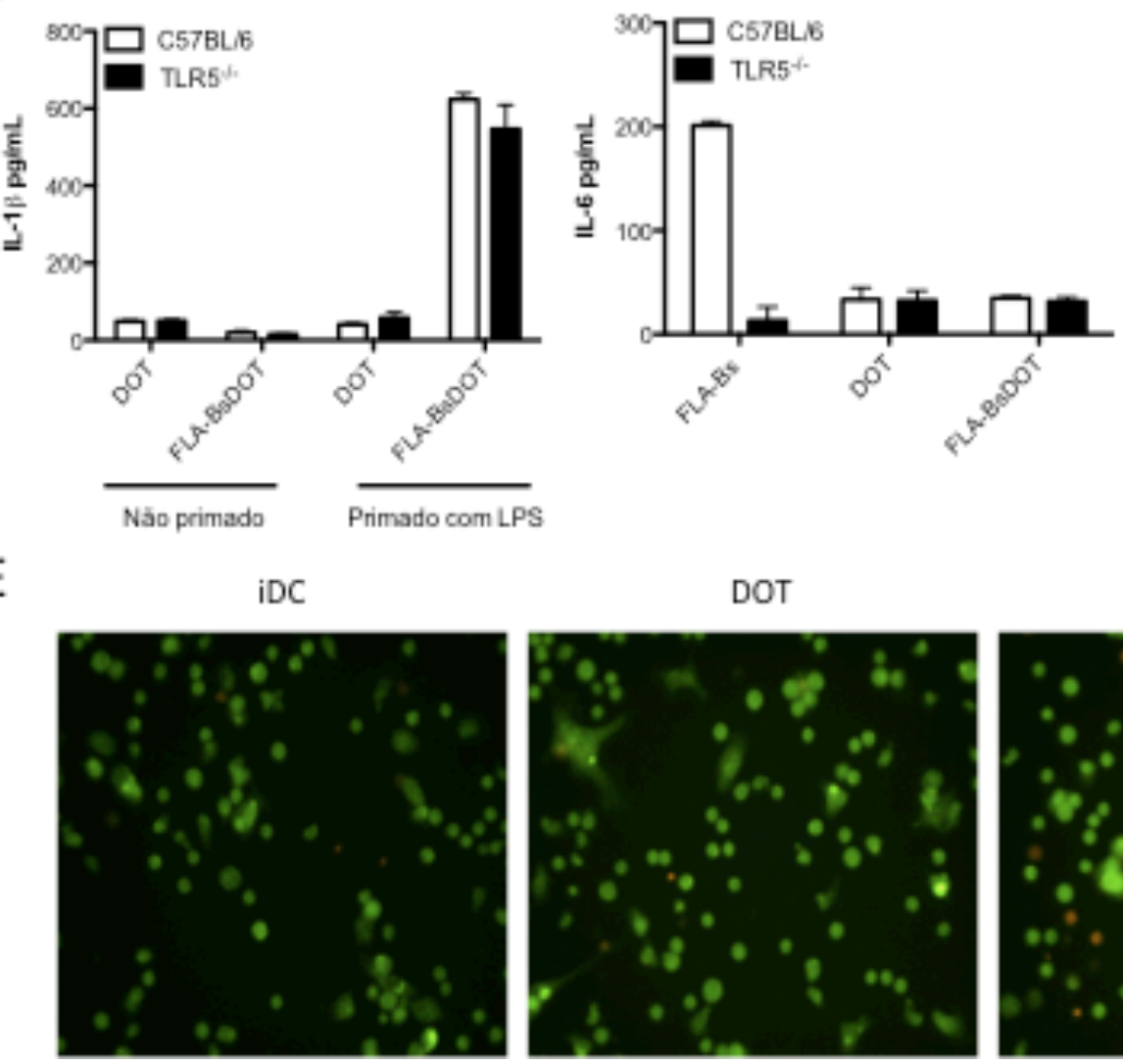

DOT

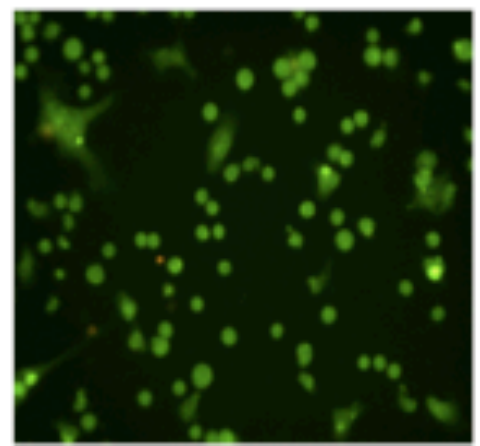

FLABsDOT

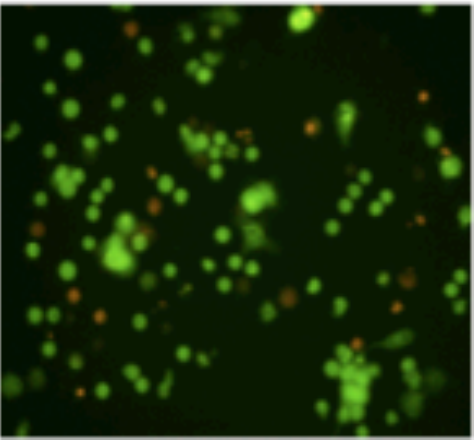


O próximo passo foi determinar a importância dos componentes do inflamassoma NLRC4 e caspase-1, e também MyD88, molécula adaptadora envolvida na sinalização do receptor para IL-1 e dos TLRs. Como podemos ver na figura 3A, a maturação de DCs se mostrou independente de NLRC4 e caspase-1, mas dependente de MyD88.

Nas culturas primadas com LPS, pudemos observar a produção de IL-1 $\beta$ e esta produção em resposta à flagelina citosólica e mostrou parcialmente dependente de NLRC4 e completamente dependente de caspase-1 (Figura 3B). Como controle para a produção de citocinas, assim como para a expressão de moléculas coestimuladoras, as DCs foram estimuladas com a vesícula lipídica vazia, para demonstrar que a produção de IL-1ß é dependente do reconhecimento da flagelina intracelular.

A citocina IL-1 $\alpha$ pertence à mesma família da IL-1 $\beta$ e tem sido considerada um sinal de perigo endógeno. Também é constitutivamente expressa por vários tipos celulares e pode ser liberada passivamente durante processos de morte celular. Ao contrário da IL-1 $\beta$, ela não precisa de processamento pela caspase-1 para ser ativada, sendo bioativa na forma de pró-IL-1 $\alpha$ (73), mas alguns trabalhos mostram a necessidade da ativação dos inflamassomas e, por consequência, ativação da caspase-1, para a liberação desta citocina $(74,52)$. Pudemos observar a produção de IL-1 $\alpha$ pelas DCs dos animais WT, TLR5 ${ }^{-/}$, quando estimulados com flagelina citosólica, mesmo sem o priming com LPS (Figura 3C). Houve uma redução na produção de IL-1 $\alpha$ pelas DCs dos animais caspase- $1^{-/}$e MyD88 $8^{-/}$, tanto nas DCs primadas quanto não primadas (Figura 3 C). Apesar de não significativa, houve uma tendência à redução da secreção de IL-1 $\alpha$ na ausência de NLRC4 (Figura 3C).

Para determinar a maturação funcional das DCs estimuladas com flagelina citosólica, estas células foram pulsadas com OVA e cocultivadas com esplenócitos de camundongos OTII, que possuem TCR transgênico para OVA nos linfócitos T CD4. Desta forma, as DCs estimuladas com flagelina podem processar e apresentar a proteína OVA para os linfócitos T que reconhecem este antígeno, permitindo assim a análise da importância do reconhecimento de flagelina por NLRs para o desenvolvimento da resposta adaptativa. Pudemos observar a produção de IFN- $\gamma$ nas co-culturas de DCs estimuladas com flagelina citosólica, mesmo na ausência de priming com LPS, indicando que houve ativação e diferenciação de linfócitos T CD4 (Figura 3D). 
Esta produção se mostrou dependente de caspase-1 e MyD88, mostrando um papel importante para estas duas moléculas na imunidade adaptativa induzida por flagelina citosólica. Nas culturas primadas com LPS, o perfil foi semelhante, com menor produção de IFN- $\gamma$ pelas co-culturas de DCs dos animais deficientes em caspase-1 e MyD88. Também foi observada produção de IL-17, no entanto apenas nas culturas primadas com LPS, e esta produção se mostrou dependente de NLRC4, caspase-1 e MyD88 (Figura 3E).

A proliferação das células T CD4 específicas para OVA foi avaliada pela marcação com CFSE. O mesmo perfil de produção de IFN- $\gamma$ foi observado para a proliferação, onde os animais deficientes em caspase-1 e MyD88 apresentaram menor proliferação de células T CD4 em comparação aos animais WT, na presença de DCs estimuladas com flagelina citosólica, como pode ser visto pela perda da marcação de CFSE (Figura 2F). 
Figura 3: Flagelina citosólica induz maturação funcional de BMDCs de maneira dependente de caspase-1 e MyD88. A: Expressão de CD80 e CD86 em células CD11c ${ }^{+}\left(3 \times 10^{5}\right.$ células) dos animais C57BL/6, NLRC4 ${ }^{-/}$, caspase- $1^{-/}$e

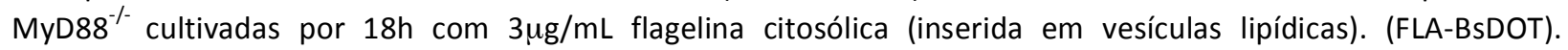
Histograma preenchido em cinza: iDC. Linha tracejada: vesícula lipídica vazia. Linha preta: flagelina citosólica. BMDCs não primadas com LPS. B e C: Produção de IL-1 $\beta$ (B) e IL- $1 \alpha$ (C) por DCs dos animais C57BL/6 e e KOs cultivadas por $18 \mathrm{~h}$ com $3 \mu \mathrm{g} / \mathrm{mL}$ flagelina citosólica (inserida em vesículas lipídicas). (FLA-BsDOT). As DCs foram primadas ou não com LPS $(100 \mathrm{ng} / \mathrm{mL})$ por $2 \mathrm{~h}$. D e E: Produção de IFN- $\gamma$ (D) e IL-17 (E) por esplenócitos de camundongos OT-II $\left(4 \times 10^{5}\right)$ co-cultivados com DCs $\left(1 \times 10^{5}\right)$ de animais WT e KOs estimuladas com $3 \mu \mathrm{g} / \mathrm{mL}$ de flagelina citosólica (FLA-BsDOT) e pulsadas com OVA $(5 \mu \mathrm{g} / \mathrm{mL})$. BMDCs primadas ou não com LPS $(100 \mathrm{ng} / \mathrm{mL}) \mathrm{por}$ 2h. F: Proliferação de linfócitos T CD4, provenientes de animais OT-II $\left(4 \times 10^{5}\right)$, em co-cultura com DCs $\left(1 \times 10^{5}\right)$ dos animais $\mathrm{C} 57 \mathrm{BL} / 6, \mathrm{TLR}^{-/-}, \mathrm{NLRC4}^{-/-}$, caspase $-1^{-/}$e $\mathrm{MyD}^{-1-}$ cultivadas por $18 \mathrm{~h}$ com $3 \mu \mathrm{g} / \mathrm{mL}$ de flagelina citosólica (FLA-BsDOT) e pulsadas com OVA $(1 \mu \mathrm{g} / \mathrm{mL})$. BMDCs não primadas com LPS. ${ }^{*} \mathrm{p}<0,05,{ }^{*} \mathrm{p}<0,005$ e ${ }^{* * *} \mathrm{p}<0,001$ em relação às DCs dos animais WT.. Dados representativos de seis ou mais experimentos. $(n=3)$. 
A

C57BL/6

$\mathrm{NLRC4}^{\%}$

Caspase- $1 \% \quad$ MyD88\%
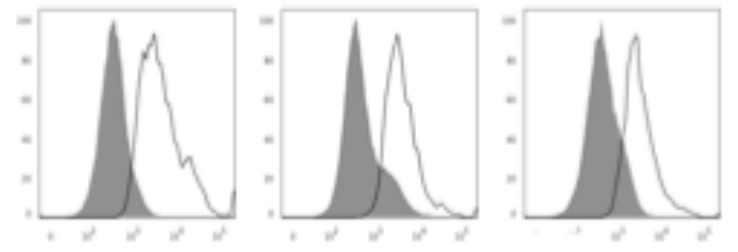

CD80
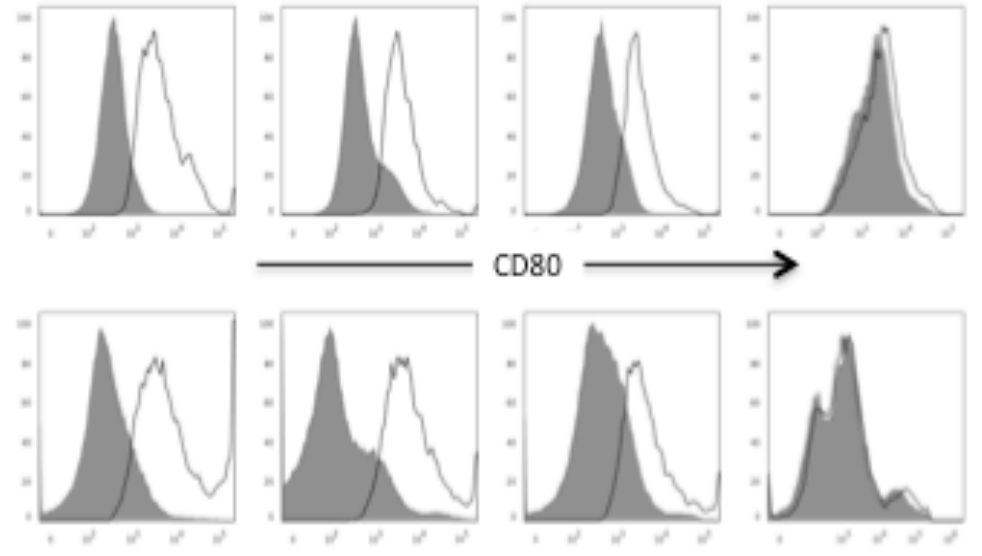

CD86

B

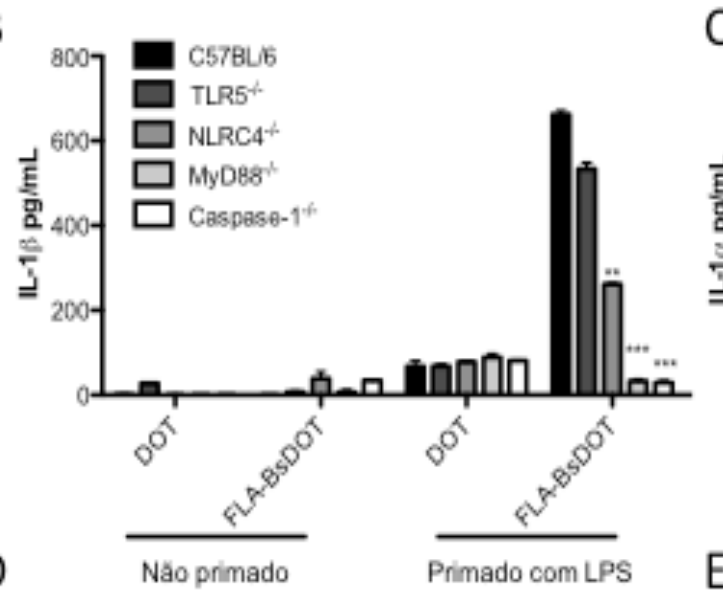

C -

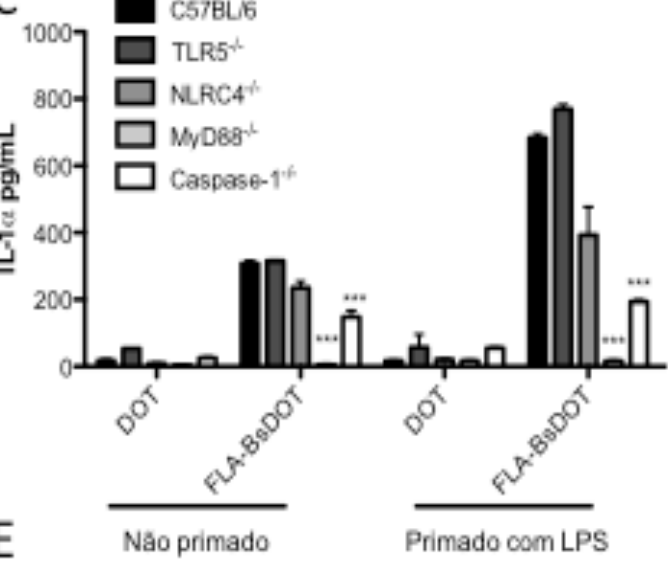

D
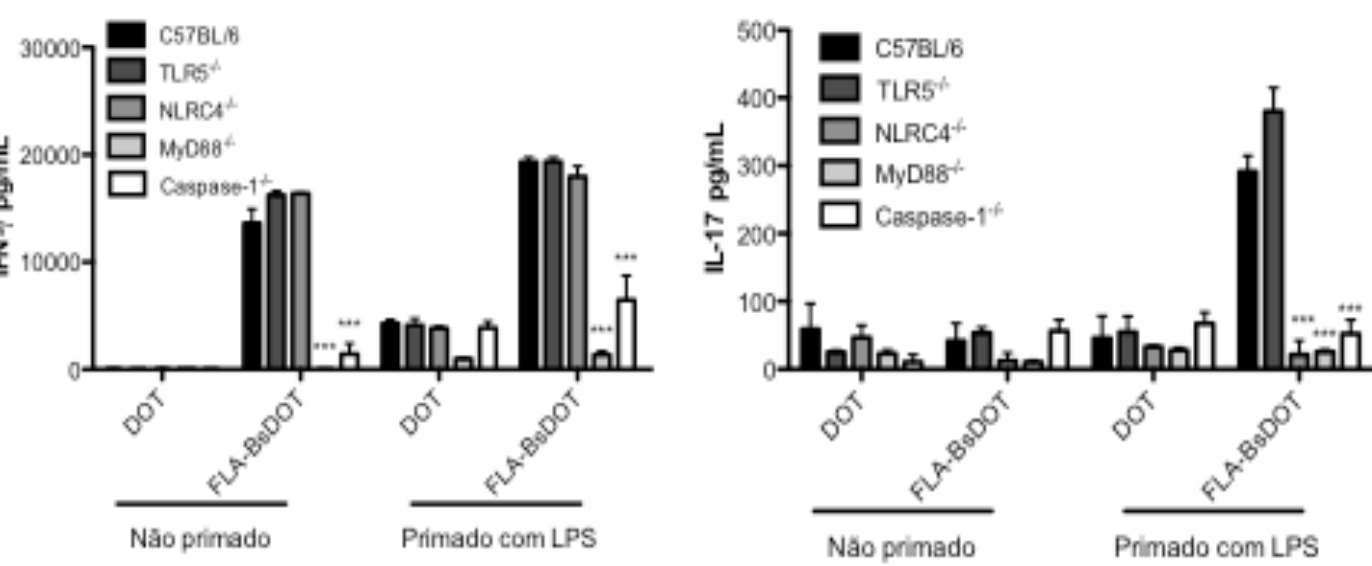

F

C57BL/6

TLR5 $*$

$\mathrm{NLRC4}^{*}$

MyD88 $/$

Caspase-1\%
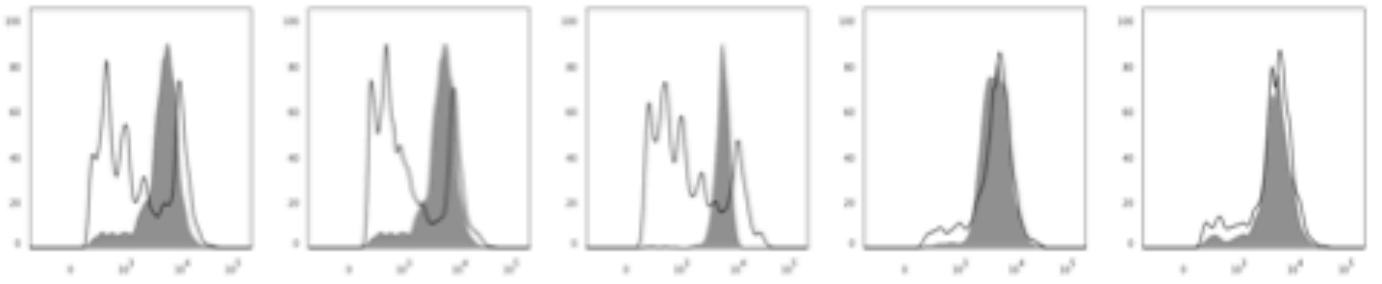
A produção de citocinas por DCs provenientes dos animais deficientes em TLR4 foi analisada para descartar a possível contaminação com LPS que a flagelina purificada pudesse apresentar. Pudemos verificar que o fenômeno decorrente da estimulação com flagelina citosólica não envolve uma possível contaminação por LPS, uma vez que a produção de IL-1 $\alpha$ não depende de TLR4, enquanto a IL-1 $\beta$ só é liberada quando há priming com LPS, dependente de TLR4 (Figura 3A e 3B).

A

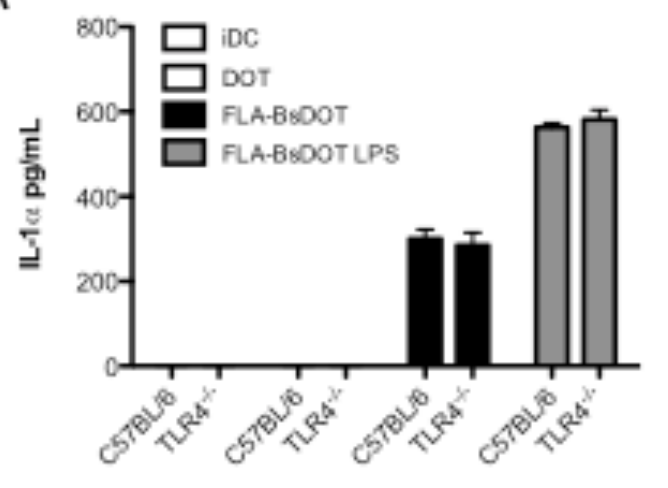

B

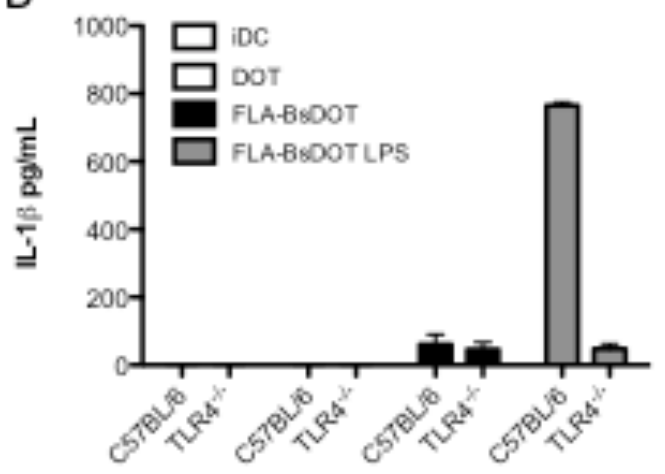

Figura 4: TLR4 não está envolvido na produção de IL-1 $\alpha$ em resposta à flagelina citosólica. Produção de IL-1 $\alpha$ (A) e IL-1 $\beta$ (B) por DCs $\left(3 \times 10^{5}\right)$ dos animais C57BL/6 e TLR4 ${ }^{-1-}$ cultivadas por $18 \mathrm{~h}$ com flagelina purificada de $B$. subitilis $(3 \mu \mathrm{g} / \mathrm{mL}$ ) inserida em vesículas lipídicas (FLA-BsDOT). As BMDCs foram previamente primadas ou não com LPS $(100 \mathrm{ng} / \mathrm{mL})$ por $2 \mathrm{~h}$. Dados representativos de três experimentos $(n=3)$.

Recentemente, alguns trabalhos mostraram a ativação de inflamassomas não canônicos pela presença de LPS no citoplasma celular $(75,76)$. A ativação deste inflamassoma, cujo sensor é desconhecido, leva à liberação de IL-1 $\alpha$, mas não IL-1 $\beta$ de maneira dependente de caspase-11. Uma vez que a caspase-11 é necessária para a liberação de IL-1 $\alpha$ em resposta à ativação dos inflamassomas não canônicos, nosso intuito foi descartar a influência dessa via não canônica na liberação de IL-1 $\alpha$ em resposta à flagelina citosólica. Para isso, usamos a mesma ferramenta utilizada para levar a flagelina para o citosol, a vesícula lipídica, só que desta vez, utilizamos LPS em três diferentes concentrações. Para melhor controle de nossa ferramenta experimental, verificamos a possibilidade de outra proteína não relacionada induzir a liberação de IL-1 $\alpha$, IL-1 $\beta$ por DCs e IFN- $\gamma$ pelos linfócitos T. Para isso, utilizamos a p24, uma proteína proveniente do vírus HIV purificada da 
mesma maneira utilizada para obter a flagelina, por coluna de níquel. Vimos que, usando DCs de camundongos C57BL/6, somente a flagelina, mas não LPS e p24, inseridos em vesículas lipídicas, foi capaz de induzir liberação de IL-1 $\alpha$ e IL-1 $\beta$ (Figura 5A e 5B) e, posteriormente IFN- $\gamma$ na co-cultura com esplenócitos de camundongos OT-II (Figura 5C). Estes resultados descartam a participação de efeitos secundários à estimulação com flagelina citosólica, para os fenômenos observados.

A
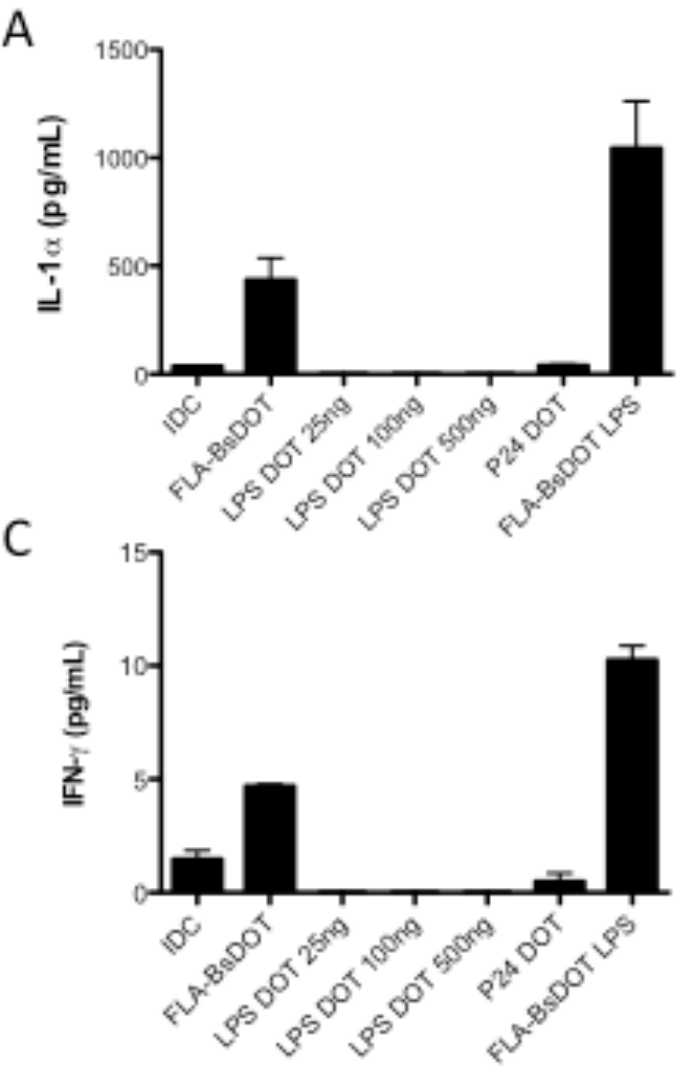

B

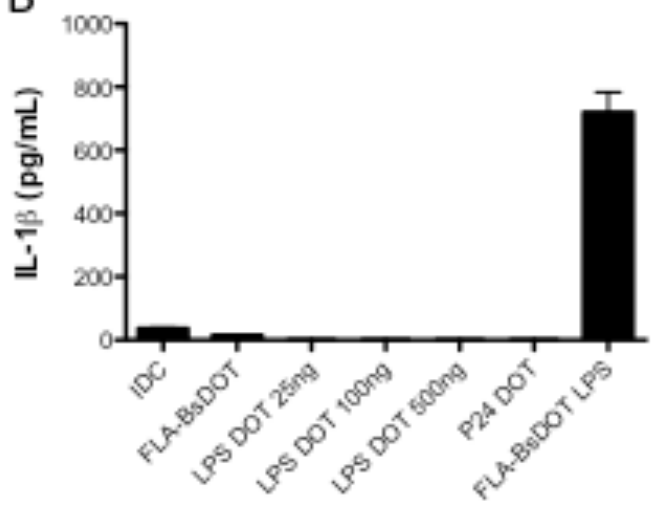

Figura 5: LPS e proteínas não relacionadas são incapazes de induzir ativação de DCs. Produção de IL-1 $\alpha$ (A) e IL-1 $\beta$ (B) por DCs $\left(3 \times 10^{5}\right)$ dos animais C57BL/6 cultivadas por $18 \mathrm{~h}$ com flagelina citosólica (FLA-BsDOT) $(3 \mu \mathrm{g} / \mathrm{mL})$, LPS em 3 concentrações diferentes e a proteína p24 de HIV $(3 \mu \mathrm{g} / \mathrm{mL})$ inseridos em vesículas lipídicas. As DCs foram previamente primadas ou não com LPS $(100 \mathrm{ng} / \mathrm{mL})$ por $2 \mathrm{~h}$. C: Produção de IFN- $\gamma$ por esplenócitos de camundongos OT-II $\left(4 \times 10^{5}\right)$ cocultivados com BMDCs de animais C57BL/6 $\left(1 \times 10^{5}\right)$ estimuladas como descrito acima e pulsadas com ovalbumina (OVA) $(5 \mu \mathrm{g} / \mathrm{mL}))$. Dados representativos de três experimentos. $(n=3)$. 
Recentes dados do nosso grupo de pesquisa demonstraram que a presença da flagelina no citosol de macrófagos peritoneais é capaz de ativar uma via lisossomal de produção de IL-1 $\alpha$ e IL-1 $\beta$ (89). Assim como verificado para os macrófagos, a inibição de catepsina B pelo reagente CA-074-Me reduziu a produção de IL-1 $\alpha$ e IL-1 $\beta$ por DCs primadas com LPS e estimuladas com flagelina citosólica, de forma dose dependente (Figura 6A e 6B). Assim como a produção de IL-1 $\alpha$ e IL-1 $\beta$, a inibição da catepsina B também reduziu a maturação de DCs, como pode ser observado pela menor expressão de CD86 (Figura 6C). Ainda, a produção de IFN- $\gamma$ por esplenócitos OT-II cultivados com as DC estimuladas com flagelina citosólica e pulsadas com OVA também foi inibida pela adição de CA-074-Me (Figura 6D). Esses dados mostram que a via lisossomal induzida pela flagelina citosólica participa na maturação funcional e fenotípica das DCs e sugerem um papel para IL-1 na indução da produção de IFN- $\gamma$ por esplenócitos, uma vez que essas citocinas apresentam perfis semelhantes de regulação. 
A

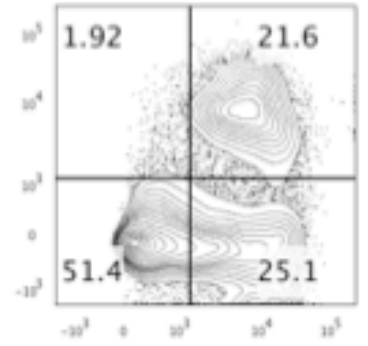

CA-074-Me 25uM

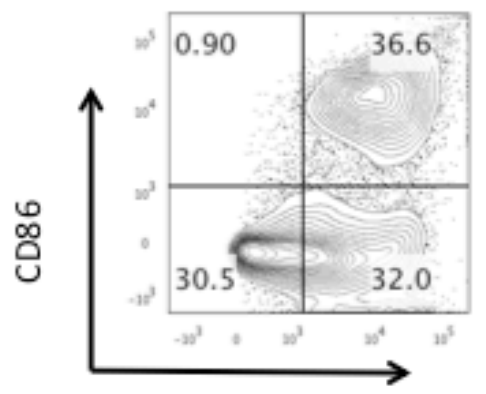

CD11c
DOT

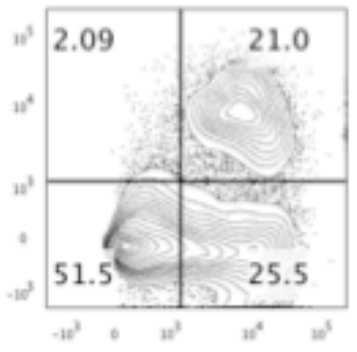

CA-074-Me 50uM

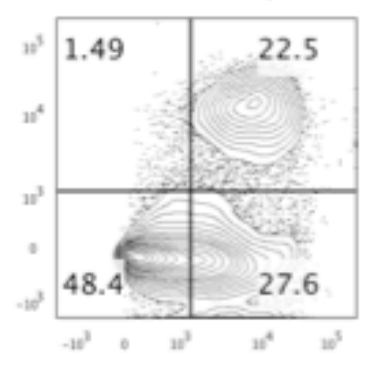

FLA-BSDOT

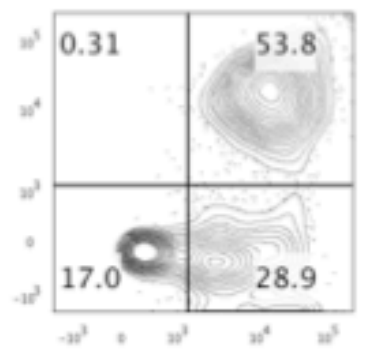

CA-074-Me $100 \mu \mathrm{M}$

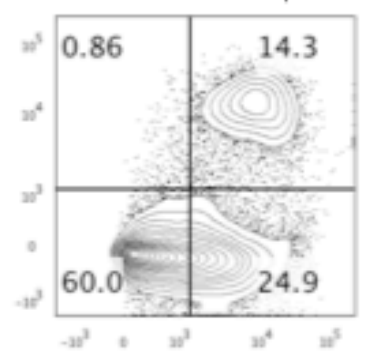

B

C
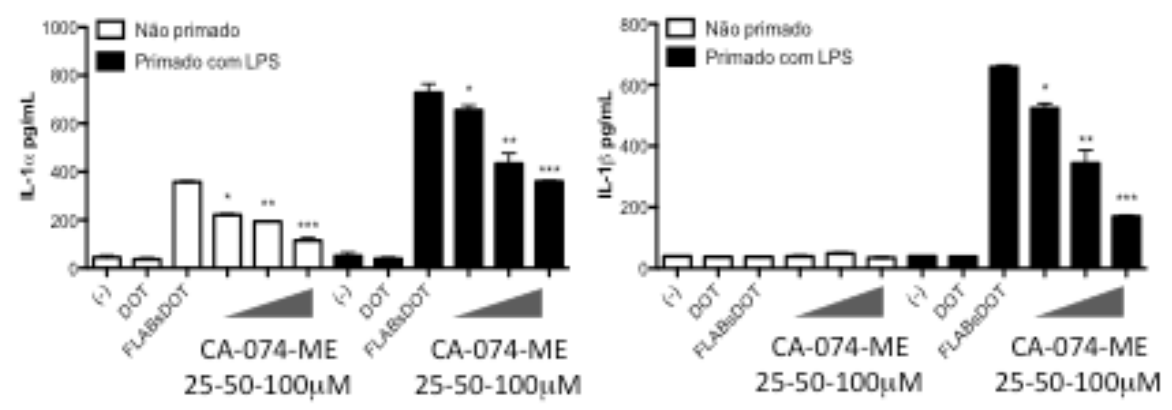

D

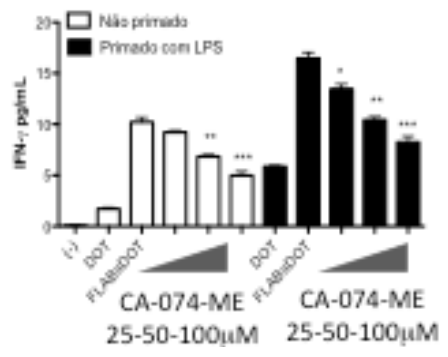

Figura 6: A catepsina B está envolvida na ativação de BMDCs por flagelina citosólica. Produção de IL$1 \alpha$ (A) e IL- $1 \beta$ (B) por BMDCs $\left(3 \times 10^{5)}\right.$ dos animais C57BL/6 cultivadas por $18 \mathrm{~h}$ com $3 \mu \mathrm{g} / \mathrm{mL}$ de flagelina inserida em vesículas lipídicas (FLA-BsDOT), na presença de doses crescentes de CA-074$M E$, inibidor de catepsina B. As BMDCs foram primadas ou não com LPS $(100 \mathrm{ng} / \mathrm{mL})$ por $2 \mathrm{~h}$. C: Expressão de CD86 em BMDCs $\left(3 \times 10^{5}\right.$ ) (gate em células CD11c ${ }^{+}$) dos animais C57BL/6 cultivadas por $18 \mathrm{~h}$ com $3 \mu \mathrm{g} / \mathrm{mL}$ de flagelina inserida em vesículas lipídicas (FLA-BsDOT), na presença de doses crescentes de CA-074-ME. D: Produção de IFN- $\gamma$ por esplenócitos de camundongos OT-II $\left(4 \times 10^{5}\right)$ cocultivados com DCs $\left(1 \times 10^{5}\right)$ de animais C57BL/6 estimuladas com $3 \mu \mathrm{g} / \mathrm{mL}$ de flagelina citosólica (FLA-BsDOT) e pulsadas com OVA $(5 \mu \mathrm{g} / \mathrm{mL})$, na presença de doses crescentes de CA-074-ME por $120 \mathrm{~h}$. As DCs foram primadas ou não com LPS (100ng/mL) por $2 \mathrm{~h} .{ }^{*} \mathrm{p}<0,05, * * \mathrm{p}<0,005$ e ${ }^{* * *} \mathrm{p}<0$, em relação DCs estimuladas com flagelina citosólica na ausência de CA-074-ME. Dados representativos de três experimentos. $(n=3)$ 
Para determinar a importância da IL-1 na maturação de DCs e na ativação de linfócitos T, utilizamos anticorpos neutralizantes para IL-1 $\alpha$, IL-1 $\beta$ e o antagonista IL-1RA, e também verificamos o perfil de DCs provenientes de animais deficientes em IL-1R. Como podemos observar na figura 6, na presença de IL-1RA, a frequência de DCs CD86 é reduzida de maneira dose-dependente, condizente com a baixa frequência de BMDC CD86 ${ }^{+}$ encontrada nos animais IL-1R ${ }^{-/-}$(Figura 7). A neutralização de ambas as citocinas IL-1 $\alpha$ e IL$1 \beta$ reduziu a frequência de $\mathrm{DCs} C D 86^{+}$, sendo que anti-IL-1 $\alpha$ apresentou um efeito mais pronunciado (Figura 7). Esses dados indicam a influência da sinalização via IL-1R na maturação de BMDCs, onde a IL-1 $\alpha$ parece ter papel primordial. 
iDC

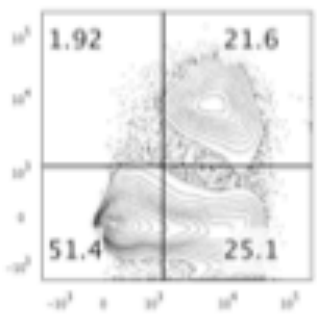

Anti IL-1 $\alpha, 25 \mu \mathrm{g} / \mathrm{mL}$

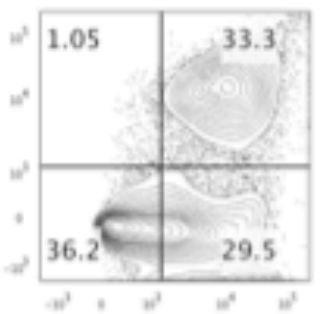

Anti IL-1 $0,25 \mu \mathrm{g} / \mathrm{mL}$

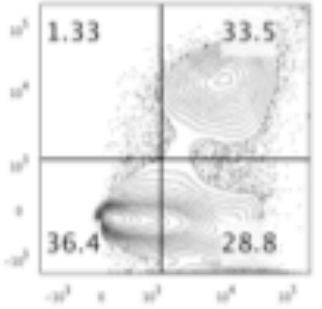

IL-1RA $0,25 \mu \mathrm{g} / \mathrm{mL}$

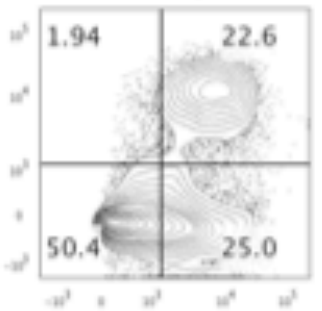

IL-1 $-1 \mathrm{R}^{-1-}$

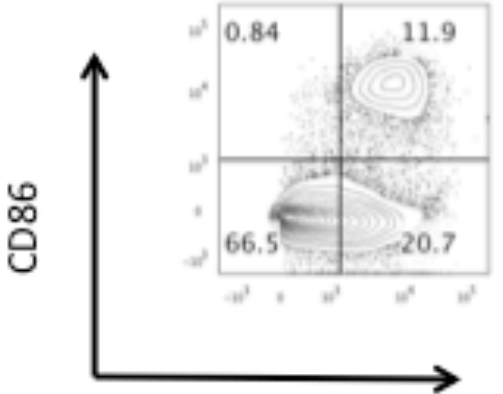

CD11c
DOT

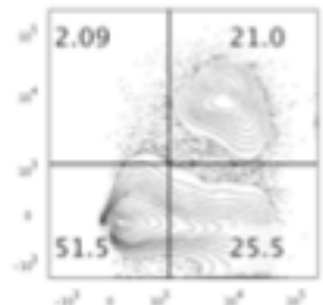

Anti IL-1 $\alpha 0,5 \mu \mathrm{g} / \mathrm{mL}$

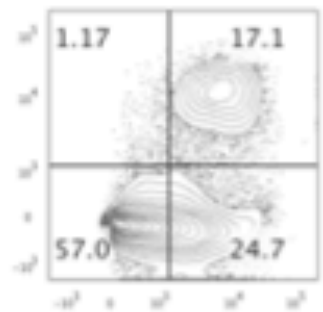

Anti IL- $1 \beta 0,5 \mu \mathrm{g} / \mathrm{mL}$

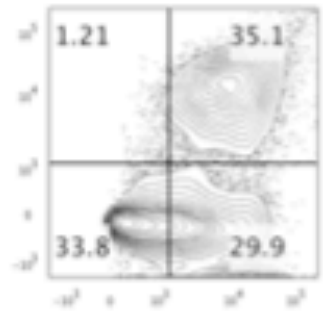

IL-1RA 0,5 $\mathrm{\mu g} / \mathrm{mL}$

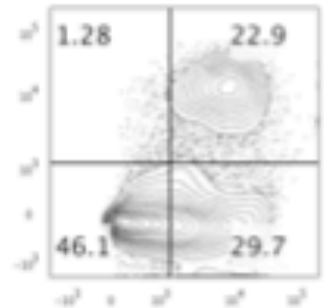

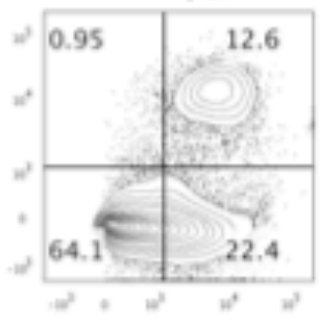

FLA-BsDOT

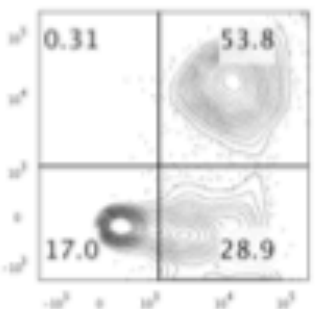

Anti IL-1 $\alpha 1 \mu \mathrm{gg} / \mathrm{mL}$

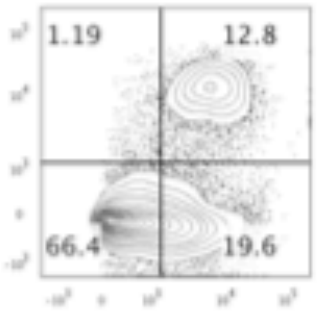

Anti IL-1ß $1 \mu \mathrm{g} / \mathrm{mL}$

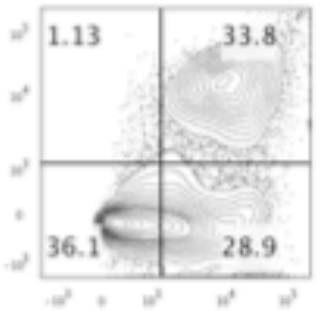

IL-1RA $1 \mu \mathrm{g} / \mathrm{mL}$

Figura 7: IL-1 influencia a maturação de BMDCs por flagelina citosólica. Expressão de CD86 em DCs $\left(3 \times 10^{5}\right.$ ) (gate em CD11c+) de animais C57BL/6 e IL-1R ${ }^{-/-}$estimuladas com flagelina citosólica $(3 \mu \mathrm{g} / \mathrm{mL})(\mathrm{FLA}-\mathrm{BsDOT})$ e tratadas com antagonista de IL-1R e anticorpos neutralizantes para IL-1 $\alpha$ e IL-1 $\beta$ nas concentrações indicadas. Dados representativos de três experimentos. $(n=3)$. 
O mesmo perfil observado na expressão de CD86 foi encontrado na produção de IFN$\gamma$ por esplenócitos de animais OT-II, onde a presença de IL-1R e anticorpos neutralizantes para IL-1 $\alpha$ e IL-1 $\beta$ reduziu de maneira dose dependente a produção dessa citocina (figura 8A e 8B). Uma vez mais, a influência da IL-1 $\alpha$ na polarização dos esplenócitos para o perfil Th1 se mostrou predominante em relação à IL-1b.

A
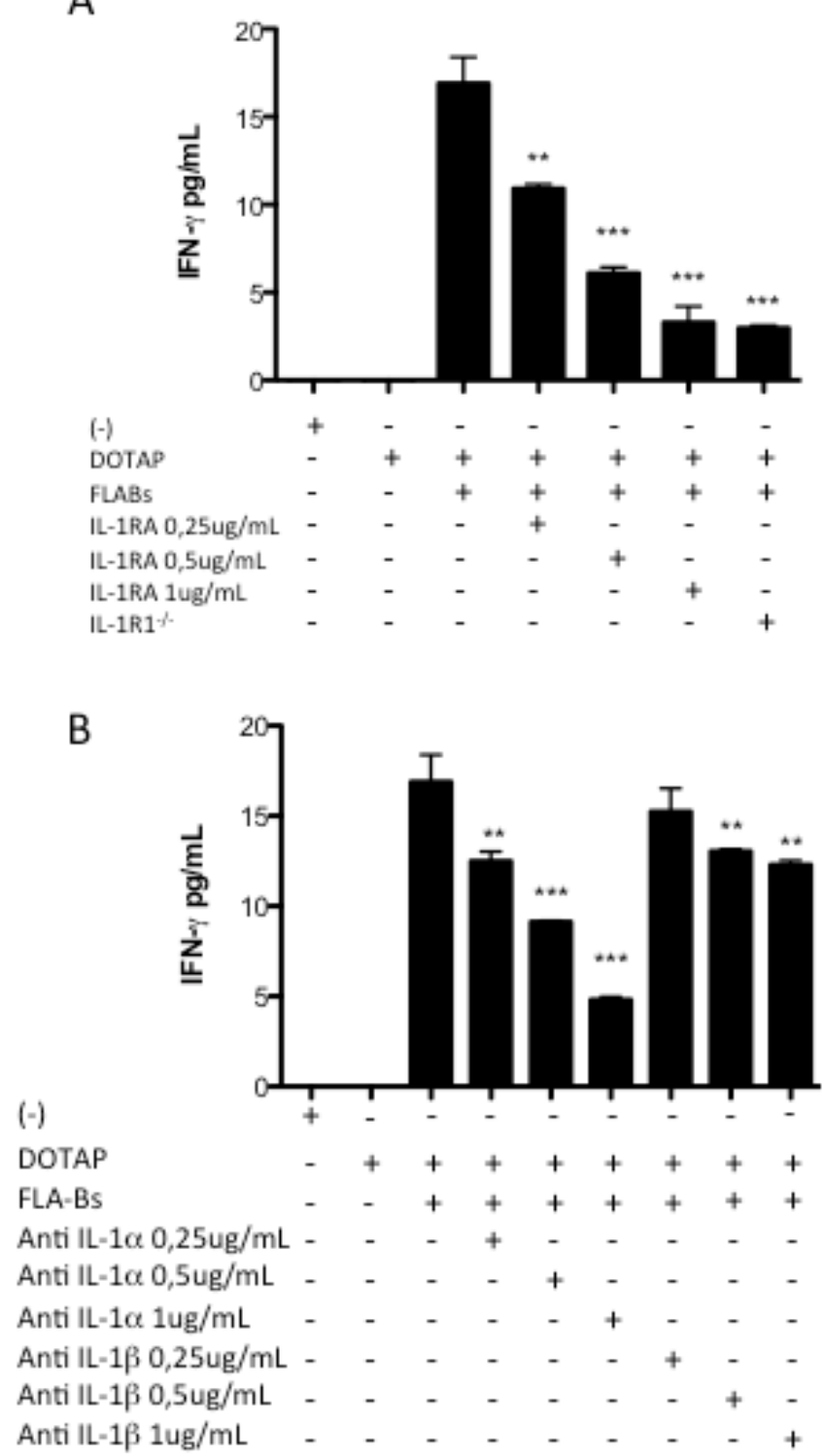

Figura 8: IL-1 participa na maturação funcional de DCs por flagelina citosólica. Produção de IFN- $\gamma$ por esplenócitos de camundongos OT-II $\left(4 \times 10^{5}\right)$ co-cultivados com BMDCs de animais C57BL/6 $\left(1 \times 10^{5}\right)$ estimuladas com $3 \mu \mathrm{g} / \mathrm{mL}$ de flagelina citosólica (FLA-BsDOT) e pulsadas com OVA $(5 \mu \mathrm{g} / \mathrm{mL})$, na presença de doses crescentes de IL-1RA (A) e anti-IL-1 $\alpha$ e anti-IL-1 $\beta$ (B) por $120 \mathrm{~h} .{ }^{*} \mathrm{p}<0,05,{ }^{* *} \mathrm{p}<0,005$ e ${ }^{* * *} \mathrm{p}<0,001$ em relação à BMDCs estimuladas com flagelina citosólica e não tratadas. Dados representativos de quatro experimentos. $(n=3)$. 
Uma vez que a sinalização de IL-12 em linfócitos T CD4 leva à diferenciação para o perfil Th1 de resposta imune (77), decidimos avaliar a produção desta citocina nas culturas de DCs estimuladas com flagelina citosólica. A produção desta citocina poderia explicar a capacidade da flagelina citosólica em induzir a produção de IFN- $\gamma$ por esplenócitos OT-II. Pudemos observar a presença de IL-12 no sobrenadante de culturas de DCs estimuladas com flagelina citosólica, após $120 \mathrm{~h}$ de cultura (Figura 9). Condizente com a produção de IFN- $\gamma$ pelos esplenócitos OT-II, a inibição de catepsina B, a neutralização de IL-1 por IL-1RA e a estimulação de $D C s$ provenientes dos animais $\mathrm{IL}_{-} 1 \mathrm{R}^{-/}$, reduziram a produção de $\mathrm{IL}-12$, mostrando novamente o papel da IL-1 contribuindo para a diferenciação para Th1. A participação da citocina IL-1 $\alpha$ neste fenômeno se mostrou mais evidente ainda, com a redução na produção de IL-12 na presença de anticorpos neutralizantes, de forma dose dependente. 


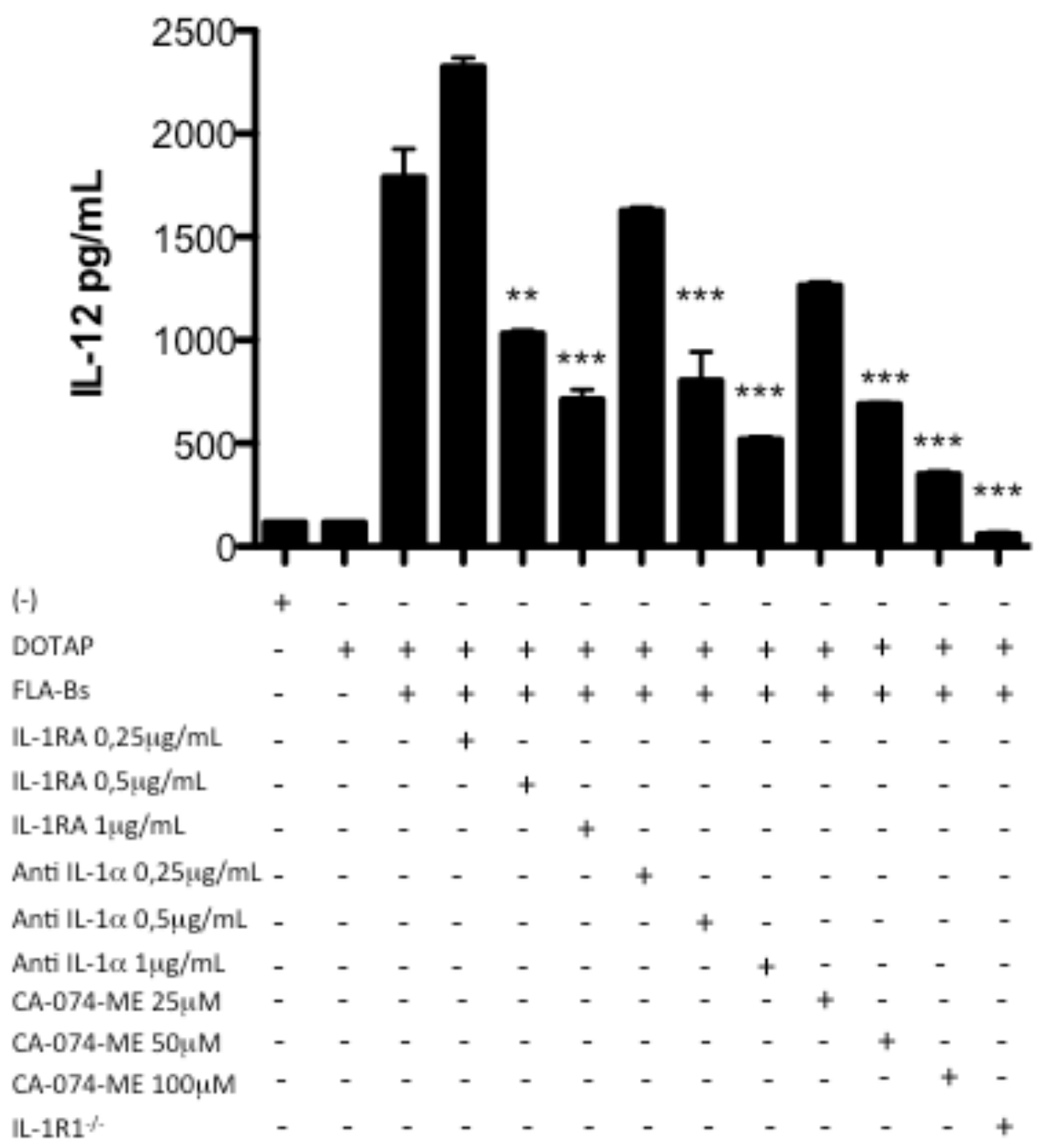

Figura 9: IL-1 é necessária para a produção de IL-12 por DCs estimuladas com flagelina citosólica. Produção de IL-12 por DCs de animais C57BL/6 $\left(1 \times 10^{5}\right)$ estimuladas com $3 \mu \mathrm{g} / \mathrm{mL}$ de flagelina citosólica (FLA-BsDOT), na presença de doses crescentes de IL-1RA, anti-IL-1 $\alpha$ e CA-074-ME por $120 \mathrm{~h}$. ${ }^{*} p<0,05,{ }^{* *} p<0,005 \mathrm{e}^{* * *} \mathrm{p}<0,001$ em relação à BMDCs estimuladas com flagelina citosólica sem tratamentos. Dados representativos de quatro experimentos. $(n=3)$.

A presença de IL-1 $\alpha$ e IL-1 $\beta$ recombinantes nas co-culturas de DCs pulsadas com OVA e esplenócitos OT-II induziu a produção de IFN-g (Figura 10A) e IL-12 (Figura 10B), de maneira dose-dependente, mesmo na ausência da flagelina, confirmando o papel das mesmas na maturação funcional de DCs. 


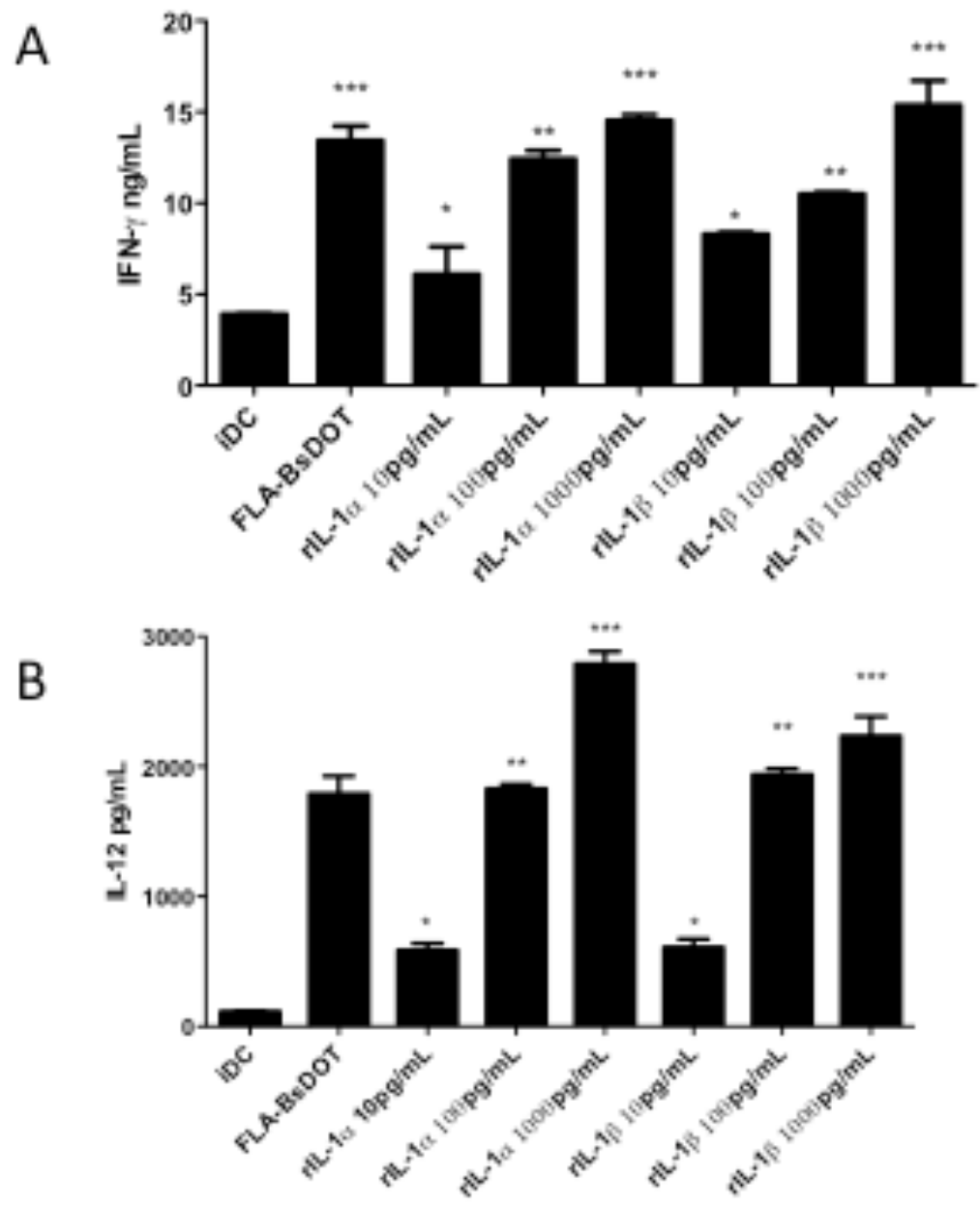

Figura 10: IL-1 induz maturação funcional de DCs. Produção de IFN- $\gamma(A)$ e IL-12 (B) por esplenócitos de camundongos OT-II $\left(4 \times 10^{5}\right)$ co-cultivados com BMDCs de animais C57BL/6 $\left(1 \times 10^{5}\right)$ estimuladas com doses crescentes de IL-1 $\alpha$ e IL- $1 \beta$ recombinantes e pulsadas com OVA $(5 \mu \mathrm{g} / \mathrm{mL})$, por $120 \mathrm{~h} .{ }^{*} p<0,05, * * p<0,005$ e $* * * p<0,001$ em relação à $D C s$ estimuladas com $3 \mu \mathrm{g} / \mathrm{mL}$ de flagelina citosólica (FLA-BsDOT). Dados representativos de quatro experimentos. $(n=3)$.

Uma vez que in vitro, DCs estimuladas com flagelina citosólica foram capazes de induzir a polarização de esplenócitos para um perfil Th1, nosso próximo passo foi determinar se esta via de ativação também ocorre in vivo. Para isso, utilizamos um protocolo que nos possibilitou analisar a resposta imune in vivo. Com um regime de "prime e boost" homólogo, $20 \mu \mathrm{g}$ de flagelina purificada de S. typhimurium foram administrados por via intraperitoneal para camundongos C57BL/6 e deficientes em TLR5, NLRC4, MyD88 e caspase-1 de acordo com o esquema da figura 12A. Utilizamos a flagelina de $S$. typhimurium, pois esta tem a 
capacidade de entrar no citosol das células sem o auxílio de vesícula lipídica, como mostrado na figura 11 por imunofluorescência. 
DAPI

FLISt Vermelho

Merge

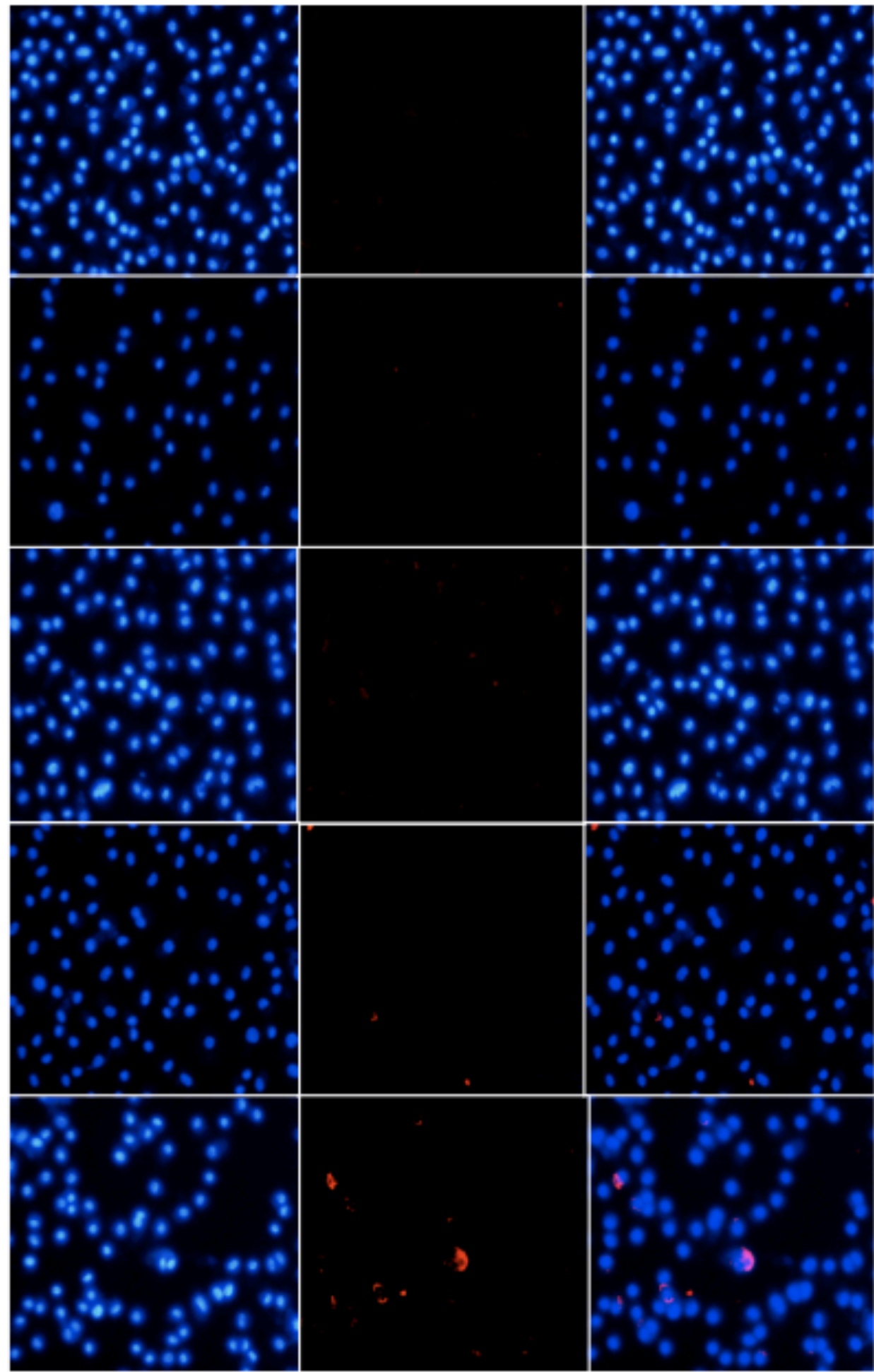

$(-)$

FLISt livre
$30 \mathrm{~min}$

FLISt livre

$1 \mathrm{~h} 30 \mathrm{~min}$

FLISt livre $3 \mathrm{~h}$

FLISt livre 6h

Figura 11: Detecção de flagelina proveniente de $S$. typhimurium no interior de macrófagos peritoneais. Macrófagos peritoneais $\left(1 \times 10^{5}\right)$ foram estimulados com $3 \mu \mathrm{g} / \mathrm{mL}$ de flagelina proveniente de $S$. typhimurium na forma livre e, após cada período determinado, as células foram preparadas para imunofluorescência para detectar a presença da flagelina no citosol dos macrófagos. Em azul, marcação dos núcleos com DAPI, em vermelho a flagelina no citosol dos macrófagos. Dados representativos de três experimentos. $(n=3)$. 
Os animais imunizados foram eutanasiados quatro dias após o boost, como esquematizado na figura $11 \mathrm{~A}$, e os esplenócitos cultivados para detecção de citocinas no sobrenadante. A imunização com flagelina foi capaz de induzir a produção de IL-1 $\alpha$ pelos esplenócitos cultivados por 24h. Também pudemos observar a produção de IL-12 e IFN- $\gamma$ nas culturas de 120h, mas não nos animais controle (Figura $12 \mathrm{C}$ e 12D), indicando que o protocolo de imunização utilizado foi capaz de promover diferenciação dos linfócitos T para Th1. Tanto a produção de IL-1 $\alpha$, quanto de IL-12 e IFN- $\gamma$ seguiram o padrão observado in vitro, sendo dependentes de caspase-1 e MyD88, pois níveis reduzidos ou ausentes foram encontrados nos esplenócitos deficientes para essas moléculas (Figura 12B, C, D). Estes resultados mostram a participação de caspase-1 e MyD88 para o desenvolvimento de resposta imune induzido por flagelina, tanto in vitro, quanto in vivo.

Também foram encontrados altos níveis de IgG anti-flagelina após o regime de imunização (Figura 11E), com predomínio do isotipo IgG1 (Figura 12F) em relação a IgG2a (Figura 12G). Interessantemente, não houve diferença estatística na produção de IgG total entre os animais estudados. No entanto, foi observada tendência à redução na produção de IgG1 na ausência de TL5, NLRC4 e MyD88, com significativo aumento na produção de IgG2a na ausência de NLRC4 e caspase-1 (Figura 12F e 12G). 
Figura 12: Flagelina induz ativação da resposta imune adaptativa in vivo. A: Protocolo de prime e boost homólogo adotado para os experimentos de imunização dos animais com flagelina. B: Produção de IL-1 $\alpha$ por $10^{6}$ esplenócitos de animais imunizados após cultura de $24 \mathrm{~h}$. C: Produção de IL-12 por $10^{6}$ esplenócitos de animais imunizados após cultura de 120h. C: Produção de IFN- $\gamma$ por $10^{6}$ esplenócitos de animais imunizados após cultura de 120h. D, E, F: Presença de anticorpos IgG (D), IgG1 (E) e IgG2c (F) específicos para flagelina de $S$. typhimurium no soro dos animais, detectados por ELISA. ${ }^{*} p<0,05$, $* * p<0,005$ e ${ }^{* * *} p<0,001$ em relação ao animal C57BL/6 imunizado. Dados representativos de três experimentos. $(n=3)$ 
A Dia 0

Dia 35

Dia 39
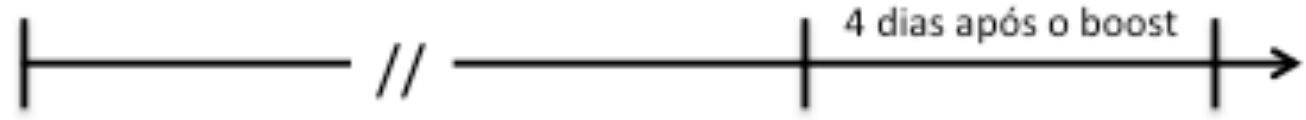

Prime com 20ug

flagelina de Salmonella

typhimurium i.p.

B

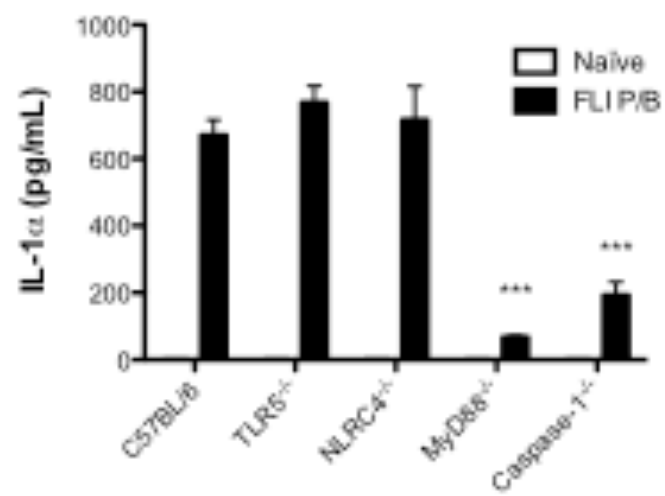

D

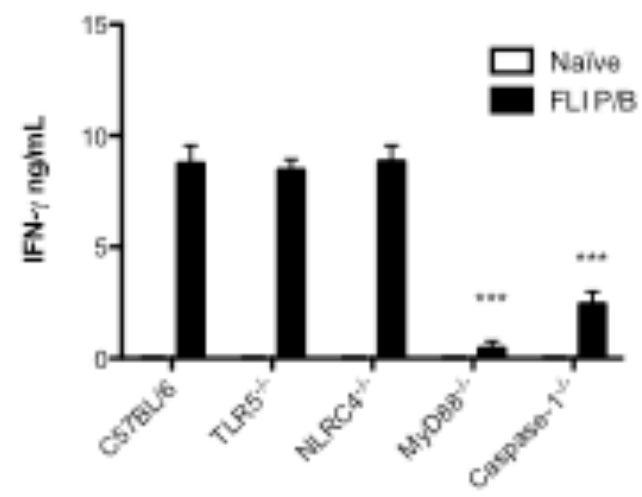

F

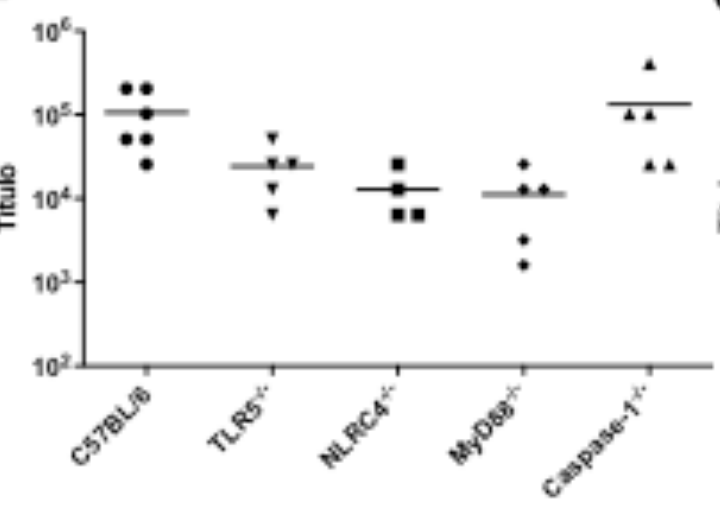

Boost com 20ug

flagelina de Salmonella

typhimurium i.p.

C

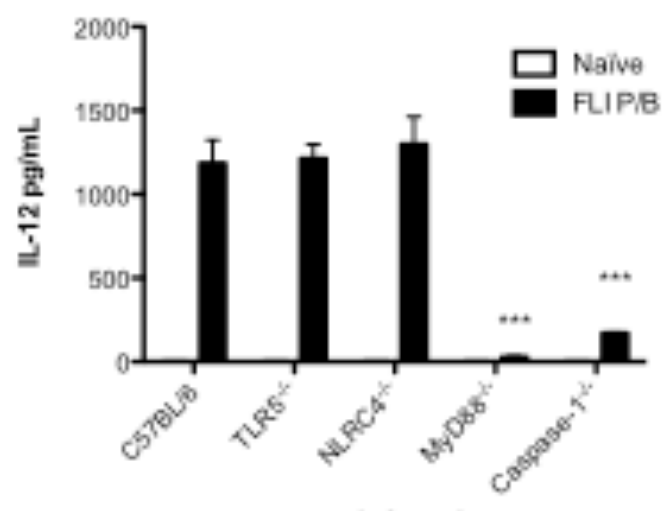

E

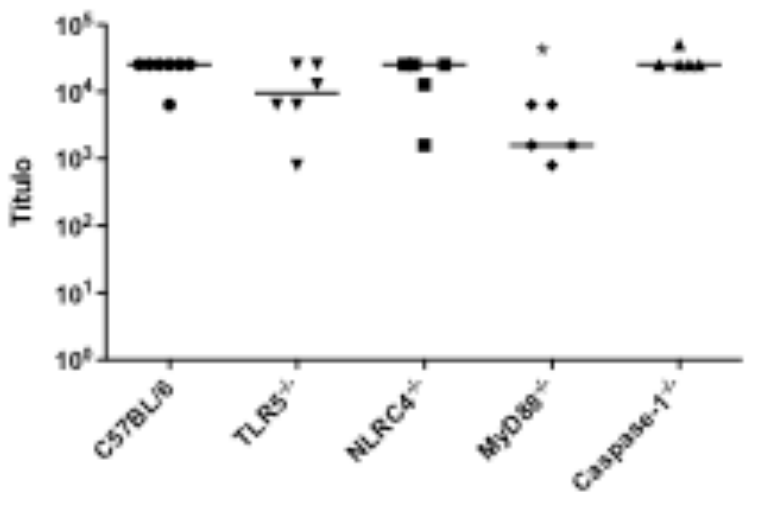

G $\quad \operatorname{lgG} 2 \mathrm{c}$

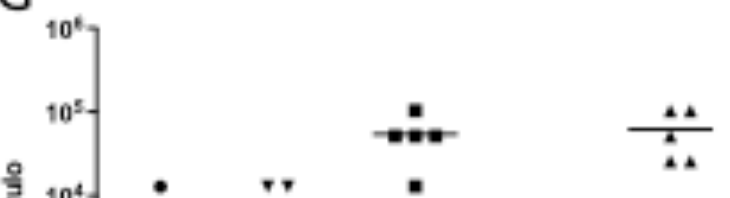


Para determinar se as respostas imunes induzidas por flagelina in vivo seriam capazes de proteger os animais contra uma infecção com S. typhimurium, nós utilizamos o mesmo protocolo descrito acima, e infectamos os animais intraperitonealmente com $5 \times 10^{3} \mathrm{CFU}$ no quarto dia após o boost (Figura 13A).

Pudemos observar que a infeç̧ão por si só já foi capaz de induzir aumento no tamanho dos baços dos animais. Este aumento foi reduzido nos animais previamente imunizados com flagelina no regime prime e boost (Figura 13B), e foi menos pronunciado nos animais deficientes em caspase-1 e MyD88 imunizados com flagelina. Nos animais imunizados, observamos uma redução no número de CFU recuperadas do baço e fígado de todos os animais estudados, mas em menor escala para os animais deficientes em MyD88. Interessantemente, com exceção dos animais $\mathrm{MyD} 88^{-/-}$, não foram encontradas bactérias nos pulmões dos animais imunizados, indicando que a disseminação bacteriana foi controlada por um mecanismo que envolve MyD88 (Figura 13C, 13D e 13E).

A infecção com S. typhimurium leva à morte dos animais WT não imunizados em aproximadamente dez dias (Figura 13 F). Pudemos observar a maior suscetibilidade dos animais $\mathrm{TLR}^{\%}{ }^{-/}, \mathrm{NLRC4}^{-/}$, , caspase- $1^{-/}$e $\mathrm{MyD} 88^{-/}$, que apresentam taxa de sobrevivência reduzida quando infectados. Já nos animais naïve, observamos a maior suscetibilidade dos animais deficientes em caspase-1 e MyD88, em relação aos animais $\mathrm{TLR}^{-/-}$e $\mathrm{NLRC4}^{-/}$que, ainda mais suscetíveis em relação aos animais WT, mostraram-se mais resistentes à infecção. Seguindo o mesmo padrão, os animais deficientes em caspase-1 e MyD88 previamente imunizados com flagelina, ainda mostraram maior suscetibilidade, sendo os animais com maior taxa de mortalidade. Em seguida estão os animais deficientes em TLR5 e NLRC4, que, por mais que tenham controle da carga bacteriana no quarto dia após a infecção, sucumbem à esta antes dos animais WT (Figura 13F). Por mais que a imunização com flagelina no regime prime e boost tenha contribuído para o controle da carga bacteriana e aumentado a sobrevida dos animais, essa não foi capaz de proteger totalmente os animais WT contra o desafio letal. 
Figura 13: A imunização com flagelina interfere no controle de S.typhimurium. A: Protocolo de prime e boost homólogo adotado para os experimentos de imunização dos animais com flagelina e posterior desafio com S.typhimurium. B: Foto dos baços dos animais naïve e imunizados 4 dias após o desafio com S.typhimurium. C: Contagem de CFU do baço dos animais naïve e imunizados 4 dias após o desafio com S.typhimurium. D: Contagem de CFU do fígado dos animais naïve e imunizados 4 dias após o desafio com S.typhimurium. E: Contagem de CFU do pulmão dos animais naïve e imunizados 4 dias após o desafio com S.typhimurium. F: Mortalidade dos animais naïve após o desafio com S.typhimurium. F: Mortalidade dos animais imunizados após o desafio com S.typhimurium. Dados representativos de três experimentos. $(n=5)$. 
A

Dia 0

Dia 35

Dia 39

Dia 42

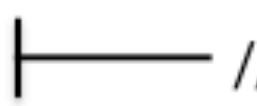

//

Prime com $20 \mu \mathrm{g}$

flagelina de Salmonella

typhimurium i.p.

Boost com 20ug Infecção com

flagelina de Salmonella $\quad 5 \times 10^{3} \mathrm{CFU}$

typhimurium i.p.
Eutanásia para contagem de CFU

nos órgåos
B

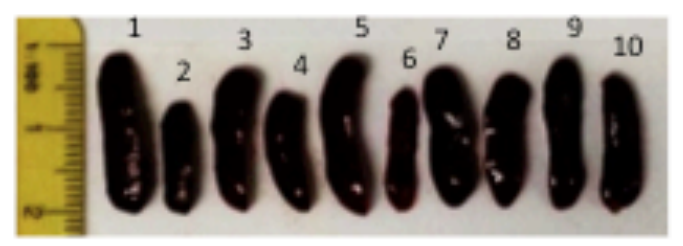

1: C57BL/6 naive

2: C57BL/6 FLI P/B

3: TLR5\% naive

4: TLR5 ${ }^{\gamma}$ FLI P/B

5: NLRC4 ${ }^{*}$ naive
6: NLRC4\% FLI P/B

7: MyD88\% naive

8: MyD88* Fu P/B

9: Caspase-1 ${ }^{\gamma}$ - naive

10: Caspase-1/-FLI P/B

C

Baços

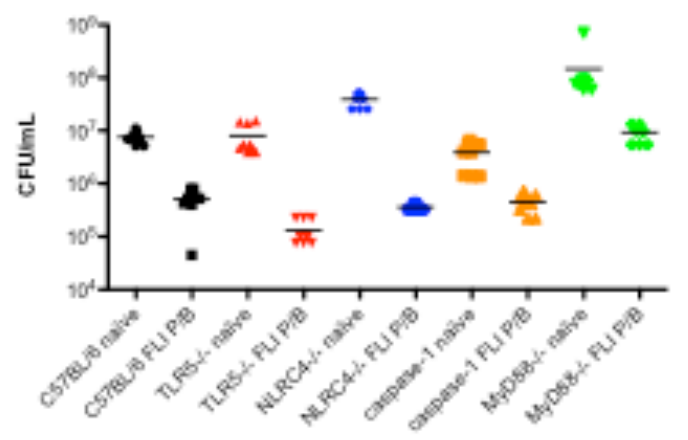

D

Figados

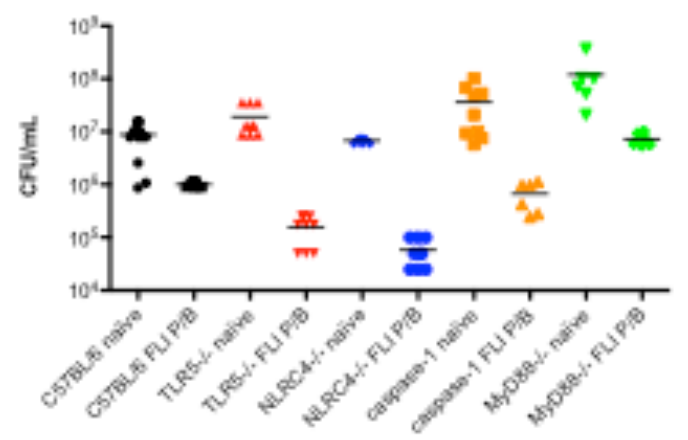

F

Nalve

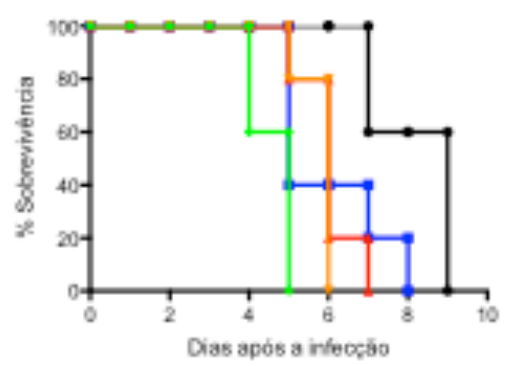

$\rightarrow$ c5tela

- TLR5.

- NLRC4.f.

- Caspase-14

+ MyDBs.

E

Pulmōes

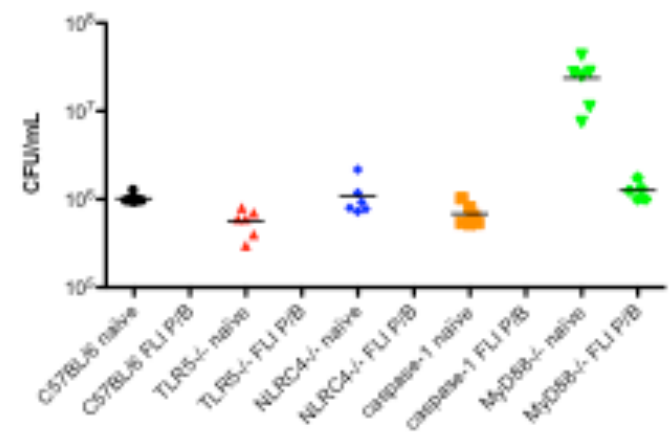

G

Imunizados

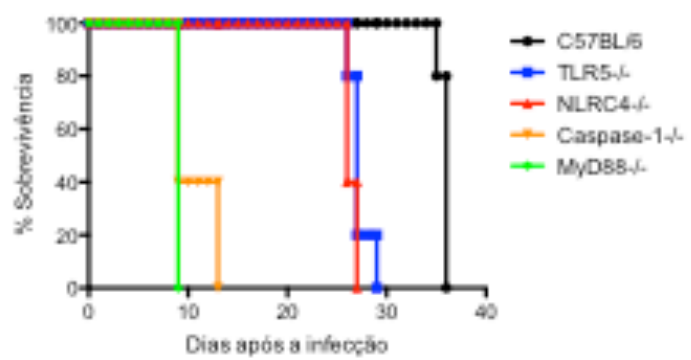




\section{DISCUSSÃO}

O reconhecimento de padrões moleculares microbianos sempre foi considerado imprescindível para o desenvolvimento de resposta imune contra patógenos. Após a infecção com S. typhimuirium, a flagelina é imediatamente reconhecida por TLR5 nas APCs, levando à ativação de NFKB e produção de citocinas próinflamatórias (64). Estes sinais montam um ambiente favorável para o recrutamento de células do sistema imune e ativação de linfócitos T. O desenvolvimento de resposta adaptativa induzido por $S$. typhimurium se baseia na ativação de linfócitos $\mathrm{T}$, posterior formação de memória $\mathrm{e}$ produção de anticorpos. Como descrito por vários grupos de pesquisa, a flagelina em sua forma livre é capaz de induzir aumento de moléculas de MHC II e coestimuladoras nas DCs de animais C57BL/6 (Figura 3A) (59-62). A maturação por flagelina livre é dependente da via de sinalização de TLR5 e, na ausência de TLR5 e MyD88 não há aumento de moléculas coestimuladoras $(63,67,65)$.

Uma vez dentro dos macrófagos, DCs e células epiteliais, S. typhimurium, entre outras bactérias virulentas, usam um sistema de secreção que libera diversas proteínas no citosol da célula infectada, dentre elas a flagelina $(78,9)$. No citosol, a flagelina é reconhecida pelo inflamassoma Naip5,6/NLRC4 que, quando ativado, promove a ativação de caspase-1, culminando na que clivagem de seus substratos IL-1 $\beta$ e IL-18, e indução de piroptose $(78,21,79,80,22)$. Esses mecanismos efetores, aliados a mecanismos menos convencionais como ativação da iNOS (25), são conhecidamente importantes para ativação da resposta inflamatória e controle inicial de bactérias patogênicas. No entanto, pouco se conhece a respeito do potencial da flagelina citosólica na ativação de DCs e indução da resposta imune adaptativa. A ativação de DCs com flagelina inserida em vesículas lipídicas catiônicas que permitem a sua entrega no citoplasma das células, induziu um aumento de moléculas coestimulatórias, similar ao obervado quando essas células foram estimuladas com a flagelina livre. Nesse caso, o efeito foi mantido em DCs de animais $\operatorname{TLR} 5^{-/}$, demonstrando que a flagelina pode ativar vias distintas que culminam na maturação de DCs.

Pouco se sabe a respeito do papel do inflamassoma Naip5,6/NLRC4 na indução da imunidade adaptativa. Quanto à imunidade celular, o trabalho de Kupz et al. (2012) (70) demonstrou a importância da IL-18, produzida em resposta à ativação de NLRC4 durante a 
infecção com S. typhimurium, para a ativação policlonal de células T CD8 não específicas para a flagelina. Como potente indutor da produção de IFN- $\gamma(81,82)$ a IL-18 poderia ter papel importante na ativação de macrófagos e DCs para auxiliar na resolução da infecção. Por outro lado, a ativação de NLRC4 pela flagelina durante a infecção por L. pneumophila está relacionada com menor proteção contra a infecção e menor ativação de células T específicas para flagelina (83), mostrando que ainda há muito a ser estudado a respeito dos potencial da flagelina citosólica na indução da resposta imune celular.

Já em relação à imunidade humoral, Naip5, NLRC4 e caspase-1 parecem ter papel na indução da produção de IgG e também no perfil dos isotipos produzidos em resposta à flagelina e também em resposta à OVA co-administrada com a flagelina $(81,103)$. VijayKumar e col. (81) mostraram que na ausência de TLR5 e NLRC4, a produção de IgG permanece inalterada. No entanto, a ausência de ambos TLR5 e NLRC4 leva à redução drástica na produção de anticorpos contra a flagelina e contra a OVA, em modelo no qual a flagelina é estudada como adjuvante, mostrando que ambas as vias exercem um papel redundante para a produção de anticorpos. Lopes-Yglesias et al., 2014 (103), demonstraram ainda que Naip5 e caspase-1 apresentam um papel redundante com TLR5 para a produção de IgG1 anti-falgelina e anti-OVA, mas apresentam um efeito aditivo para a produção de $\operatorname{lgG} 2 \mathrm{a}$.

Os dados mostrados neste trabalho demonstram uma forma alternativa de ativação de DCs, e consequentemente de linfócitos T pela flagelina citosólica, uma vez que esses efeitos acontecem de maneira independente de TLR5 e, surpreendentemente, também independente de NLRC4, porém, envolvem a caspase-1 e MyD88. Existem relatos da interação entre MyD88 e caspase-1, apesar de contraditórios. Nuñes et al. (2007) (84) apresentaram um modelo para a estrutura de MAL, no qual havia uma porção que poderia ser clivada por caspase-1. O trabalho de Miggin et al. (2007) (85) demonstra a ativação de NF-KB pela sinalização de IL-1 e que a ativação deste fator de transcrição é regulada por caspase-1. Com a sinalização de IL-1, as proteínas adaptadoras MyD88 e MAL são recrutadas e há a clivagem de MAL por esta protease. Segundo os resultados deste trabalho, a clivagem de MAL pela caspase-1 é imprescindível para que haja a ativação de NF-KB, sugerindo a colaboração dos inflamassomas para a ativação de TLRs, uma vez que MyD88 e MAL também são recrutadas para a sinalização de vários TLRs. Já o trabalho de Ulrichts et al. 
(2010) (86) rebate os resultados apresentados por Miggin et al. (2007) dizendo que a clivagem de MAL por caspase-1 não é necessária para a sua sinalização, e que as células transfectadas com um mutante de MAL que não possui a região para clivagem pela caspase1, possuem sinalização inalterada. Ainda, os autores sugerem que essa clivagem de MAL gera uma forma inibitória para a ativação de NFKB.

Em nosso modelo, a IL-1, especialmente a IL-1 $\alpha$, parece ser o fator de ligação principal de interação entre a caspase-1 e MyD88, uma vez que a produção de IL-1 $\alpha$ por DCs em resposta à flagelina citosólica se mostrou parcialmente dependente de caspase-1, assim como a indução de linfócitos Th1 por essas DCs. Ainda, a sinalização via IL-1R requer MyD88 como molécula adaptadora. Dessa maneira, podemos propor que DCs ativadas por flagelina citosólica produzem IL-1 $\alpha$ que agem de maneira autócrina, induzindo a produção de fatores necessários para a indução da polarização de linfócitos T CD4 para o perfil Th1. E, nesse caso, a IL-12, conhecida ponte entre imunidade inata e imunidade adaptativa seria o candidato mais provável. De fato, a IL-12 foi encontrada em DCs estimuladas com flagelina citosólica em situações nas quais a IL- $1 \alpha$ também estava presente e sua sinalização preservada, indicando o eixo IL-1 $\alpha /$ IL-12 como majoritário na indução de Th1 em nosso modelo. A secreção de IL-1 $\beta$ também já foi relacionada à produção de IL-12 (86-88), em diversos modelos. De fato, ainda que em menor grau quando comparado à neutralização de IL-1 $\alpha$, a neutralização da IL-1 $\beta$ induziu uma redução da produção de IL-12 por DCs em resposta à flagelina citosólica e IFN- $\gamma$ por esplenócitos OTII em cultura com essas DCs pulsadas com OVA. No entanto, a secreção de IL-1 $\alpha$, IL-12 e IFN- $\gamma$, apesar de reduzidas na ausência de caspase-1, não está abolida, como é o caso da IL-1 $\beta$, sugerindo que esse fator não é primordial para os efeitos observados. Por outro lado, a secreção de IL-17 por linfócitos OTII em cultura com DCs ativadas por flagelina citosólica é completamente abolida na ausência de NLRC4 e caspase-1 e é apenas observada quando as DCs foram previamente primadas com LPS. Este perfil é exatamente o mesmo perfil encontrado para a secreção de IL-1 $\beta$ por DCs em resposta à flagelina citosólica, condizente com o já elucidado papel dessa citocina para a polarização de linfócitos T CD4 para o perfil Th17 (55).

Uma vez que a produção de IL-1 $\alpha$ por DCs permanece preservada na ausência de NLRC4, abre-se a possibilidade de existência de vias adicionais à do inflamassoma induzidas pela flagelina citosólica que culminariam na secreção dessa citocina. De fato, há um 
crescente interesse na literatura no intuito de entender os mecanismos moleculares envolvidos na liberação de IL-1 $\alpha$. No entanto, trabalhos recentes sugerem a participação dos inflamassomas nesse processo. A participação dos inflamassomas foi demonstrada por dois grupos diferentes, que demonstraram a necessidade da presença da caspase-1, mas não a sua função enzimática para a liberação da IL-1a (52). Recentemente dois trabalhos mostraram a importância da IL-1a no desenvolvimento de imunidade contra patógenos e da doença. O trabalho de Lukens et al. (2013) (87) sugere que a IL-1a participa do processo inflamatório destrutivo, independente da participação dos inflamassomas. Entretanto, o trabalho de Barry et al. (2013) (88) mostra que a IL-1a inicia a resposta inflamatória induzida pela infecção por L. pneumophila independente de caspase-1 e NLRC4.

Dados recentes de nosso grupo mostraram que a flagelina citosólica é capaz de ativar uma via lisossomal, independente de NLRC4 e caspase-1). Ainda que o mecanismo envolvido na desestabilização dos lisossomos pela flagelina citosólica não esteja elucidado, as catepsinas lisossomais B e D, liberadas no processo, são responsáveis pela indução de um processo de morte celular inflamatória, que está acompanhada pela liberação de IL-1 $\alpha$ e é temporalmente relacionada ao controle de S. typhimurium por macrófagos. Os níveis de IL$1 \alpha$ secretada por macrófagos caspase- $1^{-/}$em resposta à flagelina citosólica são menores quando comparados aos macrófagos WT, semelhante ao observado nesse trabalho com DCs. Ainda, a inibição farmacológica de catepsina B foi capaz de abolir a produção de IL-1 $\beta$ e reduzir a produção de IL-1 $\alpha$ por macrófagos de animais selvagens, mostrando que a via lisossomal induzida pela flagelina citosólica está envolvida com a regulação das respostas do macrófagos dependentes do inflamassoma (89), como previamente demonstrado para o inflamassoma NLRP3 (52). De maneira similar, a inibição de catepsina B durante a estimulação de DCs com flagelina citosólica reduziu de maneira dose-dependente a secreção de IL-1 $\alpha$ por essas células, com o mesmo impacto na secreção de IFN-g pelos linfócitos T, pontuando mais uma ação para a via lisossomal ativada pela flagelina. No entanto, ainda não se sabe se a IL-1 $\alpha$ é liberada passivamente durante a morte lisossomal ou se há algum mecanismo ativo de secreção mediado por caspase-1 e catepsina $B$, questões que estão sendo abordadas por nosso grupo.

Estudos anteriores demonstraram a capacidade da flagelina em induzir uma resposta Th2 com alta produção de IL-4 in vivo $(68,69)$. Já durante a infecção com S. typhimurium, a 
resposta contra a flagelina presente na bactéria induz resposta do tipo Th1, com alta produção de IFN- $\gamma$, o que pode ser uma evidência do potencial da flagelina em ativar vias distintas. Ainda, os autores mostram que a imunização com flagelina é importante para o controle da infecção, indicando que, sendo Th1 ou Th2, a resposta induzida pela flagelina é utilizada durante a infecção. Nossos dados obtidos in vivo confirmam o efeito da imunização com flagelina na indução de imunidade protetora ao desafio com S. typhimurium, uma vez que animais previamente imunizados com flagelina apresentaram uma menor carga bacteriana e sobreviveram mais tempo ao desafio letal com essa bactéria em comparação com os animais não imunizados. Importante ressaltar que, apesar de proporcionar um melhor controle da infecção, a imunização com flagelina não foi capaz de induzir imunidade estéril, nem de resgatar os animais da morte.

Os dados envolvendo os mecanismos efetores operantes no controle da infecção in vivo pela S. typhimurium são contraditórios. Há relatos que mostram a necessidade de NLRC4, TLR5 e MyD88 para a resistência contra a infecção, mas sempre lembrando a importância de especificar a cepa de bactéria utilizada, as condições de manutenção e a microbiota dos animais $(17,71,90,91)$. Ainda, há diferenças na via de infecção, como o trabalho de Carvalho et al. (2012) (91), que cita o aumento na mortalidade dos animais infectados por intraperitoneal, quando comparados aos animais infectados por via oral. Também, os autores mostram que a quantidade de CFU presente nos órgãos dos animais infectados não varia entre WT e knockouts no $3^{\circ}$ dia de infecção. Essa variação só aparece a partir do $7^{\circ}$ dia, o que também pode explicar os dados observados neste trabalho, com a mesma quantidade de bactérias nos animais WT e knockouts, exceto MyD88 $8^{-1}$ no $4^{\circ}$ dia após a infecção. O fato de animais MyD88 ${ }^{-/}$e caspase- $1^{-/}$previamente imunizados com flagelina apresentarem mortalidade precoce em relação à outras linhagens estudadas, sugere a participação do eixo IL-1 $\alpha /$ Th1 na imunidade protetora à infecção com S. typhimurium. Ainda, foram encontrados altos níveis de IL-1 $\alpha$ e IFN- $\gamma$ no baço dos camundongos WT, TLR5 ${ }^{-/}$ e $\mathrm{NLRC}^{-\%}$, mas não de animais caspase- ${ }^{-/}$e, especialmente, MyD88 ${ }^{-\%}$, suportando a nossa hipótese. Recentemente, Barry et al. (2013) (88) demostraram que o papel da IL-1 $\alpha$, produzida de maneira independente de NLRC4, durante a infecção por L. pneumophila,. No entanto, nesse caso, a IL-1 $\alpha$ foi produzida na ausência também de caspase-1. 
A ativação de linfócitos T não cognatos, ou seja, não específicos, por uma via de ativação por citocinas, como a IL-12 e IL-18 $(92,93,70,94)$ já foi descrita em modelos diversificados. Nossos dados, em conjunto, propõem a ativação de linfócitos Th1 via IL-1 $\alpha$ produzida por DCs como um novo mecanismo de ação para a flagelina, conhecido estimulador da resposta imune, e largamente estudada por seu potencial adjuvante. Por uma via envolvendo a liberação de catepsinas lisossomais, a flagelina citosólica é capaz de induz a secreção ou liberação de IL-1 $\alpha$ por DCs, que, por sua vez, parece agir de maneira autócrina para induzir a secreção de IL-12, o fator conhecido como responsável pela polarização de linfócitos T para o perfil Th1 (77), protetor em diversos modelos de infecção $(68,69)$. 


\section{CONCLUSÕES}

- A flagelina citosólica induziu aumento da expressão de moléculas coestimulatórias e secreção de IL-1 $\alpha$ por DCs de maneira independente de TLR5 e NLRC4. Esses efeitos foram reduzidos na ausência de caspase-1 e abolidos na ausência de MyD88.

- A ausência de IL-1 $\beta$ e, especialmente, IL-1R e IL-1 $\alpha$ reduziu a produção de IL-12 por DCs estimuladas com flagelina citosólica e a produção de IFN-g por espelnócitos de animais OTII em co-cultura com essas DCs.

- A produção de IL-1 $\alpha$, IL-1 $\beta$, IL-12 e IFN- $\gamma$ foi alterada na presença de inibidores farmacológicos para catepsina B, sugerindo o envolvimento da via lisossomal induzida por flagelina citosólica nesses efeitos.

- A imunização prévia de animais com flagelina aumentou a sobrevivência dos mesmos contra o desafio com S. typhimurium, sendo que camundongos caspase- $1^{-/-}$e MyD88${ }^{\prime}$ apresentaram as taxas mais precoces de mortalidade. 


\section{REFERÊNCIAS}

1. Banchereau J, Steinman RM. Dendritic cells and the control of immunity. Nature. 1998 Mar 19;392(6673):245-52.

2. Sallusto F, Lanzavecchia A. Mobilizing dendritic cells for tolerance, priming, and chronic inflammation. J Exp Med.1999 Feb 15;189(4):611-4.

3. Janeway CA, Jr., Medzhitov R. Innate immune recognition. Annu Rev Immunol. [Review]. 2002;20:197-216.

4. Kaisho T, Akira S. Toll-like receptor function and signaling. J Allergy Clin Immunol. 2006 May;117(5):979-87; quiz 88.

5. Akira S, Hoshino K, Kaisho T. The role of Toll-like receptors and MyD88 in innate immune responses. J Endotoxin Res. 2000;6(5):383-7.

6. Tomalka J, Ganesan S, Azodi E, Patel K, Majmudar P, Hall BA, et al. A novel role for the NLRC4 inflammasome in mucosal defenses against the fungal pathogen Candida albicans. PLoS Pathog. 2011 Dec;7(12):e1002379.

7. Kawai T, Akira S. Signaling to NF-kappaB by Toll-like receptors. Trends Mol Med. [Review]. 2007 Nov;13(11):460-9.

8. Carty M, Goodbody R, Schroder M, Stack J, Moynagh PN, Bowie AG. The human adaptor SARM negatively regulates adaptor protein TRIF-dependent Toll-like receptor signaling. Nat Immunol.

. 2006 Oct; 7(10):1074-81.

9. Yamamoto M, Akira S. [TIR domain--containing adaptors regulate TLR-mediated signaling pathways]. Nihon Rinsho. [Review]. 2004 Dec;62(12):2197-203.

10. Yoneyama M, Fujita T. Recognition of viral nucleic acids in innate immunity. Rev Med Virol. [Review]. 2010 Jan;20(1):4-22.

11. Franchi L, Warner N, Viani K, Nunez G. Function of Nod-like receptors in microbial recognition and host defense. Immunol Rev. . 2009 Jan;227(1):106-28.

12. Inohara N, Nunez G. NODs: intracellular proteins involved in inflammation and apoptosis. Nat Rev Immunol. [Review]. 2003 May;3(5):371-82.

13. Lee MS, Kim YJ. Signaling pathways downstream of pattern-recognition receptors and their cross talk. Annu Rev Biochem. 2007;76:447-80.

*De acordo com:

International Committee of Medical Journal Editors. [Internet]. Uniform requirements for manuscripts submitted to Biomedical Journal: sample references. [updated 2011 Jul 15]. Available from: http://www.icmje.org 
14. Fritz JH, Ferrero RL, Philpott DJ, Girardin SE. Nod-like proteins in immunity, inflammation and disease. Nat Immunol. 2006 Dec;7(12):1250-7.

15. Kufer TA. Signal transduction pathways used by NLR-type innate immune receptors. Mol Biosyst. 2008 May;4(5):380-6.

16. Franchi L, Amer A, Body-Malapel M, Kanneganti TD, Ozoren N, Jagirdar R, et al. Cytosolic flagellin requires Ipaf for activation of caspase-1 and interleukin 1 beta in salmonella-infected macrophages. Nat Immunol. 2006 Jun;7(6):576-82.

17. Schroder K, Tschopp J. The inflammasomes. Cell. . 2010 Mar 19;140(6):821-32.

18. Martinon F, Mayor A, Tschopp J. The inflammasomes: guardians of the body. Annu Rev Immunol. [Review]. 2009;27:229-65.

19. O'Connor W, Jr., Harton JA, Zhu X, Linhoff MW, Ting JP. Cutting edge: CIAS1/cryopyrin/PYPAF1/NALP3/CATERPILLER 1.1 is an inducible inflammatory mediator with NF-kappa B suppressive properties. J Immunol. 2003 Dec 15;171(12):6329-33.

20. Bauernfeind FG, Horvath G, Stutz A, Alnemri ES, MacDonald K, Speert D, et al. Cutting edge: NF-kappaB activating pattern recognition and cytokine receptors license NLRP3 inflammasome activation by regulating NLRP3 expression. J Immunol. 2009 Jul 15;183(2):787-91.

21. Kufer TA, Sansonetti PJ. NLR functions beyond pathogen recognition. Nat Immunol. . 2011 Feb;12(2):121-8.

22. Hayashi F, Smith KD, Ozinsky A, Hawn TR, Yi EC, Goodlett DR, et al. The innate immune response to bacterial flagellin is mediated by Toll-like receptor 5. Nature. . 2001 Apr 26;410(6832):1099-103.

23. Amer A, Franchi L, Kanneganti TD, Body-Malapel M, Ozoren N, Brady G, et al. Regulation of Legionella phagosome maturation and infection through flagellin and host Ipaf. J Biol Chem. . 2006 Nov 17;281(46):35217-23.

24. Bortoluci KR, Medzhitov R. Control of infection by pyroptosis and autophagy: role of TLR and NLR. Cell Mol Life Sci. . 2010 May;67(10):1643-51.

25. Buzzo CL, Campopiano JC, Massis LM, Lage SL, Cassado AA, Leme-Souza R, et al. A novel pathway for inducible nitric-oxide synthase activation through inflammasomes. $J$ Biol Chem. 2010 Oct 15;285(42):32087-95.

26. Ren T, Zamboni DS, Roy CR, Dietrich WF, Vance RE. Flagellin-deficient Legionella mutants evade caspase-1- and Naip5-mediated macrophage immunity. PLoS Pathog. . 2006 Mar;2(3):e18. 
27. Zamboni DS, Kobayashi KS, Kohlsdorf T, Ogura Y, Long EM, Vance RE, et al. The Birc1e cytosolic pattern-recognition receptor contributes to the detection and control of Legionella pneumophila infection. Nat Immunol. . 2006 Mar;7(3):318-25.

28. Kofoed EM, Vance RE. Innate immune recognition of bacterial ligands by NAIPS determines inflammasome specificity. Nature. . 2011 Sep 29;477(7366):592-5.

29. Zhao Y, Yang J, Shi J, Gong YN, Lu Q, Xu H, et al. The NLRC4 inflammasome receptors for bacterial flagellin and type III secretion apparatus. Nature. . 2011 Sep 29;477(7366):596600.

30. Miao EA, Warren SE. Innate immune detection of bacterial virulence factors via the NLRC4 inflammasome. J Clin Immunol. 2010 Jul;30(4):502-6.

31. Akhter A, Gavrilin MA, Frantz L, Washington S, Ditty C, Limoli D, et al. Caspase-7 activation by the NIrc4/Ipaf inflammasome restricts Legionella pneumophila infection. PLoS Pathog. . 2009 Apr;5(4):e1000361.

32. Miao EA, Leaf IA, Treuting PM, Mao DP, Dors M, Sarkar A, et al. Caspase-1-induced pyroptosis is an innate immune effector mechanism against intracellular bacteria. Nat Immunol. . 2010 Dec;11(12):1136-42.

33. Broz P, Newton K, Lamkanfi M, Mariathasan S, Dixit VM, Monack DM. Redundant roles for inflammasome receptors NLRP3 and NLRC4 in host defense against Salmonella. J Exp Med. . 2010 Aug 2;207(8):1745-55.

34. Medzhitov R, Janeway CA, Jr. Decoding the patterns of self and nonself by the innate immune system. Science. . 2002 Apr 12;296(5566):298-300.

35. Matzinger P. The danger model: a renewed sense of self. Science. $2002 \mathrm{Apr}$ 12;296(5566):301-5.

36. Green DR, Ferguson T, Zitvogel L, Kroemer G. Immunogenic and tolerogenic cell death. Nat Rev Immunol. . 2009 May;9(5):353-63.

37. Thompson CB. Apoptosis in the pathogenesis and treatment of disease. Science. [Review]. 1995 Mar 10;267(5203):1456-62.

38. Zitvogel L, Casares $\mathrm{N}$, Pequignot $\mathrm{MO}$, Chaput $\mathrm{N}$, Albert $\mathrm{ML}$, Kroemer G. Immune response against dying tumor cells. Adv Immunol. . 2004;84:131-79.

39. Casares N, Pequignot MO, Tesniere A, Ghiringhelli F, Roux S, Chaput N, et al. Caspasedependent immunogenicity of doxorubicin-induced tumor cell death. J Exp Med. . 2005 Dec 19;202(12):1691-701.

40. Obeid M, Panaretakis T, Joza N, Tufi R, Tesniere A, van Endert $P$, et al. Calreticulin exposure is required for the immunogenicity of gamma-irradiation and UVC light-induced apoptosis. Cell Death Differ. . 2007 Oct;14(10):1848-50. 
41. Muller S, Bianchi ME, Knapp S. Thermodynamics of HMGB1 interaction with duplex DNA. Biochemistry. . 2001 Aug 28;40(34):10254-61.

42. Javaherian K, Liu JF, Wang JC. Nonhistone proteins HMG1 and HMG2 change the DNA helical structure. Science. . 1978 Mar 24;199(4335):1345-6.

43. Bustin $M$, Neihart NK. Antibodies against chromosomal HMG proteins stain the cytoplasm of mammalian cells. Cell. 1979 Jan;16(1):181-9.

44. Qin S, Wang H, Yuan R, Li H, Ochani M, Ochani K, et al. Role of HMGB1 in apoptosismediated sepsis lethality. J Exp Med. . 2006 Jul 10;203(7):1637-42.

45. Willingham SB, Allen IC, Bergstralh DT, Brickey WJ, Huang MT, Taxman DJ, et al. NLRP3 (NALP3, Cryopyrin) facilitates in vivo caspase-1 activation, necrosis, and HMGB1 release via inflammasome-dependent and -independent pathways. J Immunol. . 2009 Aug 1;183(3):2008-15.

46. Lamkanfi M, Sarkar A, Vande Walle L, Vitari AC, Amer AO, Wewers MD, et al. Inflammasome-dependent release of the alarmin HMGB1 in endotoxemia. J Immunol. 2010 Oct 1;185(7):4385-92.

47. Lu B, Nakamura T, Inouye K, Li J, Tang $\mathrm{Y}$, Lundback $\mathrm{P}$, et al. Novel role of PKR in inflammasome activation and HMGB1 release. Nature. . 2012 Aug 30;488(7413):670-4.

48. Kazama H, Ricci JE, Herndon JM, Hoppe G, Green DR, Ferguson TA. Induction of immunological tolerance by apoptotic cells requires caspase-dependent oxidation of highmobility group box-1 protein. Immunity. . 2008 Jul 18;29(1):21-32.

49. Scaffidi P, Misteli T, Bianchi ME. Release of chromatin protein HMGB1 by necrotic cells triggers inflammation. Nature. . 2002 Jul 11;418(6894):191-5.

50. Rock KL, Latz E, Ontiveros F, Kono H. The sterile inflammatory response. Annu Rev Immunol. . 2010;28:321-42.

51. Dinarello CA, Renfer L, Wolff SM. Human leukocytic pyrogen: purification and development of a radioimmunoassay. Proc Natl Acad Sci U S A. 1977 Oct;74(10):4624-7.

52. Dinarello CA, Wolff SM. The role of interleukin-1 in disease. N Engl J Med. . 1993 Jan 14;328(2):106-13.

53. Mosley B, Urdal DL, Prickett KS, Larsen A, Cosman D, Conlon PJ, et al. The interleukin1 receptor binds the human interleukin-1 alpha precursor but not the interleukin-1 beta precursor. J Biol Chem. [Comparative Study]. 1987 Mar 5;262(7):2941-4.

54. Dinarello CA. Biologic basis for interleukin-1 in disease. Blood. . 1996 Mar 15;87(6):2095-147. 
55. Acosta-Rodriguez EV, Napolitani G, Lanzavecchia A, Sallusto F. Interleukins 1beta and 6 but not transforming growth factor-beta are essential for the differentiation of interleukin 17-producing human T helper cells. Nat Immunol. . 2007 Sep;8(9):942-9.

56. Lee WW, Kang SW, Choi J, Lee SH, Shah K, Eynon EE, et al. Regulating human Th17 cells via differential expression of IL-1 receptor. Blood. . 2010 Jan 21;115(3):530-40.

57. Sutton CE, Lalor SJ, Sweeney CM, Brereton CF, Lavelle EC, Mills KH. Interleukin-1 and IL-23 induce innate IL-17 production from gammadelta T cells, amplifying Th17 responses and autoimmunity. Immunity. . 2009 Aug 21;31(2):331-41.

58. Louten J, Boniface K, de Waal Malefyt R. Development and function of TH17 cells in health and disease. J Allergy Clin Immunol. [Review]. 2009 May;123(5):1004-11.

59. Gross O, Yazdi AS, Thomas CJ, Masin M, Heinz LX, Guarda G, et al. Inflammasome activators induce interleukin-1alpha secretion via distinct pathways with differential requirement for the protease function of caspase-1. Immunity. . 2012 Mar 23;36(3):388400.

60. Agrawal S, Agrawal A, Doughty B, Gerwitz A, Blenis J, Van Dyke T, et al. Cutting edge: different Toll-like receptor agonists instruct dendritic cells to induce distinct Th responses via differential modulation of extracellular signal-regulated kinase-mitogen-activated protein kinase and c-Fos. J Immunol. 2003 Nov 15;171(10):4984-9.

61. Means TK, Hayashi F, Smith KD, Aderem A, Luster AD. The Toll-like receptor 5 stimulus bacterial flagellin induces maturation and chemokine production in human dendritic cells. J Immunol. . 2003 May 15;170(10):5165-75.

62. Merlo A, Calcaterra C, Menard S, Balsari A. Cross-talk between toll-like receptors 5 and 9 on activation of human immune responses. J Leukoc Biol. . 2007 Sep;82(3):509-18.

63. Arimilli S, Johnson JB, Clark KM, Graff AH, Alexander-Miller MA, Mizel SB, et al. Engineered expression of the TLR5 ligand flagellin enhances paramyxovirus activation of human dendritic cell function. J Virol. . 2008 Nov;82(22):10975-85.

64. Didierlaurent A, Ferrero I, Otten LA, Dubois B, Reinhardt M, Carlsen H, et al. Flagellin promotes myeloid differentiation factor 88-dependent development of Th2-type response. J Immunol. . 2004 Jun 1;172(11):6922-30.

65. Bates JT, Uematsu S, Akira S, Mizel SB. Direct stimulation of t1r5+/+ CD11c+ cells is necessary for the adjuvant activity of flagellin. J Immunol. . 2009 Jun 15;182(12):7539-47.

66. Tsujimoto $\mathrm{H}$, Uchida $\mathrm{T}$, Efron PA, Scumpia PO, Verma A, Matsumoto $\mathrm{T}$, et al. Flagellin enhances NK cell proliferation and activation directly and through dendritic cell-NK cell interactions. J Leukoc Biol. 2005 Oct;78(4):888-97. 
67. Sanders CJ, Franchi L, Yarovinsky F, Uematsu S, Akira S, Nunez G, et al. Induction of adaptive immunity by flagellin does not require robust activation of innate immunity. Eur $\mathrm{J}$ Immunol. . 2009 Feb;39(2):359-71.

68. Feuillet V, Medjane S, Mondor I, Demaria O, Pagni PP, Galan JE, et al. Involvement of Toll-like receptor 5 in the recognition of flagellated bacteria. Proc Natl Acad Sci U S A. . 2006 Aug 15;103(33):12487-92.

69. Iwasaki A, Medzhitov R. Toll-like receptor control of the adaptive immune responses. Nat Immunol. 2004 Oct;5(10):987-95.

70. Sporri R, Reis e Sousa C. Inflammatory mediators are insufficient for full dendritic cell activation and promote expansion of $\mathrm{CD} 4+\mathrm{T}$ cell populations lacking helper function. Nat Immunol. . 2005 Feb;6(2):163-70.

71. Blander JM, Medzhitov R. Toll-dependent selection of microbial antigens for presentation by dendritic cells. Nature. . 2006 Apr 6;440(7085):808-12.

72. Gavin AL, Hoebe K, Duong B, Ota T, Martin C, Beutler B, et al. Adjuvant-enhanced antibody responses in the absence of toll-like receptor signaling. Science. . 2006 Dec 22;314(5807):1936-8.

73. Nemazee D, Gavin A, Hoebe K, Beutler B. Immunology: Toll-like receptors and antibody responses. Nature. [Comment]. 2006 May 18;441(7091):E4; discussion E.

74. Palm NW, Medzhitov R. Pattern recognition receptors and control of adaptive immunity. Immunol Rev. . 2009 Jan;227(1):221-33.

75. Sabbah A, Chang TH, Harnack R, Frohlich V, Tominaga K, Dube PH, et al. Activation of innate immune antiviral responses by Nod2. Nat Immunol. . 2009 Oct;10(10):1073-80.

76. Ichinohe $\mathrm{T}$, Lee HK, Ogura $\mathrm{Y}$, Flavell $\mathrm{R}$, Iwasaki A. Inflammasome recognition of influenza virus is essential for adaptive immune responses. J Exp Med. . 2009 Jan 16;206(1):79-87.

77. Fritz JH, Le Bourhis L, Sellge G, Magalhaes JG, Fsihi H, Kufer TA, et al. Nod1-mediated innate immune recognition of peptidoglycan contributes to the onset of adaptive immunity. Immunity. . 2007 Apr;26(4):445-59.

78. Gris D, Ye Z, locca HA, Wen H, Craven RR, Gris P, et al. NLRP3 plays a critical role in the development of experimental autoimmune encephalomyelitis by mediating Th1 and Th17 responses. J Immunol. . 2010 Jul 15;185(2):974-81.

79. Cunningham AF, Khan M, Ball J, Toellner KM, Serre K, Mohr E, et al. Responses to the soluble flagellar protein FliC are Th2, while those to FliC on Salmonella are Th1. Eur J Immunol. . 2004 Nov;34(11):2986-95. 
80. Bobat S, Flores-Langarica A, Hitchcock J, Marshall JL, Kingsley RA, Goodall M, et al. Soluble flagellin, FliC, induces an Ag-specific Th2 response, yet promotes T-bet-regulated Th1 clearance of Salmonella typhimurium infection. Eur J Immunol. . 2011 Jun;41(6):1606-18.

81. Vijay-Kumar M, Carvalho FA, Aitken JD, Fifadara NH, Gewirtz AT. TLR5 or NLRC4 is necessary and sufficient for promotion of humoral immunity by flagellin. Eur J Immunol. . 2010 Dec;40(12):3528-34.

82. Inaba K, Inaba M, Romani N, Aya H, Deguchi M, Ikehara S, et al. Generation of large numbers of dendritic cells from mouse bone marrow cultures supplemented with granulocyte/macrophage colony-stimulating factor. J Exp Med. . 1992 Dec 1;176(6):1693702.

83. Cohen I, Rider P, Carmi Y, Braiman A, Dotan S, White MR, et al. Differential release of chromatin-bound IL-1alpha discriminates between necrotic and apoptotic cell death by the ability to induce sterile inflammation. Proc Natl Acad Sci U S A. . 2010 Feb 9;107(6):2574-9.

84. Broz P, Ruby T, Belhocine K, Bouley DM, Kayagaki N, Dixit VM, et al. Caspase-11 increases susceptibility to Salmonella infection in the absence of caspase-1. Nature. . 2012 Oct 11;490(7419):288-91.

85. Kayagaki N, Warming S, Lamkanfi M, Vande Walle L, Louie S, Dong J, et al. Noncanonical inflammasome activation targets caspase-11. Nature. 2011 Nov 3;479(7371):11721.

86. Kayagaki N, Wong MT, Stowe IB, Ramani SR, Gonzalez LC, Akashi-Takamura S, et al. Noncanonical inflammasome activation by intracellular LPS independent of TLR4. Science. 2013 Sep 13;341(6151):1246-9.

87. Kenneth NS, Younger JM, Hughes ED, Marcotte D, Barker PA, Saunders TL, et al. An inactivating caspase 11 passenger mutation originating from the 129 murine strain in mice targeted for c-IAP1. Biochem J. . 2012 Apr 15;443(2):355-9.

88. Lage SL, Buzzo CL, Amaral EP, Matteucci KC, Massis LM, Icimoto MY, et al. Cytosolic flagellin-induced lysosomal pathway regulates inflammasome-dependent and -independent macrophage responses. Proc Natl Acad Sci U S A. . 2013 Aug 27;110(35):E3321-30.

89. Franchi L, Nunez G. The NIrp3 inflammasome is critical for aluminium hydroxidemediated IL-1beta secretion but dispensable for adjuvant activity. Eur J Immunol. . 2008 Aug;38(8):2085-9.

90. Kool M, Petrilli V, De Smedt T, Rolaz A, Hammad H, van Nimwegen $M$, et al. Cutting edge: alum adjuvant stimulates inflammatory dendritic cells through activation of the NALP3 inflammasome. J Immunol. 2008 Sep 15;181(6):3755-9.

91. Li H, Willingham SB, Ting JP, Re F. Cutting edge: inflammasome activation by alum and alum's adjuvant effect are mediated by NLRP3. J Immunol. . 2008 Jul 1;181(1):17-21. 
92. Sutterwala FS, Ogura Y, Szczepanik M, Lara-Tejero M, Lichtenberger GS, Grant EP, et al. Critical role for NALP3/CIAS1/Cryopyrin in innate and adaptive immunity through its regulation of caspase-1. Immunity. . 2006 Mar;24(3):317-27.

93. Watanabe H, Gaide O, Petrilli V, Martinon F, Contassot E, Roques S, et al. Activation of the IL-1beta-processing inflammasome is involved in contact hypersensitivity. J Invest Dermatol. . 2007 Aug;127(8):1956-63.

94. Gross O, Poeck H, Bscheider M, Dostert C, Hannesschlager N, Endres S, et al. Syk kinase signalling couples to the Nlrp3 inflammasome for anti-fungal host defence. Nature. . 2009 May 21;459(7245):433-6. 
APÊNDICE - Emerging concepts about NAIP/NLRC4 inflammasomes - Trabalho submetido para a revista Frontiers in Immunology

\section{Emerging concepts about NAIP/NLRC4 inflammasomes}

Silvia Lucena Lage ${ }^{1}$, Carla Longo ${ }^{1,2}$, Laura Migliari Branco ${ }^{1}$, Thaís Boccia da Costa ${ }^{1}$, Carina de Lima Buzzo ${ }^{1}$, Karina Ramalho Bortoluci ${ }^{1,2,{ }^{*}}$.

${ }^{1}$ Centro de Terapia Celular e Molecular (CTC-Mol), Universidade Federal de São Paulo, São Paulo, Brazil.

${ }^{2}$ Departamento de Ciências Biológicas - Campus Diadema - Universidade Federal de São Paulo, São Paulo, Brazil.

Running title: Revisiting NAIP/NLRC4 inflammasomes

Scientific Category: Immunobiology

Keywords: NAIP, NLRC4, flagellin, caspase-1, inflammasomes, lysosomes, cell death

Grant Support: This work was supported by Fundação de Amparo à Pesquisa do Estado de São Paulo (FAPESP - Brazil) Proc 2013/16010-5, Brazilian Research Council (CNPq-Brazil), CAPES and INCTV.

* Corresponding author: Karina Ramalho Bortoluci, Departamento de Ciências Biológicas e Centro de Terapia Celular e Molecular (CTC-Mol) - Universidade Federal de São Paulo

R. Mirassol, 207, Vila Clementino

São Paulo, SP - 04044-010 - BRASIL.

Direct line: 55-11-50848807;

E-mail: kbortoluci@gmail.com 


\section{ABSTRACT}

NAIP/NLRC4 inflammasome complexes are activated in response to proteins from virulent bacteria that reach the cell cytosol. Specific NAIP proteins bind to the agonists and then physically associate with NLRC4 to form an inflammasome complex able to recruit and activate pro-caspase-1. NAIP5 and NAIP6 sense flagellin, component of flagella from motile bacteria, whereas NAIP1 and NAIP2 detect needle and rod components from bacterial type III secretion systems (T3SS), respectively. Active caspase-1 mediates the maturation and secretion of the pro-inflammatory cytokines, IL-1 $\beta$ and IL-18, and is responsible for the induction of pyroptosis, a pro-inflammatory form of cell death. In addition to these wellknown effector mechanisms, novel roles have been described for NAIP/NLRC4 inflammasomes, such as phagosomal maturation, activation of inducible Nitric Oxide Synthase (iNOS), regulation of autophagy, secretion of inflammatory mediators, antibody production, activation of T cells, among others. These effector mechanisms mediated by NAIP/NLRC4 inflammasomes have been extensively studied in the context of resistance of infections but the potential of their agonists has been exploited in therapeutic strategies to non-infectious pathologies, such as tumor protection. Thus, this review will discuss current knowledge about the activation of NAIP/NLRC4 inflammasomes and their effector mechanisms. 


\section{Introduction}

Inflammasomes are multiprotein platforms containing specialized cytosolic sensors for a wide range of pathogen-associated molecular patterns (PAMPs) or damage-associated molecular patterns (DAMPs) that are able to activate the inflammatory caspase-1 and caspase-11 (caspase-4 in humans) in a manner dependent or independent of adaptor molecules (95-98). Inflammasomes are composed of a cytosolic receptor from the nucleotide-binding domain, leucine-rich repeat (NBD-LRR) (also named NOD-like receptors (NLR)) or the pyrin and HIN domain-containing protein (PYHIN) families; the adaptor molecule ASC (apoptosis-associated speck-like protein containing a caspase activating and recruitment domain (CARD)); and pro-caspase-1 or pro-caspase-11. AIM2 is the only member of the PYHIN family described to form inflammasomes. AIM2 is composed of two domains: a C-terminal HIN200 domain and an N-terminal pyrin (PYD) domain. The members of the NLR family contain three domains: a central nucleotide-binding domain (NBD) that is responsible for protein oligomerization and common to all members; a C-terminal region composed of leucine-rich repeats (LRR) sequences that are supposed to sense PAMPs or DAMPs; and a N-terminal portion that is responsible for the specificity of their molecular interactions and, therefore, their effector functions. The NLR proteins can be classified into NLRBs (NLR containing the baculovirus inhibitory (BIR) domain), NLRCs (NLRs containing the CARD domain) and NLRPs (NLRs containing the PYD domain) (99).

NLR proteins are maintained in an autoinhibited state under physiological conditions. After agonist recognition, they undergo a conformational rearrangement, triggering the NBD domains. Then, these proteins expose the effector domain to allow the assembly of oligomeric complexes. The NLRs that lack the CARD domain to recruit and activate procaspases-1 and 11 require the assistance of the adapter molecule ASC, which contains the PYD and CARD domains for binding caspases $(12,13)$. The NLRC members can directly recruit pro-caspase-1 through homotypical interactions between CARD domains, or they can recruit the adaptor ASC to activate caspase-1 (96). The canonical effector mechanisms mediated by caspase- 1 are the maturation and secretion of IL-1 $\beta$ and IL-18 and the induction of pyroptosis, a pro-inflammatory form of cell death. Furthermore, caspase-11 seems to be able to induce pyroptosis (76). 
After a decade of inflammasome discovery (100) little is known about the molecular complex formed by most members of the NLR family. AIM2, NLRP3 and NLRC4 are the bestcharacterized inflammasome complexes. The importance of these complexes to control bacterial, viral, fungal and protozoan infections and their influence in inflammatory processes are gaining prominence in the literature, although their precise activation mechanisms remain to be elucidated. Here, we focus on NLRC4 inflammasomes, the recent advances in the understanding of their assembly and the consequences of their activation to the immune response.

\section{Assembly and activation of NAIP/NLRC4 inflammasomes}

NLRC4 was first described in 2001 as a mammalian protein homologous to CED4 of $C$. elegans, whose function is to recruit and activate caspases through its CARD domain (101, 102). Because of the ability to activate caspase-1, previously known as Interleukin-1Converting Enzyme (ICE), NLRC4 was first named IPAF (ICE-protease-activating factor). Although the involvement of NLRC4 in the control of infections was previously reported, their agonists remained a mystery until 2006, when this receptor was found to recognize cytosolic flagellin, the monomeric subunit from flagella present in motile bacteria $(103,104)$. In the same year, studies of L. pneumophila revealed that another member of the NLR family, Neuronal apoptosis inhibitory protein (NAIP)-5, was responsible for the detection of cytosolic flagellin and the restriction of infection $(20,21)$.

Flagellin is one of the best-characterized agonists of the innate immune system. Extracellular flagellin is recognized by TLR5 (17) but it can be delivered to the cell cytosol though the secretion systems present in virulent bacteria strains, such as the $S$. typhimurium type III secretion system (T3SS SPI-1) and L. pneumophila type IV (T4SS). In the cell cytosol, flagellin induces the formation of the NAIP5/NLRC4 inflammasome, leading to the subsequent activation of caspase-1 $(22,105,106)$. Notably, the activation NAIP5/NLRC4 inflammasomes by cytosolic flagellin occurs independently of TLR5 (107), and these two receptors recognize distinct regions of flagellin (17). TLR5 senses a region present in the D1 domain of the protein, whereas the aminoacid sequences recognized by NAIP5/NLRC4 inflammasomes are in the D0 domain of the molecule $(22,80,106,108,109)$. 
Previous studies have pointed to the involvement of NAIP5 in controlling $L$. pneumophila flagellated bacteria $(79,110)$ and to the involvement of NLRC4 in caspase-1 activation and the induction of macrophage death $(101,102)$, although the role of flagellin in these processes was unidentified at that time.The simultaneous demonstration of cytosolic flagellin recognition by NAIP5 and NLRC4 prompted a model that proposed the existence of two distinct inflammasomes that recognize slight differences in the structure of flagellin (20, $21,103,104)$. In 2008, with the advent of NAIP5-deficient mice, Lightfield and collaborators confirmed that NAIP5 is required for NLRC4-containing inflammasome activation in response to L. pneumophila infection in a flagellin-dependent manner; however, the NLRC4-mediated macrophage responses against $S$. typhimurium were only partially dependent on NAIP5 (108). A subsequent work from the same group demonstrated that the differential requirement for NAIP5 in response to S. typhimurium and L. pneumophila infection is not due to intrinsic differences between distinct flagellins, as a genetically engineered $L$. pneumophila developed to express the S. typhimurium flagellin also activated the NLRC4 inflammasome in a manner strictly dependent on NAIP5 (105). These data indicated that another agonist from S. typhimurium could activate NLRC4 independent of the presence of NAIP5. In fact, these studies confirm that NLRC4 responds to the S. typhimurium PrgJ protein independently of NAIP5, thus explaining why NLRC4-mediated responses to S. typhimurium are only partially dependent on NAIP5.

The inflammasome structure formed by these proteins was unveiled only recently when two independent groups proposed a model for NAIP5/NLRC4 inflammasome assembly $(22,106)$. Using the transfection of inflammasome components and microbial molecules in HEK 293 T cells or followed by biochemical assays, the authors demonstrated the ability of flagellin from different bacterial species to bind to NAIP5. This interaction was dependent on the three leucine residues of the C-terminal portion of flagellin, confirming prior data (105). Furthermore, after the recognition of flagellin, a physical association between NAIP5 and NLRC4 was demonstrated, resulting in the formation of an oligomeric complex. Reconstitution experiments using truncated receptor variants showed that NAIPs are upstream of NLRC4 and suggest that they interact via the NBD domain. Notably, NAIP6 worked similarly to NAIP5, as it induced the oligomerization of NLRC4 in response to flagellin, and this could explain the response of NAIP5 ${ }^{-/}$cells to high concentrations of flagellin.NAIP1 
and NAIP2 also recruit NLRC4 in response to the bacterial needle and inner rod proteins of type III secretion systems, respectively $(22,106)$. Therefore, NAIP proteins seem to be the universal sensors of cytosolic flagellin and secretory complex proteins, whereas NLRC4 acts as an adapter molecule and is responsible for the recruitment and activation of caspase-1. It is noteworthy that there is only one functional NAIP found in humans, which is not activated by flagellin but is able to detectneedle proteins of type III secretion systems, similar to NAIP1 (22).

Despite these recent contributions to the understanding of NAIP/NLRC4 assembly, the molecular requirements of bacterial proteins for the formation of the inflammasome complex still requires further clarification. Lightfield et al (2008) originally demonstrated that the final 35 amino acids of the C-terminal portion of the flagellin molecule are essential for the activation of NAIP5. Moreover, the replacement of three leucine residues by alanine in this region abrogated the potential of flagellin to activate NAIP5, a fact also demonstrated by Zhang et al (2011). However, these studies were based on constructs containing only the Cterminal portion of the flagellin structure. A recent study using whole flagellin with or without these regions have shown that although the three leucine residues were essential for the detection of the C- terminus, their involvement seems to be less important for fulllength flagellin recognition, as whole flagellin containing three alanines instead of three leucines still induces cell death and inflammasome complex formation, although fewer complexes are formed (109). Surprisingly, although the absence of the $\mathrm{N}$-terminal domain does not affect the ability of whole flagellin to interact with NAIP5, constructs containing only $\mathrm{N}$-terminus also retain the ability to activate NAIP5/NLRC4. Thus, the molecular interaction between flagellin and NAIP5/6 still requires clarification. Moreover, although flagellin was found inside the NAIP5/NLRC4 complex, as demonstrated by immunoprecipitation $(80,111)$ and yeast two-hybrid $(22)$ assays, providing a basis for the model of direct interaction between flagellin and NAIP5, our group recently demonstrated the ability of cytosolic flagellin to activate a lysosomal pathway and the requirement of cathepsin B for NLRC4-dependent IL-1 $\beta$ secretion and pyroptosis (89). These observations raise the possibility that NAIP5/NLRC4 can also be activated by cytosolic alterations induced by the presence of flagellin, as proposed for the activation of the NLRP3 inflammasome (112). 
Challenging prior models that hypothesized that LRR domains are responsible for the detection of NLR agonists, a recent study found that these domains are dispensable for the ligand specificity of NAIPs (111). By using a series of chimeric proteins in which the Nterminal domains of NAIP5 or NAIP6 were fused to the C-terminal domains of NAIP2 or viceversa, the authors demonstrated that NAIP proteins lost the ability to oligomerize with NLRC4 only when NOD domain-associated $\alpha$-helical domains were absent, suggesting that ligand specificity maps to this region. Interestingly, a similar region in NLRC4 was recently associated with its autoinhibition (113), whereas LRR domain from NAIPs were shown to be required for the maintenance of this protein in an autoinhibited conformation (80) Despite, these unsolved pieces of the puzzle, it has been demonstrated that the interaction of NAIPs with their ligands and the association of NLRC4 with NAIPs induce conformational changes in these molecules that enable their oligomerization and activation $(109,114)$. Predicted models for the NAIP/NLRC4 inflammasome suggest that these complexes contain an excess of NLRC4 for each NAIP protein $(109,111)$ and that NLRC4 molecules are able to recruit and activate caspase-1 either directly or through an ASC adapter. The association of pro-caspase1 with an inflammasomes-containing ASC allows its autoproteolytic cleavage to become an enzymatically active heterodimer capable of processing pro-IL-1 $\beta$ and pro-IL-18 into mature cytokines (96). In contrast, an ASC-independent complex activates caspase-1 without autoproteolysis, which is sufficient for caspase-1 to target a distinct subset of substrates critical for the induction of pyroptosis.

\section{Canonical effector mechanisms induced by NAIP/NLRC4 inflammasomes.}

\subsection{Pyroptosis}

The NAIP5/NLRC4 inflammasome is perhaps the best studied inflammasome complex with regard to resistance to infections. Their involvement has been reported against infections such as S. typhimurium $(27,115)$ L. pneumophila $(79) P$. aeruginosa $(116,117), Y$. pestis (118), S. flexneri (119) and A. veronii (120). NAIP/NLRC4-mediated responses are related to the restriction of bacterial growth due to the active caspase-1-mediated canonical and non-canonical effector mechanisms, highlighting the importance of this inflammasome as a host defense mechanism against a large number of bacterial infections. The best 
elucidated effector mechanisms involved in the control of infections mediated by caspase-1 are the secretion of inflammatory cytokines IL-1 $\beta$ and IL-18 and the induction of pyroptosis (121).

The term pyroptosis (from the Greek "pyro" meaning fire or fever, and "ptosis" to a fault) was coined in 2001 to describe a pro-inflammatory programmed cell death during $S$. typhimurium infection (122). Morphological and biochemical changes displayed by $S$. typhimurium-infected dying cells were more closely related to those found in classic necrosis compared with those observed during apoptosis, including the following: 1 . Diffuse DNA fragmentation with no chromatin condensation; 2. Early loss of membrane integrity observed by the simultaneous uptake of annexin $\mathrm{V}$ with an impermeable membrane dye; 3 . Lactate Dehydrogenase (LDH) release, suggesting a loss of intracellular content; and 4. Independence of any apoptotic caspase. Although cells dying by pyroptosis displayed features of necrosis with an inflammatory outcome, the authors found that this process was highly regulated by active caspase- 1 , as the addition of inhibitors of caspase-1 (z-YVAD-fmk) abolished S. typhimurium-induced cell death.

The induction of pyroptosis by pathogenic bacteria depends on an active secretion system that translocates bacterial proteins into the cell cytosol, such as the type III secretion system (SPI-1 T3SS) of S. typhimurium and type IV (T4SS) of L. pneumophila $(103,104,123-$ 125). Mutant $L$. pneumophila $(78)$ or $P$. aeruginosa $(117,126)$ lacking flagellin fail to activate caspase- 1 and, therefore, are not able to induce pyroptosis and IL-1 $\beta$ secretion in infected macrophages. Accordingly, the transfection of purified flagellin from L. pneumophila and $S$. typhimurium directly into the cell cytosol is sufficient to trigger caspase-1-dependent pore formation, pyroptosis and IL-1 $\beta$ secretion $(127,128)$. Importantly, infection with the nonflagellated bacteria S. flexnerii also induces NLRC4-mediated pyroptosis, most likely in response to the inner rod component of T3SS (119).

Although the molecular mechanisms that regulate pyroptosis remain to be elucidated, the model of $S$. typhimurium infection has given us important knowledge about this form of cell death. The cell lysis observed during pyroptosis seems to result from a highly regulated process of pore formation in the plasma membrane $(127,128)$. Pores dissipate cellular ionic gradients but allow the retention of larger cytoplasmic constituents, leading to increased liquid osmotic pressure and water influx. These events are followed by cell 
swelling and subsequent osmotic lysis with the release of intracellular contents, which is potentially inflammatory $(127,128)$. Caspase-1-dependent DNA cleavage also occurs during pyroptosis $(127,129)$. However, the DNA cleavage observed during $S$. typhimurium-induced pyroptosis is independent of DNase CADs $(127,129)$, unlike what is observed during apoptosis, in which the proteolysis of ICAD by apoptotic caspases mediates the release of CAD to the nucleus, where it cleaves DNA between nucleosomes. Therefore, pyroptotic cells do not display the typical pattern of oligonucleosomal fragmentation observed during apoptosis, a fact that can be used to distinguish between these two processes of cell death (130).

There is good evidence implicating pyroptosis as an important host defense mechanism mediated by NAIP/NLRC4 that clears intracellular pathogens in vitro. The death of infected macrophages by pyroptosis seems to correlate with a rapid loss of the replicative niche and high bacterial loads are recovered from macrophages deficient in components of inflammasomes or infected with mutant bacterial strains that fail to trigger their activation (reviewed by $(95,131))$. Moreover, a study conducted in vivo demonstrated that the NLRC4dependent flagellin-mediated lysis of bacteria-containing macrophages not only results in the early loss of the intracellular replication niche but also creates an inflammatory milieu with the recruitment of effector cells to the infection site, which are involved in pathogen clearance (27). Although the possible targets of caspase-1 and caspase-11 mobilized during pyroptosis remain unidentified, the studies involving NAIP/NLRC4 hugely contribute to the idea that this inflammatory form of cell death is an important effector mechanism against infections.

\subsection{IL-1 $\beta$ and IL-18 secretion}

IL-1 was the first identified cytokine and has been related to several inflammatory processes. IL-1 plays a role in virtually all cells and organs, ranging from fever and resistance to microorganisms to the activation of the hypothalamus-pituitary-adrenal axis (HPA) (132138). IL-18 was first described in 1989 as a potent IFN- $\gamma$-inducing factor and an important component of polarized Th1 and M1 responses $(81,139,140)$. Macrophages, monocytes, lymphocytes, keratinocytes, microglia, neutrophils, dendritic cells, and other cells are described as important sources of IL-1 $\beta$ and IL-18 (45, 141-144). IL-18 and IL-1 $\beta$ have similar 
processing; they are both synthesized in an inactive form that requires processing by active caspase- 1 to become biologically active $(141,145,146)$. Although extensively studied, the mechanism responsible for IL-1 $\beta$ and IL-18 release has not been fully elucidated. These cytokines can be passively released during cell lysis; however, there is recent evidence supporting the existence of active mechanisms involved in the secretion of IL-1 $\beta$ and IL-18, such as caspase-1-induced membrane pores, vesicle shedding and lysosomal exocytosis $(127,131)$.

Although the precise effector mechanisms of IL-1 $\beta$ and IL-18 remain to be elucidated, these cytokines have been reported to be important mediators induced by NAIP/NLRC4 to host resistance to bacterial infections (147). In addition to the effects of IL-1b and IL-18 in the activation and recruitment of innate immune cells, these cytokines have important roles in the activation and differentiation of T lymphocytes (134). ). IL-1b and IL-18 have been shown to drive the establishment of $\mathrm{TCD}^{+}$adaptive responses in mice and in humans and are responsible for the differentiation of Th17 and Th1, respectively $(44,148,149)$. However, little is known about the involvement of IL-1 $\beta$ and IL-18 in NAIP/NLRC4-induced adaptive immune responses. Kupz et al. (2012) demonstrated that IL-18, when produced by the activation of NLRC4 during infection by S. typhimurium, is required for the activation of noncognate $\mathrm{CD}^{+} \mathrm{T}$ cells and the production of IFN- $\gamma(70)$, supporting a role for this cytokine in the induction of cellular responses.

Additional evidence of the role of NAIP/NLRC4 in the activation of T cells came from an experimental vaccination with irradiated flagellin-expressing tumor cells. Authors demonstrated that the immunization of mice with flagellin-fused tumor cells induced tumorspecific $\mathrm{CD}^{+}$and $\mathrm{CD}^{+} \mathrm{T}$ cell responses and prevented parental tumor growth. Despite the well-known role of TLR5, the recognition of flagellin by the NAIP5/NLRC4 inflammasome was also required for the induction of a protective $\mathrm{CD} 8^{+} \mathrm{T}$ cell response and tumor suppression. Although the NAIP5/NLRC4 inflammasome mediated IL-1 $\beta$ secretion in response to the injection of flagellin-modified tumor cells, it is unclear whether the involvement of this cytokine was necessary for the success of this immunotherapy. The role of IL-1 $\beta$ and IL-18 in tumorigenesis remains controversial. There is strong evidence supporting pro-tumorigenic properties of these cytokines via the induction of chronic inflammation. However, the 
activation of CD4 and CD8 T cells by IL-1 $\beta$ and IL-18 is considered an important anti-cancer action by the immune system $(150,151)$.

\section{Emerging effector mechanisms mediated by the NAIP/NLRC4 inflammasome}

\subsection{Humoral effector mechanisms}

In addition to the well-characterized functions of NAIP/NLRC4 inflammasomes described above, non-canonical effector mechanisms have emerged. Recent data describe a range of effector functions mediated by NAIP/NLRC4 inflammasomes that operate independently of IL-1 13, IL-18 and pyroptosis. The NAIP5/NLRC4 inflammasome has been implicated in the activation of phospholipase A2 (CPLA2) with a consequent production of lipid mediators, such as prostaglandins and leukotrienes (23). Authors demonstrated that systemic cytosolic flagellin stimulation leads to an "eicosanoid storm" that initiates inflammation and the loss of vascular fluids, resulting in a very fast death in mice. Of note, these effects are mediated by NAIP5/NLRC4 and occur independently of IL-1b/IL-18 or pyroptosis.

Inflammasomes have also been implicated in the active secretion of endogenous molecules known as DAMPs, challenging the idea that these molecules are only passively released during the process of cell lysis (152). IL-1 $\alpha$ is an alarmin, whose release has been recently linked to inflammasomes. Both IL-1 $\beta$ and IL-1 $\alpha$ present some common features, such as belonging to the same family,synthesis in the cytoplasm and secretion by an unconventional pathway independent of the endoplasmic reticulum and Golgi complex (137); additionally, they are released simultaneously by various stimuli, and they act on the same receptor, IL-1R1, thus sharing some biological functions (134). However, despite these similarities, there are some important differences in the production, secretion and function of these cytokines. Unprocessed forms of both IL-1 $\alpha$ and IL-1 $\beta$ are thought to be produced in response to TLR ligands, but they have distinct activities. Unlike IL-1 processed by caspase-1 to become biologically active (145), the uncleaved form of IL-1 $\alpha$ is able to engage IL-1R1 $(45,153)$, although its full activity seems to require cleavage by calpain (154). Although IL-1 $\alpha$ is not a substrate for caspase-1, there are some reports that have 
demonstrated that macrophages from caspase-1-deficient mice release less IL-1 $\alpha$ (155-157), suggesting the involvement of inflammasomes.

The mechanism by which caspase- 1 mediates IL-1 $\alpha$ secretion is still a matter of debate. A recent study demonstrated that the requirement of inflammasomes for IL-1 $\alpha$ secretion depends on the nature of agonists (52). Caspase-1 has been described as a shuttle that facilitates the secretion of leaderless proteins, such as IL-1 $\alpha$ (157). However, it is not clear whether active caspase-1 is the shuttle itself or whether it activates another enginery that is dependent on its activity, e.g., IL-1ß (74) or IL-1R2 (154), as has been proposed for the secretion of IL-1 $\alpha$ in response to NLRP3 agonists. The involvement of NLRC4 inflammasomes in IL-1 $\alpha$ secretion is poorly understood. In one previous study, infection by $S$. typhimurium resulted in NLRC4- and caspase-1-dependent secretion of IL-1 $\alpha$ (52). Interestingly, in contrast with most of the NLRP3 agonists, the secretion of IL-1 $\alpha$ in response to $S$. typhimurium was completely independent of ASC, indicating a differential requirement for this adaptor molecule in cytokine secretion in response to NLRC4 agonists, as IL-1 $\beta$ is entirely dependent on ASC (96). However, Barry et al. (2013) showed that IL-1 $\alpha$ initiates the inflammatory response driven by L. pneumophila independent of caspase-1 and NLRC4 (88). We recently reported that the activation of macrophages with purified flagellin inserted into lipidic vesicules induced IL-1 $\alpha$ secretion in a manner partially dependent on caspase- 1 and cathepsin B (89). Therefore, the reasons for the discrepancies in the literature and the precise mechanisms involved in the cross talk between IL-1 $\alpha$ and NLRC4/caspase-1 axis remain to be addressed.

Another factor whose secretion has been linked to inflammasomes is the "High Mobility group box-1" (HMGB-1). HMGB-1 is a nuclear protein involved in the regulation of nucleosome function and DNA transcription that functions as an inflammatory mediator when released to the extracellular milieu (158). Lamkanfi, M. et al. (2010), reported a critical role for HMGB-1 secreted through the NLRP3/ASC/caspase-1-axis in LPS-induced endotoxic shock (42). Interestingly, macrophages infected with $S$. typhimurium released significant amounts of HMGB-1 in a NLRC4 and caspase-1-dependent manner but independently of ASC, which is similar to previous reports of IL-1 $\alpha$ secretion (52). During pyroptosis induced by a variety of stimuli, including S. typhimurium infection, HMGB-1 did not undergo caspase-1mediated processing before its secretion, but extracellular HMGB-1 was hyperacetylated at 
the nuclear localization sequences (NLSs) (159). Because this translational modification is essential for HMGB-1 translocation from the nucleus to the cytoplasm (160, 161), HMGB-1 release upon inflammasome activation seems to be a coordinated process. More recently, Nystrom et al., (2013) reported that NLRC4-mediated pyroptosis is the prevalent factor in the regulation of HMGB-1 secretion, leading to the release of the chemotactic acetylated HMGB-1 isoform without requiring TLR-derived priming. Although the mechanisms by which inflammasome components can regulate DAMPs secretion still need to be better understood, DAMPs are already considered important therapeutic targets because of their role in host resistance against infection and their involvement in inflammatory disorders.

With respect to antibodies production NLRC4, NAIP5 and caspase-1 have been reported to have a redundant role with TLR5 in the induction of total IgG (71) or IgG1 (162) against flagellin or co-administered OVA and an additive effect to TLR5 in the induction of IgG2a (162). In the absence of MyD88, in which TLR5, IL-1 $\beta$, IL-1 $\alpha$ and IL-18 signaling is compromised, the production of antibodies induced by flagellin was reduced but not abolished, and a large amount of antibodies was still produced (162). The same results were obtained with TLR5/caspase-1 double-knockout mice (162), supporting previous data that demonstrated that no significant difference was observed in specific anti-flagellinlgG titers in mice deficient for IL-18 (65) or IL-1R (163). These reports suggest that some yetundiscovered mechanism that acts in addition to TLR5 and inflammasome-mediated cytokines could be involved in the adjuvant properties of flagellin, requiring new investigations into this agonist.

\subsection{Cellular effector mechanisms}

In addition to inflammatory mediators and cell death processes, some cellular effector mechanisms mediated by NLRC4 have emerged. Previous studies from our group described a requirement of NAIP5, NLRC4 and caspase-1 for the activation of inducible-Nitric Oxide Synthase (iNOS) and nitric oxide (NO) secretion in response to cytosolic flagellin (25). Interestingly, cytosolic flagellin-induced iNOS activation is preserved in the absence of MYD88, ruling out the participation of TLR5, IL-1 $\beta$ and IL-18. Moreover, NO secretion through the NAIP5/NLRC4-Caspase-1 axis in response to flagellin is involved in the control of L. pneumophila (25) and S. typhimurium (unpublished data from our group) by macrophages, pointing to this pathway as an additional effector mechanism mediated by NAIP5/NLRC4. 
Autophagy is another effector mechanism used by NAIP5/NLRC4 to control $L$. pneumophila. In the presence of NAIP5, NLRC4 macrophages present a rapid turnover of $\mathrm{LC}^{+}$L. pneumophila-containing vesicles, preventing the establishment of secondary infections (24). This response is mediated by the detection of flagellin, and the inhibition of autophagy in macrophages infected with flagellin-sufficient L. pneumophila increased the rate of pyroptosis in these cells. These data confirm a previous study that demonstrated that NLRC4 plays a role in the regulation of autophagy by binding Beclin-1 in steady-state conditions (164). Because the initiation of autophagy seems to precede the induction of pyroptosis, autophagy can be considered a pathway through which macrophages raise the threshold of contaminants necessary to result in the loss of cell by inflammatory cell death. NAIP5/NLRC4 can also restrict flagellin-competent $L$. pneumophila replication by promoting the delivery of L. pneumophila-containing phagosomes (LCP) to lysosomes for degradation $(78,165)$. In the absence of NAIP5/NLRC4/caspase-1, LCP avoids fusion with lysosomes, which allows the pathogen to exponentially replicate inside macrophages. This effect is dependent on caspase-1-mediated caspase-7 processing and does not require IL-1ß/IL-18 and the classical apoptosis pathway involving caspase-8 and -9 (26). These data corroborate a previous report that demonstrated a requirement of NLRC4, caspase-1 and ASC for caspase-7 processing during infection with flagellin-competent S. typhimurium (166). NLRC4 and ASC-dependent caspase-8 proteolysis was also reported during S. typhimurium infection (167). Interestingly, caspase-8 contributes to Salmonella-induced IL-1ß production, but it is dispensable for inducing pyroptosis, whereas caspase-1 processes pro-IL-1 $\beta$ and coordinates pyroptosis. These data highlight the fact that inflammasomes are dynamic complexes that are able to recruit distinct members of the caspase family to induce diverse effector functions in response to Salmonella infection.

Similar to what has been demonstrated during apoptosis $(168,169)$ and necrosis (170), the cleavage of PARP1 (also called ARTD1) was also observed during pyroptosis induced by S. typhimurium (171). PARP1 processing in S. typhimurium-infected macrophages was abrogated in $\mathrm{N}_{\mathrm{rCC}} 4^{-/}$but not in $\mathrm{N}_{\mathrm{rpp}} 3^{-/}$cells, consistent with the role of the NAIP5/NLRC4 inflammasome in the induction of pyroptosis during S. typhimurium infection $(103,115,172)$. PARP1 is a nuclear chromatin-associated multifunctional enzyme that catalyzes the polymerization of ADP-ribose units from donor NAD+ molecules $(173,174)$. 
Although it has been historically studied in the context of genotoxic stress signaling and consequent apoptosis, PARP1 has been related to chromatin structure regulation, transcription and chromosomal organization $(175,176)$. Previous reports showed that inflammasomes are able to use PARP1 to induce the transcription of NF-kB-dependent target genes independently of any type of programmed cell death (177). Upon LPS stimulation, caspase-7 is activated by caspase- 1 , which is translocated to the nucleus to induce PARP-1 cleavage at the promoters of a subset of NF-kB-dependent target genes that are negatively regulated by PARP1. Mutating the PARP1 cleavage site D214 renders PARP1 uncleavable and inhibits PARP1 release from chromatin and, therefore, chromatin decondensation, thereby restraining the expression of cleavage-dependent NF-кB target genes, such as il-6, cfs2 and lif, but not ip-10 (177). Preliminary and unpublished data from our group suggest the involvement of caspase-1-dependent PARP1 cleavage in iNOS gene expression upon cytosolic flagellin stimulation, as iNOS expression is significantly reduced in macrophages that harbor non-cleavable PARP1 (D214N). This is important evidence of the involvement of inflammasomes in epigenetic regulation and gene expression, although many of these outputs require further evaluation.

An important process of lysosomal exocytosis occurs during pyroptosis. Bergsbaken and Cookson (131) demonstrated that caspase-1-mediated pore formation induced during $S$. typhimurium infection promotes an influx of extracellular calcium, which is critical for lysosomal exocytosis. The release of lysosomal proteases with known antimicrobial activity contributes to the control of extracellular bacteria. In addition to the effect of lysosomal contents in the extracellular compartment, recent data from our group demonstrated that cytosolic flagellin is also able to activate a lysosomal pathway that culminates in an inflammasome-independent inflammatory form of cell death. This inflammasomeindependent cell death induced by cytosolic flagellin is regulated by cathepsins B and D and is temporally correlated with the restriction of S. typhimurium infection by macrophages (89). Together, these data indicate cross-talk between lysosomes and NAIP/NLRC4 inflammasomes that impacts the control of bacterial infections and opens new avenues for the development of inflammasome-based therapeutic strategies for non-infectious pathologies such as tumors. In fact, lysosomes have been considered important targets for the development of anti-tumor drugs (178). Lysosomes from cancer cells appear to be less 
stable than normal cells, which has given rise to the development of therapies based on Iysosomotropic detergents. In this sense, flagellin could be an alternative that in addition to the induction of lysosomal cell death, is able to mediate several effector mechanisms as described throughout this review (Figure 1).

\section{Conclusions and future directions}

Only ten years after their discovery $(101,102)$, the molecular mechanisms involved in the activation of NAIP/NLRC4 began to be elucidated $(22,80,105)$. From two distinct inflammasome complexes, NAIPs emerged as universal sensors for cytosolic bacterial proteins, whereas NLRC4 became an adaptor molecule responsible for the recruitment and activation of caspase-1. At same time, in addition to NAIP5, novel NAIPs members were described, amplifying the potential of these proteins to detect bacterial infections $(22,80$, 179, 180). Despite this important information, the molecular signatures of agonists recognized by NAIP/NLRC4 inflammasomes still require further study. Moreover, NLRC4 has been associated with host resistance against a mucosal Candida albicans infection (181) and in a colitis-associated colorectal cancer (CAC) model $(182,183)$. Interestingly, in both cases, NLRC4 seems to exert a protective role in non-hematopoietic compartments. However, the precise mechanism of NLRC4 activation in these models is unknown, raising the possibility that NLRC4 functions as an adaptor molecule for other NLR members in addition to NAIP and providing new insights into inflammasome signaling.

NAIP/NLRC4 are most likely the best-studied inflammasomes in the context of host resistance against infections. In addition to the extensively described IL-1 $\beta$ and IL-18 secretion and pyroptosis, other important effector mechanisms mediated by these inflammasomes have recently emerged (Figure 1). Moreover, flagellin, the best studied NAIP/NLRC4 ligand, has been reported to activate distinct pathways, such as autophagy (24) and a lysosome pathway (89) (Figure 1). Although the precise mechanism involved in the lysosome disruption by flagellin is still under investigation, it culminates in an inflammatory process of cell death that is accompanied by IL-1 $\alpha$ secretion and contributes to the control of $S$. typhimurium by macrophages. This peculiar process of cell death occurs in the absence of inflammasome components. Additionally, the inhibition of cathepsin B disrupted IL-1 $\beta$ secretion and pyroptosis in response to cytosolic flagellin, indicating a role for lysosomal 
proteases in the regulation of NAIP/NLRC4-dependent responses. Because human cells do not express NAIP5 or NAIP6 (22), the activation of the lysosomal pathway by flagellin might be an alternative pathway used when human cells interact with flagellated bacteria that reach cell cytosol. In the context of therapeutic strategies, this knowledgecould be an important gain, as the immune properties of flagellin have been extensively exploited in different models. At least in the context of anti-tumor vaccination (184) and antibody production $(71,162)$, the protective and adjuvancy roles of flagellin require its cytosolic detection. Together, these reports open up new avenues to explore the immune potential of NAIP/NLRC4 agonists as therapeutic targets. 


\section{References}

1. Banchereau J, Steinman RM. Dendritic cells and the control of immunity. Nature. [Research Support, U.S. Gov't, P.H.S.

Review]. 1998 Mar 19;392(6673):245-52.

2. Sallusto F, Lanzavecchia A. Mobilizing dendritic cells for tolerance, priming, and chronic inflammation. J Exp Med. [Comment

Research Support, Non-U.S. Gov't

Review]. 1999 Feb 15;189(4):611-4.

3. Akira S, Hoshino K, Kaisho T. The role of Toll-like receptors and MyD88 in innate immune responses. J Endotoxin Res. [Research Support, Non-U.S. Gov't]. 2000;6(5):383-7.

4. Janeway CA, Jr., Medzhitov R. Innate immune recognition. Annu Rev Immunol. [Review]. 2002;20:197-216.

5. Kawai T, Akira S. Signaling to NF-kappaB by Toll-like receptors. Trends Mol Med. [Review]. 2007 Nov;13(11):460-9.

6. Carty M, Goodbody R, Schroder M, Stack J, Moynagh PN, Bowie AG. The human adaptor SARM negatively regulates adaptor protein TRIF-dependent Toll-like receptor signaling. Nat Immunol. [Research Support, Non-U.S. Gov't]. 2006 Oct;7(10):1074-81.

7. Yamamoto M, Akira S. [TIR domain--containing adaptors regulate TLRmediated signaling pathways]. Nihon Rinsho. [Review]. 2004 Dec;62(12):2197-203.

8. Yoneyama M, Fujita T. Recognition of viral nucleic acids in innate immunity. Rev Med Virol. [Review]. 2010 Jan;20(1):4-22.

9. Franchi L, Warner N, Viani K, Nunez G. Function of Nod-like receptors in microbial recognition and host defense. Immunol Rev. [Research Support, N.I.H., Extramural

Review]. 2009 Jan;227(1):106-28.

10. Fritz JH, Ferrero RL, Philpott DJ, Girardin SE. Nod-like proteins in immunity, inflammation and disease. Nat Immunol. [Research Support, Non-U.S. Gov't Review]. 2006 Dec;7(12):1250-7.

11. Kufer TA. Signal transduction pathways used by NLR-type innate immune receptors. Mol Biosyst. [Research Support, Non-U.S. Gov't

Review]. 2008 May;4(5):380-6.

12. Schroder K, Tschopp J. The inflammasomes. Cell. [Research Support, NonU.S. Gov't

Review]. 2010 Mar 19;140(6):821-32.

13. Martinon F, Mayor A, Tschopp J. The inflammasomes: guardians of the body. Annu Rev Immunol. [Review]. 2009;27:229-65.

14. O'Connor W, Jr., Harton JA, Zhu X, Linhoff MW, Ting JP. Cutting edge: CIAS1/cryopyrin/PYPAF1/NALP3/CATERPILLER 1.1 is an inducible inflammatory mediator with NF-kappa B suppressive properties. J Immunol. 2003 Dec 15;171(12):6329-33.

15. Bauernfeind FG, Horvath G, Stutz A, Alnemri ES, MacDonald K, Speert D, et al. Cutting edge: NF-kappaB activating pattern recognition and cytokine receptors license NLRP3 inflammasome activation by regulating NLRP3 expression. J Immunol. [Research Support, N.I.H., Extramural 
Research Support, Non-U.S. Gov't]. 2009 Jul 15;183(2):787-91.

16. Kufer TA, Sansonetti PJ. NLR functions beyond pathogen recognition. Nat Immunol. [Research Support, Non-U.S. Gov't]. 2011 Feb;12(2):121-8.

17. Hayashi F, Smith KD, Ozinsky A, Hawn TR, Yi EC, Goodlett DR, et al. The innate immune response to bacterial flagellin is mediated by Toll-like receptor 5. Nature. [Research Support, U.S. Gov't, P.H.S.]. 2001 Apr 26;410(6832):1099-103. 18. Franchi L, Amer A, Body-Malapel M, Kanneganti TD, Ozoren N, Jagirdar R, et al. Cytosolic flagellin requires Ipaf for activation of caspase-1 and interleukin 1 beta in salmonella-infected macrophages. Nat Immunol. [Research Support, N.I.H., Extramural

Research Support, Non-U.S. Gov't]. 2006 Jun;7(6):576-82.

19. Lightfield KL, Persson J, Trinidad NJ, Brubaker SW, Kofoed EM, Sauer JD, et al. Differential requirements for NAIP5 in activation of the NLRC4 inflammasome.

Infect Immun. [Research Support, N.I.H., Extramural

Research Support, Non-U.S. Gov't]. 2011 Apr;79(4):1606-14.

20. Molofsky AB, Byrne BG, Whitfield NN, Madigan CA, Fuse ET, Tateda K, et al. Cytosolic recognition of flagellin by mouse macrophages restricts Legionella pneumophila infection. J Exp Med. [Research Support, N.I.H., Extramural Research Support, Non-U.S. Gov't]. 2006 Apr 17;203(4):1093-104.

21. Ren T, Zamboni DS, Roy CR, Dietrich WF, Vance RE. Flagellin-deficient Legionella mutants evade caspase-1- and Naip5-mediated macrophage immunity. PLoS Pathog. [Research Support, N.I.H., Extramural

Research Support, Non-U.S. Gov't]. 2006 Mar;2(3):e18.

22. Zhao Y, Yang J, Shi J, Gong YN, Lu Q, Xu H, et al. The NLRC4 inflammasome receptors for bacterial flagellin and type III secretion apparatus. Nature. [Research Support, Non-U.S. Gov't]. 2011 Sep 29;477(7366):596-600. 23. von Moltke J, Trinidad NJ, Moayeri M, Kintzer AF, Wang SB, van Rooijen N, et al. Rapid induction of inflammatory lipid mediators by the inflammasome in vivo. Nature. [Research Support, N.I.H., Extramural Research Support, Non-U.S. Gov't]. 2012 Oct 4;490(7418):107-11.

24. Byrne BG, Dubuisson JF, Joshi AD, Persson JJ, Swanson MS. Inflammasome components coordinate autophagy and pyroptosis as macrophage responses to infection. MBio. [Research Support, N.I.H., Extramural

Research Support, Non-U.S. Gov't]. 2013;4(1):e00620-12.

25. Buzzo CL, Campopiano JC, Massis LM, Lage SL, Cassado AA, Leme-Souza $\mathrm{R}$, et al. A novel pathway for inducible nitric-oxide synthase activation through inflammasomes. J Biol Chem. [Research Support, Non-U.S. Gov't]. 2010 Oct 15;285(42):32087-95.

26. Akhter A, Gavrilin MA, Frantz L, Washington S, Ditty C, Limoli D, et al. Caspase-7 activation by the NIrc4/Ipaf inflammasome restricts Legionella pneumophila infection. PLoS Pathog. [Research Support, N.I.H., Extramural Research Support, Non-U.S. Gov't]. 2009 Apr;5(4):e1000361.

27. Miao EA, Leaf IA, Treuting PM, Mao DP, Dors M, Sarkar A, et al. Caspase-1induced pyroptosis is an innate immune effector mechanism against intracellular bacteria. Nat Immunol. [Research Support, N.I.H., Extramural]. 2010 Dec;11(12):1136-42.

28. Medzhitov R, Janeway CA, Jr. Decoding the patterns of self and nonself by the innate immune system. Science. [Research Support, Non-U.S. Gov't Research Support, U.S. Gov't, P.H.S.]. 2002 Apr 12;296(5566):298-300. 
29. Matzinger P. The danger model: a renewed sense of self. Science. $2002 \mathrm{Apr}$ 12;296(5566):301-5.

30. Green DR, Ferguson T, Zitvogel L, Kroemer G. Immunogenic and tolerogenic cell death. Nat Rev Immunol. [Research Support, N.I.H., Extramural

Research Support, Non-U.S. Gov't

Review]. 2009 May;9(5):353-63.

31. Thompson CB. Apoptosis in the pathogenesis and treatment of disease.

Science. [Review]. 1995 Mar 10;267(5203):1456-62.

32. Zitvogel L, Casares N, Pequignot MO, Chaput N, Albert ML, Kroemer G.

Immune response against dying tumor cells. Adv Immunol. [Research Support, NonU.S. Gov't

Review]. 2004;84:131-79.

33. Casares N, Pequignot MO, Tesniere A, Ghiringhelli F, Roux S, Chaput N, et al. Caspase-dependent immunogenicity of doxorubicin-induced tumor cell death. $J$

Exp Med. [Comparative Study

Research Support, Non-U.S. Gov't]. 2005 Dec 19;202(12):1691-701.

34. Obeid M, Panaretakis T, Joza N, Tufi R, Tesniere A, van Endert P, et al.

Calreticulin exposure is required for the immunogenicity of gamma-irradiation and UVC light-induced apoptosis. Cell Death Differ. [Letter

Research Support, Non-U.S. Gov't]. 2007 Oct; 14(10):1848-50.

35. Muller S, Bianchi ME, Knapp S. Thermodynamics of HMGB1 interaction with duplex DNA. Biochemistry. [Comparative Study

Research Support, Non-U.S. Gov't]. 2001 Aug 28;40(34):10254-61.

36. Javaherian K, Liu JF, Wang JC. Nonhistone proteins HMG1 and HMG2 change the DNA helical structure. Science. [Research Support, U.S. Gov't, P.H.S.]. 1978 Mar 24;199(4335):1345-6.

37. Bustin M, Neihart NK. Antibodies against chromosomal HMG proteins stain the cytoplasm of mammalian cells. Cell. 1979 Jan;16(1):181-9.

38. Kazama H, Ricci JE, Herndon JM, Hoppe G, Green DR, Ferguson TA. Induction of immunological tolerance by apoptotic cells requires caspase-dependent oxidation of high-mobility group box-1 protein. Immunity. [Research Support, N.I.H., Extramural

Research Support, Non-U.S. Gov't]. 2008 Jul 18;29(1):21-32.

39. Scaffidi P, Misteli T, Bianchi ME. Release of chromatin protein HMGB1 by necrotic cells triggers inflammation. Nature. [Research Support, Non-U.S. Gov't]. 2002 Jul 11;418(6894):191-5.

40. Qin S, Wang H, Yuan R, Li H, Ochani M, Ochani K, et al. Role of HMGB1 in apoptosis-mediated sepsis lethality. J Exp Med. [Research Support, N.I.H., Extramural

Research Support, Non-U.S. Gov't]. 2006 Jul 10;203(7):1637-42.

41. Willingham SB, Allen IC, Bergstralh DT, Brickey WJ, Huang MT, Taxman DJ, et al. NLRP3 (NALP3, Cryopyrin) facilitates in vivo caspase-1 activation, necrosis, and HMGB1 release via inflammasome-dependent and -independent pathways. $J$ Immunol. [Research Support, N.I.H., Extramural

Research Support, Non-U.S. Gov't]. 2009 Aug 1;183(3):2008-15.

42. Lamkanfi M, Sarkar A, Vande Walle L, Vitari AC, Amer AO, Wewers MD, et al. Inflammasome-dependent release of the alarmin HMGB1 in endotoxemia. J Immunol. [Research Support, N.I.H., Extramural

Research Support, Non-U.S. Gov't]. 2010 Oct 1;185(7):4385-92. 
43. Dinarello CA, Renfer L, Wolff SM. Human leukocytic pyrogen: purification and development of a radioimmunoassay. Proc Natl Acad Sci U S A. 1977 Oct;74(10):4624-7.

44. Dinarello CA, Wolff SM. The role of interleukin-1 in disease. N Engl J Med. [Research Support, U.S. Gov't, P.H.S.

Review]. 1993 Jan 14;328(2):106-13.

45. Mosley B, Urdal DL, Prickett KS, Larsen A, Cosman D, Conlon PJ, et al. The interleukin-1 receptor binds the human interleukin-1 alpha precursor but not the interleukin-1 beta precursor. J Biol Chem. [Comparative Study]. 1987 Mar 5;262(7):2941-4.

46. Kobayashi Y, Yamamoto K, Saido T, Kawasaki H, Oppenheim JJ, Matsushima $\mathrm{K}$. Identification of calcium-activated neutral protease as a processing enzyme of human interleukin 1 alpha. Proc Natl Acad Sci U S A. 1990 Jul;87(14):5548-52. 47. Dinarello CA. Biologic basis for interleukin-1 in disease. Blood. [Research Support, U.S. Gov't, P.H.S.

Review]. 1996 Mar 15;87(6):2095-147.

48. Acosta-Rodriguez EV, Napolitani G, Lanzavecchia A, Sallusto F. Interleukins 1 beta and 6 but not transforming growth factor-beta are essential for the differentiation of interleukin 17-producing human T helper cells. Nat Immunol. [Research Support, N.I.H., Extramural Research Support, Non-U.S. Gov't]. 2007 Sep;8(9):942-9.

49. Lee WW, Kang SW, Choi J, Lee SH, Shah K, Eynon EE, et al. Regulating human Th17 cells via differential expression of IL-1 receptor. Blood. [Research Support, N.I.H., Extramural]. 2010 Jan 21;115(3):530-40.

50. Sutton CE, Lalor SJ, Sweeney CM, Brereton CF, Lavelle EC, Mills KH. Interleukin-1 and IL-23 induce innate IL-17 production from gammadelta T cells, amplifying Th17 responses and autoimmunity. Immunity. [Research Support, NonU.S. Gov't]. 2009 Aug 21;31(2):331-41.

51. Louten J, Boniface K, de Waal Malefyt R. Development and function of TH17 cells in health and disease. J Allergy Clin Immunol. [Review]. 2009 May;123(5):100411.

52. Gross O, Yazdi AS, Thomas CJ, Masin M, Heinz LX, Guarda G, et al. Inflammasome activators induce interleukin-1alpha secretion via distinct pathways with differential requirement for the protease function of caspase-1. Immunity. [Research Support, Non-U.S. Gov't]. 2012 Mar 23;36(3):388-400.

53. Iwasaki A, Medzhitov R. Toll-like receptor control of the adaptive immune responses. Nat Immunol. [Research Support, Non-U.S. Gov't

Research Support, U.S. Gov't, P.H.S.

Review]. 2004 Oct;5(10):987-95.

54. Sporri R, Reis e Sousa C. Inflammatory mediators are insufficient for full dendritic cell activation and promote expansion of CD4+ T cell populations lacking helper function. Nat Immunol. [Research Support, Non-U.S. Gov't]. 2005 Feb;6(2):163-70.

55. Blander JM, Medzhitov R. Toll-dependent selection of microbial antigens for presentation by dendritic cells. Nature. [Research Support, N.I.H., Extramural Research Support, Non-U.S. Gov't]. 2006 Apr 6;440(7085):808-12.

56. Gavin AL, Hoebe K, Duong B, Ota T, Martin C, Beutler B, et al. Adjuvantenhanced antibody responses in the absence of toll-like receptor signaling. Science. [Research Support, N.I.H., Extramural]. 2006 Dec 22;314(5807):1936-8. 
57. Nemazee D, Gavin A, Hoebe K, Beutler B. Immunology: Toll-like receptors and antibody responses. Nature. [Comment]. 2006 May 18;441(7091):E4; discussion E.

58. Palm NW, Medzhitov R. Pattern recognition receptors and control of adaptive immunity. Immunol Rev. [Research Support, Non-U.S. Gov't

Review]. 2009 Jan;227(1):221-33.

59. Agrawal S, Agrawal A, Doughty B, Gerwitz A, Blenis J, Van Dyke T, et al. Cutting edge: different Toll-like receptor agonists instruct dendritic cells to induce distinct Th responses via differential modulation of extracellular signal-regulated kinase-mitogen-activated protein kinase and c-Fos. J Immunol. [Comparative Study Research Support, U.S. Gov't, P.H.S.]. 2003 Nov 15;171(10):4984-9.

60. Means TK, Hayashi F, Smith KD, Aderem A, Luster AD. The Toll-like receptor 5 stimulus bacterial flagellin induces maturation and chemokine production in human dendritic cells. J Immunol. [Research Support, U.S. Gov't, P.H.S.]. 2003 May 15;170(10):5165-75.

61. Merlo A, Calcaterra C, Menard S, Balsari A. Cross-talk between toll-like receptors 5 and 9 on activation of human immune responses. J Leukoc Biol. [Research Support, Non-U.S. Gov't]. 2007 Sep;82(3):509-18.

62. Arimilli S, Johnson JB, Clark KM, Graff AH, Alexander-Miller MA, Mizel SB, et al. Engineered expression of the TLR5 ligand flagellin enhances paramyxovirus activation of human dendritic cell function. J Virol. [Research Support, N.I.H., Extramural]. 2008 Nov;82(22):10975-85.

63. Didierlaurent A, Ferrero I, Otten LA, Dubois B, Reinhardt M, Carlsen H, et al. Flagellin promotes myeloid differentiation factor 88-dependent development of Th2type response. J Immunol. [Research Support, Non-U.S. Gov't]. 2004 Jun 1;172(11):6922-30.

64. Bates JT, Uematsu S, Akira S, Mizel SB. Direct stimulation of tir5+/+ CD11c+ cells is necessary for the adjuvant activity of flagellin. J Immunol. [Research Support, N.I.H., Extramural]. 2009 Jun 15;182(12):7539-47.

65. Sanders CJ, Franchi L, Yarovinsky F, Uematsu S, Akira S, Nunez G, et al. Induction of adaptive immunity by flagellin does not require robust activation of innate immunity. Eur J Immunol. [Research Support, N.I.H., Extramural]. 2009 Feb;39(2):359-71.

66. Tsujimoto H, Uchida T, Efron PA, Scumpia PO, Verma A, Matsumoto T, et al. Flagellin enhances NK cell proliferation and activation directly and through dendritic cell-NK cell interactions. J Leukoc Biol. [In vitro

Research Support, N.I.H., Extramural

Research Support, U.S. Gov't, P.H.S.]. 2005 Oct;78(4):888-97.

67. Feuillet V, Medjane S, Mondor I, Demaria O, Pagni PP, Galan JE, et al. Involvement of Toll-like receptor 5 in the recognition of flagellated bacteria. Proc Natl Acad Sci U S A. [Research Support, Non-U.S. Gov't]. 2006 Aug 15;103(33):1248792.

68. Cunningham AF, Khan M, Ball J, Toellner KM, Serre K, Mohr E, et al. Responses to the soluble flagellar protein FliC are Th2, while those to FliC on Salmonella are Th1. Eur J Immunol. [Research Support, Non-U.S. Gov't]. 2004 Nov;34(11):2986-95.

69. Bobat S, Flores-Langarica A, Hitchcock J, Marshall JL, Kingsley RA, Goodall $\mathrm{M}$, et al. Soluble flagellin, FliC, induces an Ag-specific Th2 response, yet promotes T- 
bet-regulated Th1 clearance of Salmonella typhimurium infection. Eur J Immunol. [Research Support, Non-U.S. Gov't]. 2011 Jun;41(6):1606-18.

70. Kupz A, Guarda G, Gebhardt T, Sander LE, Short KR, Diavatopoulos DA, et al. NLRC4 inflammasomes in dendritic cells regulate noncognate effector function by memory CD8(+) T cells. Nat Immunol. [Research Support, Non-U.S. Gov't]. 2012 Feb;13(2):162-9.

71. Vijay-Kumar M, Carvalho FA, Aitken JD, Fifadara NH, Gewirtz AT. TLR5 or NLRC4 is necessary and sufficient for promotion of humoral immunity by flagellin. Eur J Immunol. [Research Support, N.I.H., Extramural

Research Support, Non-U.S. Gov't]. 2010 Dec;40(12):3528-34.

72. Inaba K, Inaba M, Romani N, Aya H, Deguchi M, Ikehara S, et al. Generation of large numbers of dendritic cells from mouse bone marrow cultures supplemented with granulocyte/macrophage colony-stimulating factor. J Exp Med. [Research

Support, Non-U.S. Gov't

Research Support, U.S. Gov't, P.H.S.]. 1992 Dec 1;176(6):1693-702.

73. Cohen I, Rider P, Carmi Y, Braiman A, Dotan S, White MR, et al. Differential release of chromatin-bound IL-1alpha discriminates between necrotic and apoptotic cell death by the ability to induce sterile inflammation. Proc Natl Acad Sci U S A.

[Research Support, N.I.H., Extramural

Research Support, Non-U.S. Gov't]. 2010 Feb 9;107(6):2574-9.

74. Fettelschoss A, Kistowska M, LeibundGut-Landmann S, Beer HD, Johansen

$P$, Senti G, et al. Inflammasome activation and IL-1beta target IL-1alpha for secretion as opposed to surface expression. Proc Natl Acad Sci U S A. [Research Support, Non-U.S. Gov't]. 2011 Nov 1;108(44):18055-60.

75. Broz P, Ruby T, Belhocine K, Bouley DM, Kayagaki N, Dixit VM, et al. Caspase-11 increases susceptibility to Salmonella infection in the absence of caspase-1. Nature. [Research Support, N.I.H., Extramural]. 2012 Oct 11;490(7419):288-91.

76. Kayagaki N, Warming S, Lamkanfi M, Vande Walle L, Louie S, Dong J, et al. Non-canonical inflammasome activation targets caspase-11. Nature. $2011 \mathrm{Nov}$ 3;479(7371):117-21.

77. Trinchieri G. Interleukin-12 and the regulation of innate resistance and adaptive immunity. Nat Rev Immunol. [Review]. 2003 Feb;3(2):133-46.

78. Amer A, Franchi L, Kanneganti TD, Body-Malapel M, Ozoren N, Brady G, et al. Regulation of Legionella phagosome maturation and infection through flagellin and host Ipaf. J Biol Chem. [Research Support, N.I.H., Extramural

Research Support, Non-U.S. Gov't]. 2006 Nov 17;281(46):35217-23.

79. Zamboni DS, Kobayashi KS, Kohlsdorf T, Ogura Y, Long EM, Vance RE, et al. The Birc1e cytosolic pattern-recognition receptor contributes to the detection and control of Legionella pneumophila infection. Nat Immunol. [Research Support, N.I.H., Extramural

Research Support, Non-U.S. Gov't]. 2006 Mar;7(3):318-25.

80. Kofoed EM, Vance RE. Innate immune recognition of bacterial ligands by NAIPs determines inflammasome specificity. Nature. [Research Support, N.I.H., Extramural

Research Support, Non-U.S. Gov't]. 2011 Sep 29;477(7366):592-5.

81. Nakanishi K, Yoshimoto T, Tsutsui H, Okamura H. Interleukin-18 is a unique cytokine that stimulates both Th1 and Th2 responses depending on its cytokine milieu. Cytokine Growth Factor Rev. [Review]. 2001 Mar;12(1):53-72. 
82. Siegmund B, Fantuzzi G, Rieder F, Gamboni-Robertson F, Lehr HA, Hartmann G, et al. Neutralization of interleukin-18 reduces severity in murine colitis and intestinal IFN-gamma and TNF-alpha production. Am J Physiol Regul Integr Comp Physiol. [In vitro

Research Support, Non-U.S. Gov't

Research Support, U.S. Gov't, P.H.S.]. 2001 Oct;281(4):R1264-73.

83. Sauer JD, Pereyre S, Archer KA, Burke TP, Hanson B, Lauer P, et al. Listeria monocytogenes engineered to activate the NIrc4 inflammasome are severely attenuated and are poor inducers of protective immunity. Proc Natl Acad Sci U S A. [Research Support, N.I.H., Extramural]. 2011 Jul 26;108(30):12419-24.

84. Nunez Miguel R, Wong J, Westoll JF, Brooks HJ, O'Neill LA, Gay NJ, et al. A dimer of the Toll-like receptor 4 cytoplasmic domain provides a specific scaffold for the recruitment of signalling adaptor proteins. PLoS One. [Research Support, NonU.S. Gov't]. 2007;2(8):e788.

85. Miggin SM, Palsson-McDermott E, Dunne A, Jefferies C, Pinteaux E, Banahan $\mathrm{K}$, et al. NF-kappaB activation by the Toll-IL-1 receptor domain protein MyD88 adapter-like is regulated by caspase-1. Proc Natl Acad Sci U S A. [Comparative Study

Research Support, N.I.H., Extramural

Research Support, Non-U.S. Gov't]. 2007 Feb 27;104(9):3372-7.

86. Ulrichts P, Bovijn C, Lievens S, Beyaert R, Tavernier J, Peelman F. Caspase1 targets the TLR adaptor Mal at a crucial TIR-domain interaction site. J Cell Sci.

[Research Support, Non-U.S. Gov't]. 2010 Jan 15;123(Pt 2):256-65.

87. Lukens JR, Vogel P, Johnson GR, Kelliher MA, Iwakura Y, Lamkanfi M, et al. RIP1-driven autoinflammation targets IL-1alpha independently of inflammasomes and RIP3. Nature. [Research Support, N.I.H., Extramural

Research Support, Non-U.S. Gov't]. 2013 Jun 13;498(7453):224-7.

88. Barry KC, Fontana MF, Portman JL, Dugan AS, Vance RE. IL-1alpha signaling initiates the inflammatory response to virulent Legionella pneumophila in vivo. $\mathrm{J}$ Immunol. [Research Support, N.I.H., Extramural

Research Support, Non-U.S. Gov't

Research Support, U.S. Gov't, Non-P.H.S.]. 2013 Jun 15;190(12):6329-39.

89. Lage SL, Buzzo CL, Amaral EP, Matteucci KC, Massis LM, Icimoto MY, et al. Cytosolic flagellin-induced lysosomal pathway regulates inflammasome-dependent and -independent macrophage responses. Proc Natl Acad Sci U S A. [Research Support, Non-U.S. Gov't]. 2013 Aug 27;110(35):E3321-30.

90. Letran SE, Lee SJ, Atif SM, Flores-Langarica A, Uematsu S, Akira S, et al. TLR5-deficient mice lack basal inflammatory and metabolic defects but exhibit impaired CD4 T cell responses to a flagellated pathogen. J Immunol. [Research Support, N.I.H., Extramural

Research Support, Non-U.S. Gov't]. 2011 May 1;186(9):5406-12.

91. Carvalho FA, Nalbantoglu I, Aitken JD, Uchiyama R, Su Y, Doho GH, et al. Cytosolic flagellin receptor NLRC4 protects mice against mucosal and systemic challenges. Mucosal Immunol. [Research Support, N.I.H., Extramural Research Support, Non-U.S. Gov't]. 2012 May;5(3):288-98.

92. Berg RE, Cordes CJ, Forman J. Contribution of CD8+ T cells to innate immunity: IFN-gamma secretion induced by IL-12 and IL-18. Eur J Immunol. [Research Support, U.S. Gov't, P.H.S.]. 2002 Oct;32(10):2807-16. 
93. Beadling C, Slifka MK. Differential regulation of virus-specific T-cell effector functions following activation by peptide or innate cytokines. Blood. [Research Support, Non-U.S. Gov't

Research Support, U.S. Gov't, P.H.S.]. 2005 Feb 1;105(3):1179-86.

94. Freeman BE, Hammarlund E, Raue HP, Slifka MK. Regulation of innate CD8+ T-cell activation mediated by cytokines. Proc Natl Acad Sci U S A. [Research Support, N.I.H., Extramural]. 2012 Jun 19;109(25):9971-6.

95. Bortoluci KR, Medzhitov R. Control of infection by pyroptosis and autophagy: role of TLR and NLR. Cell Mol Life Sci. [Research Support, Non-U.S. Gov't Review]. 2010 May;67(10):1643-51.

96. Broz P, von Moltke J, Jones JW, Vance RE, Monack DM. Differential requirement for Caspase-1 autoproteolysis in pathogen-induced cell death and cytokine processing. Cell Host Microbe. [Research Support, N.I.H., Extramural Research Support, Non-U.S. Gov't]. 2010 Dec 16;8(6):471-83.

97. Broz P, Monack DM. Noncanonical inflammasomes: caspase-11 activation and effector mechanisms. PLoS Pathog. 2013 Feb;9(2):e1003144.

98. Maslanik T, Mahaffey L, Tannura K, Beninson L, Greenwood BN, Fleshner M. The inflammasome and danger associated molecular patterns (DAMPs) are implicated in cytokine and chemokine responses following stressor exposure. Brain, behavior, and immunity. 2013 Feb;28:54-62.

99. Ting JP, Lovering RC, Alnemri ES, Bertin J, Boss JM, Davis BK, et al. The NLR gene family: a standard nomenclature. Immunity. 2008 Mar;28(3):285-7. 100. Martinon F, Burns K, Tschopp J. The inflammasome: a molecular platform triggering activation of inflammatory caspases and processing of prolL-beta. Molecular cell. 2002 Aug;10(2):417-26.

101. Geddes BJ, Wang L, Huang WJ, Lavellee M, Manji GA, Brown M, et al. Human CARD12 is a novel CED4/Apaf-1 family member that induces apoptosis. Biochemical and biophysical research communications. 2001 Jun 1;284(1):77-82. 102. Poyet JL, Srinivasula SM, Tnani M, Razmara M, Fernandes-Alnemri T, Alnemri ES. Identification of Ipaf, a human caspase-1-activating protein related to Apaf-1. J Biol Chem. 2001 Jul 27;276(30):28309-13.

103. Franchi L, Amer A, Body-Malapel M, Kanneganti TD, Ozoren N, Jagirdar R, et al. Cytosolic flagellin requires Ipaf for activation of caspase-1 and interleukin 1 beta in salmonella-infected macrophages. Nat Immunol. 2006 Jun;7(6):576-82.

104. Miao EA, Alpuche-Aranda CM, Dors M, Clark AE, Bader MW, Miller SI, et al. Cytoplasmic flagellin activates caspase-1 and secretion of interleukin 1beta via Ipaf. Nat Immunol. 2006 Jun;7(6):569-75.

105. Lightfield KL, Persson J, Trinidad NJ, Brubaker SW, Kofoed EM, Sauer JD, et al. Differential requirements for NAIP5 in activation of the NLRC4 inflammasome. Infection and immunity. 2011 Apr;79(4):1606-14.

106. Kofoed EM, Vance RE. NAIPs: building an innate immune barrier against bacterial pathogens. NAIPs function as sensors that initiate innate immunity by detection of bacterial proteins in the host cell cytosol. BioEssays : news and reviews in molecular, cellular and developmental biology. 2012 Jul;34(7):589-98.

107. Faustin B, Lartigue L, Bruey JM, Luciano F, Sergienko E, Bailly-Maitre B, et al. Reconstituted NALP1 inflammasome reveals two-step mechanism of caspase-1 activation. Molecular cell. 2007 Mar 9;25(5):713-24. 
108. Lightfield KL, Persson J, Brubaker SW, Witte CE, von Moltke J, Dunipace EA, et al. Critical function for Naip5 in inflammasome activation by a conserved carboxyterminal domain of flagellin. Nat Immunol. 2008 Oct;9(10):1171-8.

109. Halff EF, Diebolder CA, Versteeg M, Schouten A, Brondijk TH, Huizinga EG. Formation and structure of a NAIP5-NLRC4 inflammasome induced by direct interactions with conserved $\mathrm{N}$ - and C-terminal regions of flagellin. J Biol Chem. 2012 Nov 9;287(46):38460-72.

110. Diez E, Lee SH, Gauthier S, Yaraghi Z, Tremblay M, Vidal S, et al. Birc1e is the gene within the Lgn1 locus associated with resistance to Legionella pneumophila. Nature genetics. 2003 Jan;33(1):55-60.

111. Tenthorey JL, Kofoed EM, Daugherty MD, Malik HS, Vance RE. Molecular Basis for Specific Recognition of Bacterial Ligands by NAIP/NLRC4 Inflammasomes. Molecular cell. 2014 Apr 10;54(1):17-29.

112. Sutterwala FS, Ogura Y, Zamboni DS, Roy CR, Flavell RA. NALP3: a key player in caspase-1 activation. J Endotoxin Res. [Research Support, N.I.H., Extramural

Research Support, Non-U.S. Gov't]. 2006;12(4):251-6.

113. Hu Z, Yan C, Liu P, Huang Z, Ma R, Zhang C, et al. Crystal structure of NLRC4 reveals its autoinhibition mechanism. Science. 2013 Jul 12;341(6142):172-5. 114. Qu Y, Misaghi S, Izrael-Tomasevic A, Newton K, Gilmour LL, Lamkanfi M, et al. Phosphorylation of NLRC4 is critical for inflammasome activation. Nature. 2012 Oct 25;490(7421):539-42.

115. Mariathasan S, Newton K, Monack DM, Vucic D, French DM, Lee WP, et al. Differential activation of the inflammasome by caspase-1 adaptors ASC and Ipaf. Nature. 2004 Jul 8;430(6996):213-8.

116. Sutterwala FS, Mijares LA, Li L, Ogura Y, Kazmierczak BI, Flavell RA. Immune recognition of Pseudomonas aeruginosa mediated by the IPAF/NLRC4 inflammasome. J Exp Med. 2007 Dec 24;204(13):3235-45.

117. Miao EA, Ernst RK, Dors M, Mao DP, Aderem A. Pseudomonas aeruginosa activates caspase 1 through Ipaf. Proc Natl Acad Sci U S A. 2008 Feb 19;105(7):2562-7.

118. Brodsky IE, Palm NW, Sadanand S, Ryndak MB, Sutterwala FS, Flavell RA, et al. A Yersinia effector protein promotes virulence by preventing inflammasome recognition of the type III secretion system. Cell Host Microbe. 2010 May 20;7(5):376-87.

119. Suzuki T, Franchi L, Toma C, Ashida H, Ogawa M, Yoshikawa Y, et al. Differential regulation of caspase-1 activation, pyroptosis, and autophagy via Ipaf and ASC in Shigella-infected macrophages. PLoS Pathog. 2007 Aug 10;3(8):e111. 120. McCoy AJ, Koizumi Y, Higa N, Suzuki T. Differential regulation of caspase-1 activation via NLRP3/NLRC4 inflammasomes mediated by aerolysin and type III secretion system during Aeromonas veronii infection. J Immunol. 2010 Dec 1;185(11):7077-84.

121. Franchi L, Munoz-Planillo R, Nunez G. Sensing and reacting to microbes through the inflammasomes. Nat Immunol. 2012 Apr;13(4):325-32.

122. Cookson BT, Brennan MA. Pro-inflammatory programmed cell death. Trends in microbiology. 2001 Mar;9(3):113-4.

123. Chen LM, Kaniga K, Galan JE. Salmonella spp. are cytotoxic for cultured macrophages. Molecular microbiology. 1996 Sep;21(5):1101-15. 
124. Lundberg U, Vinatzer U, Berdnik D, von Gabain A, Baccarini M. Growth phase-regulated induction of Salmonella-induced macrophage apoptosis correlates with transient expression of SPI-1 genes. Journal of bacteriology. 1999 Jun;181(11):3433-7.

125. Brennan MA, Cookson BT. Salmonella induces macrophage death by caspase-1-dependent necrosis. Molecular microbiology. 2000 Oct;38(1):31-40. 126. Franchi L, Stoolman J, Kanneganti TD, Verma A, Ramphal R, Nunez G. Critical role for Ipaf in Pseudomonas aeruginosa-induced caspase-1 activation. Eur $\mathrm{J}$ Immunol. 2007 Nov;37(11):3030-9.

127. Fink SL, Cookson BT. Caspase-1-dependent pore formation during pyroptosis leads to osmotic lysis of infected host macrophages. Cellular microbiology. 2006 Nov;8(11):1812-25.

128. Silveira TN, Zamboni DS. Pore formation triggered by Legionella spp. is an NIrc4 inflammasome-dependent host cell response that precedes pyroptosis. Infection and immunity. 2010 Mar;78(3):1403-13.

129. Bergsbaken T, Cookson BT. Macrophage activation redirects yersinia-infected host cell death from apoptosis to caspase-1-dependent pyroptosis. PLoS Pathog. 2007 Nov;3(11):e161.

130. Lage SL, Amarante-Mendes GP, Bortoluci KR. Evaluation of pyroptosis in macrophages using cytosolic delivery of purified flagellin. Methods. [Research Support, Non-U.S. Gov't]. 2013 Jun 1;61(2):110-6.

131. Bergsbaken T, Fink SL, den Hartigh AB, Loomis WP, Cookson BT. Coordinated host responses during pyroptosis: caspase-1-dependent lysosome exocytosis and inflammatory cytokine maturation. J Immunol. 2011 Sep $1 ; 187(5): 2748-54$.

132. Van der Meer JW, Van de Gevel JS, Van Hinsbergh VW, Leijh PC. The influence of culture conditions and serum lipids on interleukin-1 production by human monocytes. Journal of immunological methods. 1988 Apr 6;108(1-2):19-26.

133. Delaleu N, Bickel M. Interleukin-1 beta and interleukin-18: regulation and activity in local inflammation. Periodontology 2000. 2004;35:42-52.

134. Dinarello CA. Immunological and inflammatory functions of the interleukin-1 family. Annu Rev Immunol. 2009;27:519-50.

135. Dinarello CA. Anti-inflammatory Agents: Present and Future. Cell. 2010 Mar 19;140(6):935-50.

136. Gabay C, Lamacchia C, Palmer G. IL-1 pathways in inflammation and human diseases. Nature reviews Rheumatology. 2010 Apr;6(4):232-41.

137. Sims JE, Smith DE. The IL-1 family: regulators of immunity. Nat Rev Immunol. 2010 Feb;10(2):89-102.

138. Dinarello CA. Grand challenge in inflammation. Frontiers in immunology. 2012;3:12.

139. Siegmund B, Fantuzzi G, Rieder F, Gamboni-Robertson F, Lehr HA, Hartmann G, et al. Neutralization of interleukin-18 reduces severity in murine colitis and intestinal IFN-gamma and TNF-alpha production. American journal of physiology Regulatory, integrative and comparative physiology. 2001 Oct;281(4):R1264-73. 140. Bastos KR, Barboza R, Sardinha L, Russo M, Alvarez JM, Lima MR. Role of endogenous IFN-gamma in macrophage programming induced by IL-12 and IL-18. Journal of interferon \& cytokine research : the official journal of the International Society for Interferon and Cytokine Research. 2007 May;27(5):399-410. 
141. Puren AJ, Fantuzzi G, Dinarello CA. Gene expression, synthesis, and secretion of interleukin 18 and interleukin 1 beta are differentially regulated in human blood mononuclear cells and mouse spleen cells. Proc Natl Acad Sci U S A. 1999 Mar 2;96(5):2256-61.

142. Berda-Haddad Y, Robert S, Salers P, Zekraoui L, Farnarier C, Dinarello CA, et al. Sterile inflammation of endothelial cell-derived apoptotic bodies is mediated by interleukin-1alpha. Proc Natl Acad Sci U S A. [Research Support, N.I.H., Extramural Research Support, Non-U.S. Gov't]. 2011 Dec 20;108(51):20684-9.

143. Dinarello CA. Interleukin-1 in the pathogenesis and treatment of inflammatory diseases. Blood. 2011 Apr 7;117(14):3720-32.

144. Carta S, Lavieri R, Rubartelli A. Different Members of the IL-1 Family Come Out in Different Ways: DAMPs vs. Cytokines? Frontiers in immunology. 2013;4:123. 145. Dinarello CA. Interleukin-1 beta, interleukin-18, and the interleukin-1 beta converting enzyme. Annals of the New York Academy of Sciences. 1998 Sep 29;856:1-11.

146. Bellora F, Castriconi R, Doni A, Cantoni C, Moretta L, Mantovani A, et al. MCSF induces the expression of a membrane-bound form of IL-18 in a subset of human monocytes differentiating in vitro toward macrophages. Eur J Immunol. 2012 Jun;42(6):1618-26.

147. von Moltke J, Ayres JS, Kofoed EM, Chavarria-Smith J, Vance RE.

Recognition of bacteria by inflammasomes. Annu Rev Immunol. 2013;31:73-106.

148. Chung Y, Chang SH, Martinez GJ, Yang XO, Nurieva R, Kang HS, et al. Critical regulation of early Th17 cell differentiation by interleukin-1 signaling.

Immunity. [Research Support, N.I.H., Extramural

Research Support, N.I.H., Intramural

Research Support, Non-U.S. Gov't]. 2009 Apr 17;30(4):576-87.

149. Lasiglie D, Traggiai E, Federici S, Alessio M, Buoncompagni A, Accogli A, et al. Role of IL-1 beta in the development of human $\mathrm{T}(\mathrm{H}) 17$ cells: lesson from NLPR3 mutated patients. PLoS One. [Research Support, Non-U.S. Gov't]. 2011;6(5):e20014. 150. Kolb R, Liu GH, Janowski AM, Sutterwala FS, Zhang W. Inflammasomes in cancer: a double-edged sword. Protein \& cell. 2014 Jan;5(1):12-20.

151. Janowski AM, Kolb R, Zhang W, Sutterwala FS. Beneficial and Detrimental Roles of NLRs in Carcinogenesis. Frontiers in immunology. 2013;4:370.

152. Chen CJ, Kono H, Golenbock D, Reed G, Akira S, Rock KL. Identification of a key pathway required for the sterile inflammatory response triggered by dying cells.

Nature medicine. 2007 Jul;13(7):851-6.

153. Howard AD, Kostura MJ, Thornberry N, Ding GJ, Limjuco G, Weidner J, et al. IL-1-converting enzyme requires aspartic acid residues for processing of the IL-1 beta precursor at two distinct sites and does not cleave 31-kDa IL-1 alpha. J Immunol. 1991 Nov 1;147(9):2964-9.

154. Zheng Y, Humphry M, Maguire JJ, Bennett MR, Clarke MC. Intracellular interleukin-1 receptor 2 binding prevents cleavage and activity of interleukin-1alpha, controlling necrosis-induced sterile inflammation. Immunity. 2013 Feb 21;38(2):28595.

155. Kuida K, Lippke JA, Ku G, Harding MW, Livingston DJ, Su MS, et al. Altered cytokine export and apoptosis in mice deficient in interleukin-1 beta converting enzyme. Science. 1995 Mar 31;267(5206):2000-3. 
156. Li P, Allen H, Banerjee S, Franklin S, Herzog L, Johnston C, et al. Mice deficient in IL-1 beta-converting enzyme are defective in production of mature IL-1 beta and resistant to endotoxic shock. Cell. 1995 Feb 10;80(3):401-11.

157. Keller M, Ruegg A, Werner S, Beer HD. Active caspase-1 is a regulator of unconventional protein secretion. Cell. 2008 Mar 7;132(5):818-31.

158. Muller S, Scaffidi P, Degryse B, Bonaldi T, Ronfani L, Agresti A, et al. New EMBO members' review: the double life of HMGB1 chromatin protein: architectural factor and extracellular signal. The EMBO journal. 2001 Aug 15;20(16):4337-40. 159. Lu B, Nakamura T, Inouye K, Li J, Tang Y, Lundback P, et al. Novel role of PKR in inflammasome activation and HMGB1 release. Nature. [Research Support, N.I.H., Extramural

Research Support, Non-U.S. Gov't]. 2012 Aug 30;488(7413):670-4.

160. Bonaldi T, Talamo F, Scaffidi P, Ferrera D, Porto A, Bachi A, et al. Monocytic cells hyperacetylate chromatin protein HMGB1 to redirect it towards secretion. The EMBO journal. 2003 Oct 15;22(20):5551-60.

161. Evankovich J, Cho SW, Zhang R, Cardinal J, Dhupar R, Zhang L, et al. High mobility group box 1 release from hepatocytes during ischemia and reperfusion injury is mediated by decreased histone deacetylase activity. J Biol Chem. $2010 \mathrm{Dec}$ 17;285(51):39888-97.

162. Lopez-Yglesias AH, Zhao X, Quarles EK, Lai MA, VandenBos T, Strong RK, et al. Flagellin induces antibody responses through a TLR5- and inflammasomeindependent pathway. J Immunol. [Research Support, N.I.H., Extramural]. 2014 Feb 15;192(4):1587-96.

163. Sanders CJ, Moore DA, 3rd, Williams IR, Gewirtz AT. Both radioresistant and hemopoietic cells promote innate and adaptive immune responses to flagellin. $J$ Immunol. 2008 Jun 1;180(11):7184-92.

164. Jounai N, Kobiyama K, Shiina M, Ogata K, Ishii KJ, Takeshita F. NLRP4 negatively regulates autophagic processes through an association with beclin $1 . \mathrm{J}$ Immunol. 2011 Feb 1;186(3):1646-55.

165. Fortier A, de Chastellier C, Balor S, Gros P. Birc1e/Naip5 rapidly antagonizes modulation of phagosome maturation by Legionella pneumophila. Cellular microbiology. 2007 Apr;9(4):910-23.

166. Lamkanfi M, Kanneganti TD, Van Damme P, Vanden Berghe T, Vanoverberghe I, Vandekerckhove J, et al. Targeted peptidecentric proteomics reveals caspase- 7 as a substrate of the caspase- 1 inflammasomes. Molecular \& cellular proteomics : MCP. 2008 Dec;7(12):2350-63.

167. Man SM, Tourlomousis P, Hopkins L, Monie TP, Fitzgerald KA, Bryant CE. Salmonella infection induces recruitment of Caspase-8 to the inflammasome to modulate IL-1 beta production. J Immunol. 2013 Nov 15;191(10):5239-46.

168. Nicholson DW, Ali A, Thornberry NA, Vaillancourt JP, Ding CK, Gallant M, et al. Identification and inhibition of the ICE/CED-3 protease necessary for mammalian apoptosis. Nature. 1995 Jul 6;376(6535):37-43.

169. Casciola-Rosen L, Rosen A, Petri M, Schlissel M. Surface blebs on apoptotic cells are sites of enhanced procoagulant activity: implications for coagulation events and antigenic spread in systemic lupus erythematosus. Proc Natl Acad Sci U S A. 1996 Feb 20;93(4):1624-9.

170. Nosseri C, Coppola S, Ghibelli L. Possible involvement of poly(ADP-ribosyl) polymerase in triggering stress-induced apoptosis. Experimental cell research. 1994 Jun;212(2):367-73. 
171. Malireddi RK, Ippagunta S, Lamkanfi M, Kanneganti TD. Cutting edge: proteolytic inactivation of poly(ADP-ribose) polymerase 1 by the Nlrp3 and NIrc4 inflammasomes. J Immunol. 2010 Sep 15;185(6):3127-30.

172. Kanneganti TD, Lamkanfi M, Kim YG, Chen G, Park JH, Franchi L, et al. Pannexin-1-mediated recognition of bacterial molecules activates the cryopyrin inflammasome independent of Toll-like receptor signaling. Immunity. 2007 Apr;26(4):433-43.

173. Kim MY, Zhang T, Kraus WL. Poly(ADP-ribosyl)ation by PARP-1: 'PAR-laying' NAD+ into a nuclear signal. Genes \& development. 2005 Sep 1;19(17):1951-67. 174. Hassa PO, Haenni SS, Elser M, Hottiger MO. Nuclear ADP-ribosylation reactions in mammalian cells: where are we today and where are we going? Microbiology and molecular biology reviews : MMBR. 2006 Sep;70(3):789-829. 175. Kraus WL, Lis JT. PARP goes transcription. Cell. 2003 Jun 13;113(6):677-83. 176. Krishnakumar R, Kraus WL. PARP-1 regulates chromatin structure and transcription through a KDM5B-dependent pathway. Molecular cell. 2010 Sep 10;39(5):736-49.

177. Erener S, Petrilli V, Kassner I, Minotti R, Castillo R, Santoro R, et al. Inflammasome-activated caspase 7 cleaves PARP1 to enhance the expression of a subset of NF-kappaB target genes. Molecular cell. 2012 Apr 27;46(2):200-11. 178. Aits S, Jaattela M. Lysosomal cell death at a glance. J Cell Sci. 2013 May 1;126(Pt 9):1905-12.

179. Rayamajhi M, Zak DE, Chavarria-Smith J, Vance RE, Miao EA. Cutting edge: Mouse NAIP1 detects the type III secretion system needle protein. J Immunol. 2013 Oct 15;191(8):3986-9.

180. Yang J, Zhao Y, Shi J, Shao F. Human NAIP and mouse NAIP1 recognize bacterial type III secretion needle protein for inflammasome activation. Proc Natl Acad Sci U S A. 2013 Aug 27;110(35):14408-13.

181. Tomalka J, Ganesan S, Azodi E, Patel K, Majmudar P, Hall BA, et al. A novel role for the NLRC4 inflammasome in mucosal defenses against the fungal pathogen Candida albicans. PLoS Pathog. [Research Support, N.I.H., Extramural]. 2011 Dec;7(12):e1002379.

182. Hu B, Elinav E, Huber S, Booth CJ, Strowig T, Jin C, et al. Inflammationinduced tumorigenesis in the colon is regulated by caspase-1 and NLRC4. Proc Natl Acad Sci U S A. 2010 Dec 14;107(50):21635-40.

183. Hu B, Elinav E, Flavell RA. Inflammasome-mediated suppression of inflammation-induced colorectal cancer progression is mediated by direct regulation of epithelial cell proliferation. Cell cycle. 2011 Jun 15;10(12):1936-9.

184. Garaude J, Kent A, van Rooijen N, Blander JM. Simultaneous targeting of tolland nod-like receptors induces effective tumor-specific immune responses. Science translational medicine. 2012 Feb 8;4(120):120ra16. 